\title{
EFEITO DA INCORPORAÇÃO DE FLÚOR NAS PROPRIEDADES DE SUPERFÍCIE DE FILMES DE a-C:H
}

Tese apresentado ao programa de Pós-Graduação da Universidade Estadual Paulista, Campus de Guaratinguetá, para obtenção do título de Doutor em Engenharia Mecânica na área de Materiais.

Orientadora: Prof ${ }^{\mathrm{a}}$. Dr ${ }^{\mathrm{a}}$. Elidiane Cipriano Rangel Co-orientador: Prof. Dr. Rogério Pinto Mota

\section{GUARATINGUETÁ}




\section{Marins, Nazir Monteiro dos Santos}

Efeito da incorporação de flúor nas propriedades de superfície de

M339e filmes de a-C:H. / Nazir Monteiro dos Santos Marins - Guaratinguetá :

[s.n.], 2010.

141f. : il.

Bibliografia: f. 117-135

Tese (doutorado) - Universidade Estadual Paulista, Faculdade de Engenharia de Guaratinguetá, 2010.

Orientadora: Prof $^{a}$. Dr ${ }^{a}$. Elidiane Cipriano Rangel

Co-orientador: Prof. Dr. Rogério Pinto Mota

1. Filmes finos de diamantes 2. Plasma (Gases ionizados) I. Título 
NAZIR MONTEIRO SANTOS MARINS

ESTA TESE FOI JULGADA ADEQUADA PARA A OBTENÇÃO DO TÍTULO DE "DOUTOR EM ENGENHARIA MECÂNICA"

$$
\begin{aligned}
& \text { PROGRAMA: ENGENHARIA MECÂNICA } \\
& \text { ÁREA: MATERIAIS }
\end{aligned}
$$

APROVADA EM SUA FORMA FINAL PELO PROGRAMA DE PÓS-GRADUAÇÃO

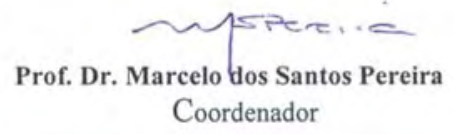

BANCA EXAMINADORA:

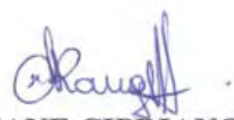

Prof". Dra". ELIDIANE CIPRIANO RANGEL

Orientador/Unesp-Sorocaba

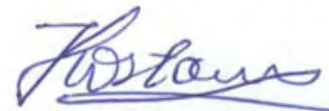

Prof. Dr. KONSTANTIN GEORGIEV KOSTOV Unesp-Feg
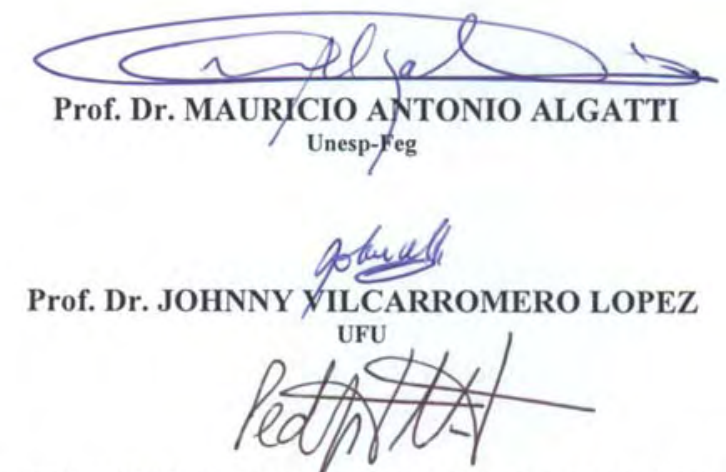

Prof. Dr. PEDRO AUGUSTO DE PAULA NASCENTE UFSCar 


\section{DADOS CURRICULARES}

\section{NAZIR MONTEIRO DOS SANTOS MARINS}

NASCIMENTO

14.10.1962 - CUNHA / SP

FILIAÇÃO

Juventino Monteiro dos Santos

Maria Rodrigues de Campos Santos

$1982 / 1989$

Curso de Graduação em Engenharia Química, na Faculdade de Engenharia Química de Lorena - FAENQUIL, Lorena, SP, Brasil - Atual EEL/USP.

$1990 / 1991$

Curso de Especialização em Engenharia da Qualidade, na Faculdade de Engenharia Química de Lorena, FAENQUIL, Lorena, SP, Brasil - Atual EEL/USP.

$2002 / 2003$

Curso de Pós-Graduação em Engenharia Biomédica - Área: Bioengenharia, nível de Mestrado, na Universidade do Vale do Paraíba, UNIVAP, São José dos Campos, SP, Brasil.

$2003 / 2003$

Curso de Graduação - Licenciatura Plena em Química, na Faculdade de Filosofia, Ciências e Letras "Oswaldo Cruz", FFCLOC, São Paulo, Brasil.

$2005 / 2006$

Curso de Graduação - Licenciatura Plena em Pedagogia, com Habilitações em Administração e Supervisão Escolar do Ensino Fundamental e Médio, no Centro Universitário Claretiano CEUCLAR, Batatais, SP, Brasil.

$2005 / 2010$

Curso de Pós-Graduação em Engenharia Mecânica, Área de Materiais, nível de Doutorado, na Faculdade de Engenharia do Campus de Guaratinguetá da Universidade Estadual Paulista UNESP. 
"Os pequenos atos que se executam são melhores que todos aqueles grandes que se planejam."

George C. Marshal 


\section{AGRADECIMENTOS}

Em primeiro lugar agradeço a Deus, pois sem Ele nada seria possível.

Aos meus filhos André Luiz e Vanessa, pela compreensão, paciência e que apesar das dificuldades, sempre incentivaram meus estudos.

À minha orientadora, Prof ${ }^{\mathrm{a}}$. Dr ${ }^{\mathrm{a}}$. Elidiane Cipriano Rangel pelas valiosas discussões, paciência e confiança, para a realização deste trabalho.

Ao Prof. Dr. Rogério Pinto Mota que jamais deixou de me incentivar. Sem a sua Coorientação, dedicação e auxílio, o estudo aqui apresentado seria praticamente impossível.

Ao Prof. Dr. Roberto Yzumi Honda, pela amizade, pelo carinho e contribuição nos trabalhos experimentais, sem a qual seria difícil concluí-lo.

Ao Sr. José Benedito Galhardo pela pronta ajuda com os equipamentos do laboratório.

Aos Profs. Drs. Milton Eiji Kayama, Konstantin Georgiev Kostov e Maurício Antônio Algatti, pelo apoio, cooperação e assistência na elaboração de artigos.

Ao Prof. Dr. Carlos Eduardo da Silva Amorim, pela amizade, carinho, paciência e orientação no estágio docência.

Ao Profs. Drs. Nilson Cristino da Cruz e José Roberto Ribeiro Bortoleto, pelas análises de dureza e microscopia de força atômica.

Ao Prof. Dr. Pedro Augusto de Paula Nascente, pela amizade, confiança, carinho e pelas análises XPS.

Às secretárias Vânia e Silvana, pela amizade, competência e dedicação.

Às secretárias da pós-graduação Regina e Cristina pela dedicação e alegria no atendimento.

Aos amigos Deborah, Ivanira, Leidi, Alessandro, Regiane, Rita e Gê, pela amizade, incentivo, solidariedade e companhia.

Aos amigos do INPE, Gil Capote, Luís Bonetti, Adriana, Romina, Érica, Anderson e Giovanna, pela amizade, paciência, confiança e ajuda nas análises de espessura, Raman e rugosidade.

Aos Profs. Drs. Corat, Paulo Motisuke e Lúcia Vieira Santos (LAS/INPE) pela colaboração e assistência nas análises de Raman, Infravermelho e Rugosidade.

A CAPES pelo suporte financeiro. 
Aos funcionários Roberto Binder e Márcio (EMBRACO) pela análise de coeficiente de atrito.

Enfim, a todos que de alguma forma contribuíram para a finalização desse trabalho: muito obrigada! 
MARINS, N. M. S. Efeito da Incorporação de Flúor nas Propriedades de Superfície de Filmes de a-C:H. 2010. 141 f. Tese (Doutorado em Engenharia Mecânica) - Faculdade de Engenharia do Campus de Guaratinguetá, Universidade Estadual Paulista, Guaratinguetá.

\section{RESUMO}

Filmes finos de carbono amorfo hidrogenado (a-C:H) e fluorados (a-C:H:F) foram depositados a partir de plasmas de misturas de acetileno/argônio e acetileno/argônio/hexafluoreto de enxofre. Para a primeira mistura de gases, o plasma foi mantido por 5 e 10 minutos a uma pressão de $9,5 \mathrm{~Pa}\left(30 \% \mathrm{C}_{2} \mathrm{H}_{2}\right.$ e $\left.70 \% \mathrm{Ar}\right)$ enquanto para a segunda ele foi mantido por 5 minutos utilizando-se $30 \% \mathrm{C}_{2} \mathrm{H}_{2}, 65 \%$ Ar e $5 \% \mathrm{SF}_{6}$ a uma pressão total de 9,5 Pa. A potência do sinal de excitação foi variada de 5 a $125 \mathrm{~W}$ e o efeito deste parâmetro nas propriedades do filme foi investigado. De modo a fluorar os filmes obtidos a partir da mistura acetileno/argônio estes foram submetidos, imediatamente após a deposição e sem exposição ao ar atmosférico, a tratamentos em plasmas de $\mathrm{SF}_{6}$. Tais procedimentos foram conduzidos durante 5 minutos utilizando-se uma fonte de rádiofrequência $(13,56 \mathrm{MHz}, 70 \mathrm{~W})$ a uma pressão total de 13,3 Pa. Foram utilizadas as técnicas de espectroscopia Raman e espectroscopia de fotoelétrons - XPS para investigar as respectivas microestruturas e composições químicas das amostras. A dureza e o coeficiente de atrito dos filmes foram determinados pelas técnicas de nanoindentação e tribometria, respectivamente. A receptividade das amostras à água foi analisada através de dados de ângulo de contato e a rugosidade foi determinada por interferometria ótica. Os filmes de a-C:H obtidos a partir de plasmas de $\mathrm{C}_{2} \mathrm{H}_{2}$ e $\mathrm{Ar}$ em potências mais baixas (5 e $25 \mathrm{~W}$ ) apresentaram estruturas e composições de natureza polimérica, enquanto os preparados em potências intermediárias (50 e $75 \mathrm{~W}$ ) apresentaram maiores proporções de ligações de carbono tetraédricos e baixo teor de hidrogênio, indicando uma estrutura do tipo DLC (Diamond-Like Carbon). Os filmes depositados com as potências mais elevadas (100 e $125 \mathrm{~W}$ ) apresentaram estrutura do tipo grafitica. Quando os filmes depositados em baixas potências foram submetidos a tratamentos pós-deposição em plasma de $\mathrm{SF}_{6}$, 
a composição química da superfície foi alterada, mas o caráter polimérico foi mantido. Já os filmes preparados com as maiores potências tiveram o caráter grafitico acentuado quando submetidos ao tratamento pós-deposição. Os filmes obtidos a partir de plasmas de misturas de $\mathrm{C}_{2} \mathrm{H}_{2}$, Ar e $\mathrm{SF}_{6}$ também revelaram estrutura polimérica quando baixas potências foram empregadas e grafitica para potências intermediárias (50 e $75 \mathrm{~W}$ ). Neste caso, o material com a maior proporção de carbono com hibridização $\mathrm{sp}^{3}$ foi obtido para os maiores valores de potência (100 e 125 W). Os resultados de ângulo de contato mostraram que os filmes de a-C:H depositados nas diferentes condições são essencialmente hidrofílicos. Após tratamento em plasmas de $\mathrm{SF}_{6}$, os filmes depositados durante 10 minutos tiveram sua molhabilidade alterada, mudando de hidrofílicos para hidrofóbicos. Os tratamentos pós-deposição foram mais efetivos para a incorporação de flúor e para alterar a molhabilidade dos mesmos. A espessura dos filmes de a-C:H, depositados durante 5 minutos, diminuiu de 130 para $20 \mathrm{~nm}$ quando a potência foi variada de 5 para $125 \mathrm{~W}$. Após tratamento a plasma de $\mathrm{SF}_{6}$ ocorreu redução mais intensa na espessura, principalmente nos filmes depositados durante 10 minutos. Este resultado foi atribuído ao constante crescimento na ablação produzido pelo aquecimento térmico durante a deposição e pelo etching promovido pelo plasma de $\mathrm{SF}_{6}$. $\mathrm{O}$ tratamento a plasma de $\mathrm{SF}_{6}$ nas amostras promoveu alteração no coeficiente de atrito e na rugosidade de suas superfícies. Valores mais reduzidos de coeficiente de atrito e de rugosidade foram obtidos após o tratamento a plasma de $\mathrm{SF}_{6}$ dos filmes depositados durante 10 minutos.

PALAVRAS-CHAVE: Filmes de a-C:H. Filmes de a-C:H:F. Tratamento a plasma. PECVD. Molhabilidade. Rugosidade. Coeficiente de atrito. 
MARINS, N. M. S. Effect of the Incorporation of Fluoride in the Surface Properties of Films of a-C: H. 2010. 141 f. Tese (Doutorado em Engenharia Mecânica) - Faculdade de Engenharia do Campus de Guaratinguetá, Universidade Estadual Paulista, Guaratinguetá.

\section{ABSTRACT}

Hydrogenated amorphous carbon $(\mathrm{a}-\mathrm{C}: \mathrm{H})$ and fluorinated $(\mathrm{a}-\mathrm{C}: \mathrm{H}: \mathrm{F})$ thin films were deposited from acetylene/argon and acetylene/argon/sulfur hexafluoride mixtures. For the first gas mixture, the plasma was kept for 5 or 10 minutes using $9.5 \mathrm{~Pa}$ of pressure $\left(30 \% \mathrm{C}_{2} \mathrm{H}_{2}\right.$ e $70 \%$ Ar) while for the second it was kept for 5 minutes using $30 \% \mathrm{C}_{2} \mathrm{H}_{2}$, $65 \%$ Ar e $5 \% \mathrm{SF}_{6}$ at a total pressure of $9.5 \mathrm{~Pa}$. The power of the excitation signal was changed from 5 to $125 \mathrm{~W}$ and the effect of such parameter on the properties of the films was investigated. To fluorinate the a-C:H films they were submitted, immediately after deposition and without exposure to atmosphere, to $\mathrm{SF}_{6}$ plasma treatments. Such procedures were conducted for 5 minutes in radiofrequency (13.56 $\mathrm{MHz}, 70 \mathrm{~W}$ ) plasmas of $13.3 \mathrm{~Pa}$ of pressure. Raman and X-Ray photoelectron spectroscopes were employed to investigate, respectively, the microstructure and chemical composition of the films. Film hardness and friction coefficient were determined from nanoindentation and tribometry techniques, respectively. The receptivity of the samples towards water was evaluated through contact angle data and roughness was measured by optical interferometry. The a-C:H films obtained from the $\mathrm{C}_{2} \mathrm{H}_{2}$ and Ar plasma mixtures in lower power (5 e $25 \mathrm{~W}$ ) presented polymer-like structures and compositions while those prepared using intermediary power levels ( 50 e $75 \mathrm{~W}$ ) presented higher proportions of tetrahedral carbon bonds and low proportions of hydrogen, suggesting a Diamond like Carbon $(D L C)$ structure. Films deposited using the higher power (100 e $125 \mathrm{~W}$ ) plasmas presented a graphitic structure. As the material prepared with lower power signals were submitted to the $\mathrm{SF}_{6}$ post deposition treatment, surface chemical composition was changed but the polymeric nature of the films was kept. The graphitic nature of the films synthesized in the higher power 
regime was intensified after the post deposition treatment. The films obtained from $\mathrm{C}_{2} \mathrm{H}_{2}, \mathrm{Ar}$ and $\mathrm{SF}_{6}$ plasma mixtures also revealed a polymeric structure as lower power were used and a graphitic for intermediary power levels (50 e $75 \mathrm{~W}$ ). In this case, the material with the higher proportion of $\mathrm{sp}^{3}$ carbon-carbon bonds was that prepared with for higher power signals $(100$ e $125 \mathrm{~W})$. Contact angle results revealed that a-C:H films deposited in different conditions are essentially hydrophilic. After $\mathrm{SF}_{6}$ plasma treatment, the films deposited in 10 minutes have their wettability altered, from hydrophilic to hydrophobic. The post deposition treatments were more effective for the fluorine incorporation and consequently to alter the film wettability than the $\mathrm{SF}_{6}$ incorporation in the deposition process. Thickness of the films deposited in 5 minutes decreased from 130 to $20 \mathrm{~nm}$ as excitation power was varied from 5 to $125 \mathrm{~W}$. After SF6 plasma treatment film thickness was substantially reduced mainly for the 10 minutes deposited samples. This result was ascribed to the increasing effect of the ablation produced by the thermal heating during deposition and by the etchant effect of the $\mathrm{SF}_{6}$ treatment. Friction coefficient increased upon film fluorination but still good results were attained to the samples deposited for 10 minutes and to those in wich fluorine was incorporated to the depositing plasmas.

KEYWORDS: a-C:H Films. a-C:H:F Films. Plasma treatment. PECVD. Wettability. Roughness. Coefficient of friction. 
SUMÁRIO

LISTA DE FIGURAS

LISTA DE TABELAS

1 INTRODUÇÃO.

2 REVISÃO BIBLIOGRÁFICA.............................................................................. 22

2.1 CARBONO AMORFO HIDROGENADO (a-C:H)...................................... 22

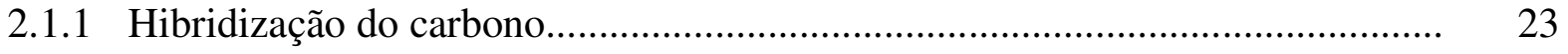

2.2 MECANISMOS DE DEPOSIÇÃO DOS FILMES a-C:H.............................. 25

2.3 ESTRUTURA ATÔMICA DOS FILMES a-C:H........................................ 31

2.4 PROCESSOS DE INCORPORAÇÃO DE FLÚOR NOS FILMES a-C:H....... 34

2.4.1 O efeito do flúor nas propriedades estruturais dos filmes de a-C:H.................. 34

3 MÉTOdOS DE CARACTERIZAÇÃO DOS FILMES DE a-C:H E aC:H FLUORADO.................................................................................................. 36

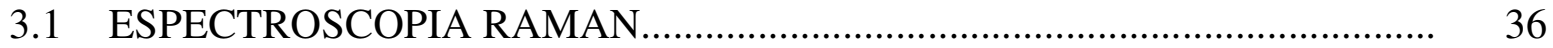

3.2 ESPECTROSCOPIA DE FOTOELÉTRONS EXCITADOS POR RAIOS-X

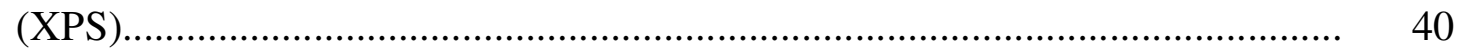

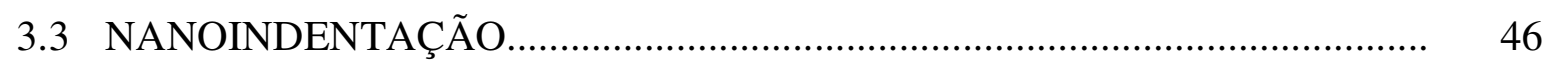

3.4 ÂNGULO DE CONTATO..................................................................... 50

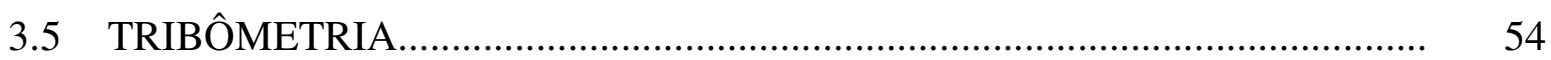

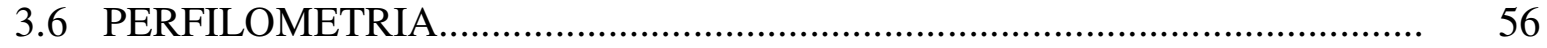

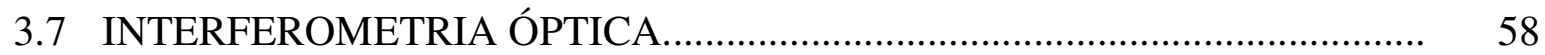

4 METODOLOGIA EXPERIMENTAL_............................................................ 60

4.1 SISTEMA EXPERIMENTAL PARA DEPOSIÇÃO E TRATAMENTO DOS

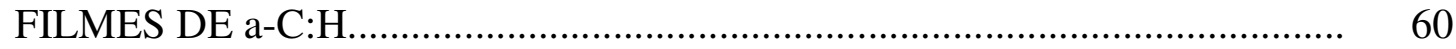

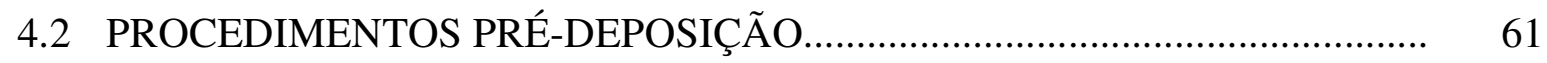

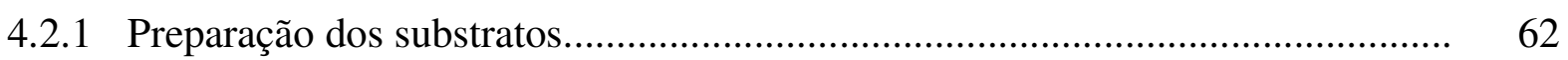




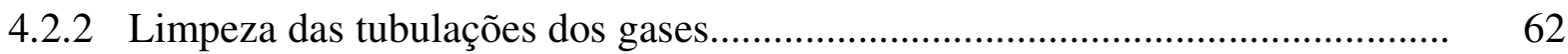

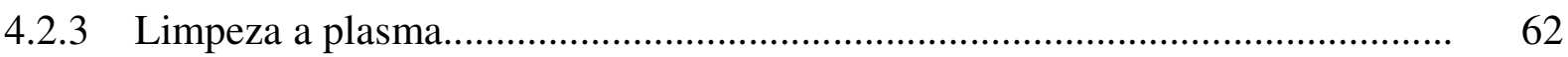

4.3 PARÂMETROS DAS DEPOSIÇÕES......................................................... 63

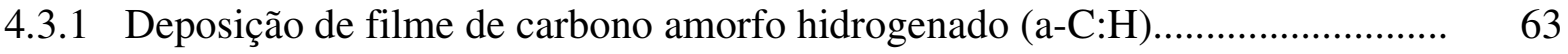

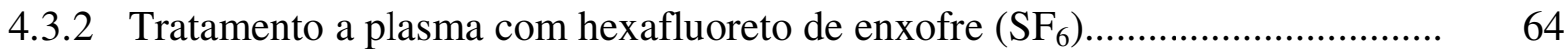

4.3.3 Deposição de filme de carbono amorfo hidrogenado fluorado (a-C:H:F)......... 64

5 RESULTADOS E DISCUSSÕES...................................................................... 66

5.1 EFEITOS DA POTÊNCIA DE EXCITAÇÃO DO PLASMA NAS PROPRIEDADES DOS FILMES DE a-C:H................................................ 66

5.1.1 Estrutura Molecular e Composição Química dos Filmes de $\mathrm{a}-\mathrm{C}: \mathrm{H}$

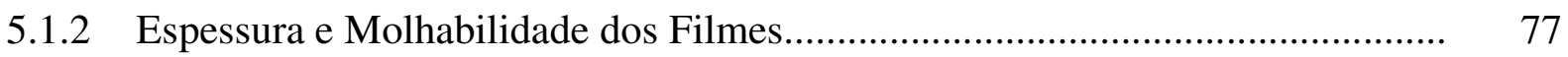

5.1.3 Propriedades Mecânicas e Tribológicas dos Filmes.......................................... 79

5.1.4 Rugosidade dos Filmes.................................................................................. 82

5.2 PROPRIEDADES DE FILMES DE a-C:H TRATADOS EM PLASMAS DE

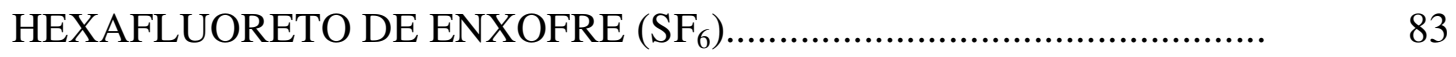

5.2.1 Estrutura Molecular e Composição Química dos filmes .................................. 83

5.2.2 Espessura e Molhabilidade dos Filmes .......................................................... 94

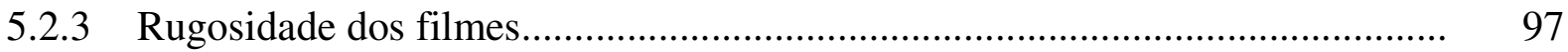

5.2.4 Dureza e coeficiente de atrito dos filmes.......................................................... 99

5.3 PROPRIEDADES DE FILMES DE CARBONO AMORFO HIDROGENADO FLUORADO .......................................................... 101

5.3.1 Estrutura Molecular e Composição Química dos Filmes................................... 101

5.3.2 Espessura e Molhabilidade dos Filmes........................................................... 109

5.3.3 Coeficiente de Atrito dos Filmes....................................................................... 111

5.3.4 Rugosidade dos Filmes de a-C:H:F......................................................... 112

6 CONCLUSÕES E PERSPECTIVAS FUTURAS........................................ 115

REFERÊNCIAS........................................................................................ 117 


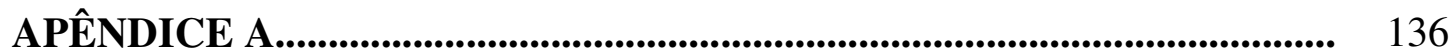

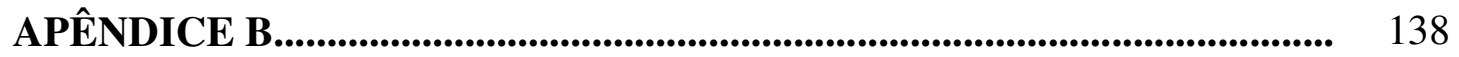




\section{LISTA DE FIGURAS}

FIGURA 1 - Representação das três formas de hibridizações do carbono: $\mathrm{sp}^{3}$, $\mathrm{sp}^{2}$ e $\mathrm{sp}^{1}$

FIGURA 2 - Diagrama de fase ternária das ligações nos possíveis tipos de carbono amorfo em função das concentrações de ligações $\mathrm{sp}^{3}, \mathrm{sp}^{2}$ e hidrogênio

FIGURA 3 - Processos envolvidos no mecanismo de crescimento dos filmes de a-C:H

FIGURA 4 - Esquema do processo de densificação por subimplantação.

FIGURA 5 - Esquema dos processos de subimplantação iônica: a) a Penetração direta, b) indireta e c) a relaxação da região densificada.

FIGURA 6 - Diagrama esquemático da estrutura de bandas do carbono amorfo.

FIGURA 7 - Esquema da estrutura molecular dos filmes de a-C:H, (a) tipo polímero depositado a plasma e (b) tipo grafite (cluster $\mathrm{sp}^{2}$ ).

FIGURA 8 - Espalhamento Rayleigh, Linha Raman Stokes e Anti-Stockes......

FIGURA 9 - Espectro Raman característico de um filme de a-C:H depositado no sistema PECVD, enfatizando os fatores que afetam a mudança nas posições e nas intensidades das bandas $\mathrm{D}$ e $\mathrm{G}$ dos filmes

FIGURA 10 - Fotografias do equipamento utilizado para determinação dos espectros Raman.

FIGURA 11 - (a) processo de emissão do fotoelétron e (b) processo de relaxação com emissão de elétron Auger.

FIGURA 12 - Espectro survey representativo de filmes de a-C:H.

FIGURA 13 - Espectro C 1s característico dos filmes de a-C:H.

FIGURA 14 - Espectro C 1s característico dos filmes de a-C:H fluorados

FIGURA 15 - Representação esquemática da geometria da superfície da 
amostra nas situações de carga máxima e após retirada do indentador.

FIGURA 16 - Curva característica carga-deslocamento de materiais com deformação elástica e plástica.......................................................................... 48

FIGURA 17 - Representação esquemática do equipamento de indentação.......... 49

FIGURA 18 - Ângulo de contato entre a gota de um líquido e uma superfície sólida.

FIGURA 19 - Situações para uma gota de água deionizada ao tocar uma superfície.

FIGURA 20 - Fotografia do goniômetro utilizado nas medidas de ângulo de contato e energia de superfície dos filmes

FIGURA 21 - Fotografia do Tribômetro modelo UMT utilizado para caracterização do coeficiente de atrito dos filmes

FIGURA 22 - Desenho esquemático do sistema utilizado para os testes tribológicos, no modo recíproco linear.

FIGURA 23 - Fotografia do perfilômetro utilizado nas medidas de espessura dos filmes.

FIGURA 24 - Degrau para medida de espessura; (a) substrato de vidro parcialmente recoberta por uma máscara; (b) deposição do filme sobre o substrato de vidro parcialmente recoberta pela máscara e (c) substrato de vidro recoberto pelo filme depois de retirada da máscara.

FIGURA 25 - Fotografia do interferômetro ótico utilizado na obtenção da rugosidade das superfícies dos filmes.

FIGURA 26 - Fotografias do sistema utilizado na deposição e tratamento dos filmes

FIGURA 27 - Espectros Raman dos filmes de a-C:H depositados por 5 e 10 minutos, em plasmas de em diferentes potências.

FIGURA 28 - Razão ID/IG, posição e largura das bandas D e G dos filmes de a-C:H, depositados por 5 e 10 minutos em função da potência.

FIGURA 29 - espectros de longa varredura dos filmes de a-C:H depositados em plasmas de diferentes potência.

FIGURA 30 - Proporções relativas das espécies presentes nas amostras 
depositadas por 5 e 10 minutos, em função da potência, após deconvolução do pico fotoelétrico C $1 \mathrm{~s}(284,8 \mathrm{eV})$.

FIGURA 31 - Concentração em percentagem atômica das espécies presentes nos filmes depositados durante 5 e 10 minutos, em função da potência

FIGURA 32 - Espessura dos filmes depositados durante 5 e 10 minutos, em função da potência..

FIGURA 33 - Ângulo de contato dos filmes depositados durante 5 e 10 minutos em função da potência.

FIGURA 34 - Comportamento da dureza dos filmes em função da potência de deposição.

FIGURA 35 - Coeficiente de atrito dos filmes de a-C:H depositados em 5 e 10 minutos, em função da potência.

FIGURA 36 - Raiz quadrática média (RMS) da rugosidade dos filmes de aC:H em função da potência de deposição.

FIGURA 37 - Espectros Raman dos filmes a-C:H após tratamento com $\mathrm{SF}_{6}$

FIGURA 38 - Razão $\mathrm{I}_{\mathrm{D}} / \mathrm{I}_{\mathrm{G}}$ em função da potência para os filmes de a-C:H, depositados durante 5 e 10 minutos e tratados em plasmas de $\mathrm{SF}_{6}$

FIGURA 39 - Posição central $\left(\varpi_{\mathrm{G}}\right)$ e largura $(\Delta \mathrm{G})$ da banda $\mathrm{G}$ em função da potência para os filmes de a-C:H depositados por 5 e 10 minutos antes e após exposição ao plasma de $\mathrm{SF}_{6}$

FIGURA 40 - Espectros de longa varredura (survey) dos filmes de a-C:H depositados em diferentes potências, após tratamento em plasmas de $\mathrm{SF}_{6} \ldots \ldots \ldots . . .$.

FIGURA 41 - Proporção das espécies presentes nas amostras de a-C:H (depositados por 5 e 10 minutos) em função da potência, após tratamento em plasma de $\mathrm{SF}_{6}$

FIGURA 42 - - Proporção de espécies fluoradas presentes nas amostras, depositadas por 5 e 10 minutos, em função da potência.

FIGURA 43 -. Concentrações relativas das espécies presentes nos filmes de a- 
$\mathrm{C}: \mathrm{H}(\mathrm{F})$, depositados por 5 e 10 minutos, em função da potência.

FIGURA 44 - Espessura dos filmes de a-C:H e a-C:H(F) em função da potência para as deposições com 5 e 10 minutos de duração.

FIGURA 45 - Ângulo de contato dos filmes de a-C:H em função da potência, para as amostras como-depositadas e as fluoradas.

FIGURA 46 - Rugosidade dos filmes de a-C:H e a-C:H(F), depositados por 5 e 10 minutos, com diferentes potências

FIGURA 47 - Dureza em função da potência para os filmes de a-C:H e a$\mathrm{C}: \mathrm{H}(\mathrm{F})$ depositados durante 5 minutos.

FIGURA 48 - Coeficiente de atrito $\mu$ dos filmes de a-C:H e a-C:H:F, depositados por 5 e 10 minutos, em plasmas de diferentes potências

FIGURA 49 - Espectro de espalhamento Raman dos filmes depositados em diferentes potências.

FIGURA 50 - Razão $\mathrm{I}_{\mathrm{D}} / \mathrm{I}_{\mathrm{G}}$, posição central $\left(\omega_{\mathrm{G}}\right)$ e largura da banda $\mathrm{G}(\Delta \mathrm{G})$ dos filmes, depositados em diferentes potências.

FIGURA 51 - Espectros XPS de longa varredura do substrato de vidro sem filme (a) e com filmes de a-C:H:F (b) depositados com potências de excitação do plasma de 5 a $125 \mathrm{~W}$

FIGURA 52 - Proporção das espécies presentes nos filmes de a-C:H:F em função da potência de deposição, conforme a deconvolução do pico C $1 \mathrm{~s}$

FIGURA 53 - Proporção de flúor presente nos filmes em função da potência de deposição.

FIGURA 54 - Concentrações atômicas totais de carbono, oxigênio, flúor, enxofre e silício nos filmes depositados em diferentes potências.....

FIGURA 55 - Espessura dos filmes em função da potência de deposição.

FIGURA 56 - Ângulo de contato dos filmes em função da potência de deposição. 
FIGURA 57 - Coeficiente de atrito dos filmes de a-C:H:F em função da potência........

FIGURA 58 - Rugosidade média quadrática dos filmes de a-C:H:F em função da variação de potência. 


\section{LISTA DE TABELAS}

TABELA 1 - Parâmetros de deposição dos filmes de a-C:H............................ 63

TABELA 2 - Parâmetro do tratamento a plasma de $\mathrm{SF}_{6}$ dos filmes de a-C:H.... 64

TABELA 3 - Tabela 3- Parâmetros das deposições dos filmes de a-C:H:F....... 65

TABELA 4 - Posição, largura e intensidade das bandas D e G dos espectros dos filmes depositados em 5 e 10 minutos, em plasmas de potências entre 5 e $125 \mathrm{~W}$

TABELA 5 - Ligações químicas e suas hibridizações, energias de ligação e proporções relativas, derivadas das componentes do pico C 1s dos filmes preparados com diferentes potências.

TABELA 6 - Tipo de ligação química, suas energias de ligação e proporções relativas, derivadas dos componentes do pico $\mathrm{O}$ 1s dos filmes de a-C:H depositados por 5 e 10 minutos, em plasmas de diferentes potências

TABELA 7 - Posição, largura e intensidade das bandas dos espectros dos filmes de a-C:H preparados durante 5 e 10 minutos em plasmas de diferentes potências e tratados em plasmas de $\mathrm{SF}_{6}$

TABELA 8 - Tipos de ligações químicas, energias de ligação e respectivas proporções dos componentes do pico $\mathrm{C} 1 \mathrm{~s}$ de filmes de a-C:H, depositados por 5 e 10 minutos e tratados em plasmas de $\mathrm{SF}_{6}$ 


\section{INTRODUÇÃO}

Muitos setores do mercado atual empregam produtos cada vez mais descartáveis, enquanto existem aplicações que exigem materiais de baixo custo, alta qualidade e durabilidade. O revestimento de superfícies com filmes duros é um procedimento ainda pouco adotado, mas muito eficiente no aumento de tempo de vida de materiais expostos a condições severas de operação. Entretanto, a complexidade de muitas peças automotivas, próteses ósseas e materiais metalúrgicos, tornam o recobrimento de toda a sua extensão, difícil. Em muitos casos, necessita-se de sistemas de rotação sofisticados, tornando o processo demorado e caro. Tais dificuldades podem ser facilmente contornadas quando técnicas de deposição de filmes a plasma são empregadas. Como neste processo a peça pode ficar inteiramente exposta ao plasma, ela recebe uma camada uniforme de filme em toda a sua extensão.

Filmes de carbono amorfo hidrogenado (a-C:H) depositado a plasma são atrativos para uma série de aplicações práticas pela combinação de propriedades como alta resistividade elétrica e condutividade térmica, resistência química, transparência ótica e alta dureza associada a baixo coeficiente de atrito (VALENTINI et al, 2001; LAMPERTI, 2005; MA, 2007).

Atualmente esses materiais já são utilizados como revestimentos de discos rígidos de microcomputadores (ROBERTSON, 2001). Nesses dispositivos, quanto menor a distância entre a cabeça de gravação e a superfície, maior a densidade de informações que pode ser armazenada. Nesse sentido, filmes de elevada dureza, resistência a riscos e ao desgaste, com espessuras reduzidas são de suma importância tecnológica.

Engrenagens automotivas, que se movimentam em altas velocidades umas contra as outras, são sujeitas a atrito severo. Confeccionadas a partir de metais, seu desgaste é intenso mesmo sob lubrificação. Assim, camadas de baixo coeficiente de atrito e alta resistência ao desgaste aumentam o tempo de vida útil dessas peças amplamente difundidas no mercado (GUNTHER, 1993).

Carbonos amorfos hidrogenados combinam também muitos das propriedades exigidas por revestimentos de implantes ósseos. O mecanismo de falha mais comum 
nesses dispositivos é o desgaste de juntas, que limita o seu tempo de vida. Partículas geradas pelo desgaste do material do implante podem induzir a osteólise, causando morte de células ósseas e perda da prótese (BLACK, 1988). Além de suas propriedades mecânicas e tribológicas adequadas, filmes de a-C:H demonstram excelente biocompatibilidade e hemocompatibilidade (BENDAVID, 2009; HASEBE et al., 2006; HAUERT, 2003). Assim, se mostra útil a aplicação dessa tecnologia de revestimento para aumentar o desempenho e consequentemente a longevidade de materiais tipo juntas ortopédicas.

É importante ressaltar ainda que a durabilidade de um material está diretamente relacionada com sua resistência física. Portanto, mesmo em aplicações onde resistência mecânica não seja importante, a durabilidade é um fator essencial. Aplicações de a$\mathrm{C}: \mathrm{H}$ em dispositivos óticos e eletro-eletrônicos podem ser tomados como exemplos destes casos. Eles incluem camadas dielétricas e semicondutoras em circuitos integrados (RODIL et al., 2000), e filmes anti-reflexivos em sensores de infravermelho (METIN et al., 1994).

Neste trabalho objetivou-se estudar a influência da incorporação de flúor em filmes de carbono amorfo hidrogenados (a-C:H) obtidos a partir da mistura de acetileno/argônio, antes e após tratamento com plasma de $\mathrm{SF}_{6}$, e as propriedades dos filmes a-C:H:F depositados a partir da mistura de acetileno/argônio/SF 6 . A fluoração promove mudanças nas propriedades de filmes de a-C:H, como: redução da densidade; alteração na espessura (ENDO, 1995; YOKOMICHI, 1998; GRILL, 1998); redução da tensão interna (JACOBSOHN, 2000); alteração no coeficiente de atrito (PRIOLI, 2003; GRILL, 1998); aumento na hidrofobicidade (PRIOLI, 2003; YAO 2004); baixa energia superficial (YU, 2003); anti-aderência de bactérias (YAO, 2004); e outras. Logo, a compreensão dessas mudanças foi a motivação para a obtenção de filmes de aC:H e sua modificação através do processo de fluoração. Tal processo, geralmente é realizado através de misturas de: $\mathrm{CH}_{4}+\mathrm{CF}_{4}$ (DURRANT et al., 1996; FREIRE, 2001), $\mathrm{C}_{2} \mathrm{H}_{2}+\mathrm{C}_{2} \mathrm{~F}_{6}$ (RONNING et al, 2001), $\mathrm{CHF}_{3}+\mathrm{Ar}$ (JIANG, 2006), $\mathrm{C}_{2} \mathrm{~F}_{6}+\mathrm{H}_{2}$ (D’AGOSTINO et al., 1993), $\mathrm{C}_{2} \mathrm{H}_{2}+\mathrm{CF}_{4}$ (LAMPERTI, 2001) e outros, com obtenção de filmes de carbono amorfo fluorados. 
O grande desafio neste trabalho foi modificar a superfície dos filmes de a-C:H a partir do tratamento a plasma de $\mathrm{SF}_{6}$, utilizando o método de Deposição Química na Fase Vapor Assistida por Plasma (PECVD), visando aplicações em revestimentos protetores com baixo coeficiente de atrito. $\mathrm{O}$ hexafluoreto de enxofre $\left(\mathrm{SF}_{6}\right)$ é um composto químico inorgânico, formado por 1 átomo de enxofre e 6 átomos de flúor. É um gás sintético, utilizado principalmente pela indústria elétrica, como meio isolante e extintor de arco elétrico, tanto em disjuntores, como em uma subestação blindada. Possui grande eletronegatividade, é quimicamente inerte e representa menos de $1 \%$ de colaboração no aquecimento global. Assim, a utilização do $\mathrm{SF}_{6}$ é economicamente e ambientalmente mais viável. 


\section{REVISÃO BIBLIOGRÁFICA}

\subsection{CARBONO AMORFO HIDROGENADO (a-C:H)}

Ao longo das últimas décadas, a pesquisa e o desenvolvimento de materiais nanoestruturados à base de carbono vem se tornando cada vez mais fundamental para o avanço das indústrias aeroespaciais, eletrônica, biomédicas entre outras (BRISCOE, 1990; ROBERTS, 1990; BUTTER et al., 1995; RODIL, 2000; SANTOS L, 2004; ERDEMIR, 2001; RANGEL et al., 2004).

Carbono amorfo hidrogenado (a-C:H), carbono tipo diamante (Diamond-Like Carbon - DLC), carbono amorfo tipo diamante (a-DLC) ou carbono amorfo (a-C), são termos usados na literatura que se referem ao mesmo material (ANGUS, 1991; INAGO, 1996; MARSH, 2001; ROBERTSON, 2002).

O carbono amorfo possui estrutura com ordem a curta distância e suas propriedades elétricas, mecânicas e estruturais, são dependentes da razão entre as hibridizações $\mathrm{sp}^{2} \mathrm{e} \mathrm{sp}^{3}$. Atualmente, existem várias subdivisões deste carbono amorfo, tais como: grafite micro cristalino, diamante micro-cristalino, carbono amorfo tipo polimérico, carbono amorfo tipo diamante e carbono tetraédrico tipo diamante. Essas subdivisões são definidas de acordo com o tamanho do cristalito e com o grau de cristalinidade (LIFSHITZ, 1994; GRILL, 1999).

Os filmes de a-C:H foram produzidos pela primeira vez em 1969 ( TZENG, 1999). Desde 1971, os filmes de a-C:H, têm sido produzidos por diversas técnicas de deposição (ROBERTSON, 2002). Entre estas técnicas, estão os processos de deposição química a vapor assistido por plasma DC ou RF (PECVD - Plasma Enhanced Chemical Vapor Deposition) (CHOI et al., 1997; SUN et al., 1997; SUN, 1999; VENCAMMEN et al., 2000; SANCHEZ et al., 2000; KUMAR et al., 2001; FEDOSENKO et al., 2002; BAN et al., 2002; LAMPERTI, 2003;), os processos de deposição física (Sputtering) (VENCAMMEN, 2000; WEBB, 1998; KORMNINOU et al., 2000; KULIKOVSKY et al., 2001), processos de deposição por feixe de íons (VENCAMMEN et al., 2000; WALTER et al., 1995; AVASTHI, 1996; LACERDA et al., 2000), processos de deposição por vapor químico (CVD) (SUN, 1999), além de 
outras técnicas de deposição (VENCAMMEN et al., 2000; GIELEN, 1995; HAKOVIRTA, 1999; WANG, 1999).

Os filmes de a-C:H podem apresentar características metaestáveis com hibridizações $\mathrm{sp}^{3}, \mathrm{sp}^{2}$ e $\mathrm{sp}^{1}$ (ROBERTSON, 2002) e possuírem propriedades semelhantes às do diamante (ROBERTSON, 2002; INAGO, 1996; MARSH, 2001). Eles podem ser considerados como uma forma intermediária entre o diamante e a grafite. As propriedades dos filmes de a-C:H, variam dependendo da quantidade de hibridizações $\mathrm{sp}^{3}, \mathrm{sp}^{2}$ e $\mathrm{sp}^{1}$ e da concentração de hidrogênio nos mesmos (WASA, 1992; BRAUN, 1998). O diamante é um material que possui propriedades bem conhecidas e determinadas. As propriedades dos filmes de a-C:H apresentam transição entre as propriedades do diamante, da grafite e de polímeros. Como por exemplo, suas propriedades mecânicas e tribológicas dependem da estrutura atômica desse material (ROBERTSON, 2002).

\subsubsection{Hibridização do Carbono}

Os filmes de a-C:H possuem uma mistura de hibridizações do tipo $\mathrm{sp}^{3}, \mathrm{sp}^{2}$ e $\mathrm{sp}^{1}$ e podem apresentar propriedades similares às do diamante, tais como, alta dureza e módulo elástico e são quimicamente inertes. Eles são produzidos como filmes finos isotropicamente desordenados com limites de grão não definidos.

Na figura 1, são apresentadas as três formas de hibridações do carbono.

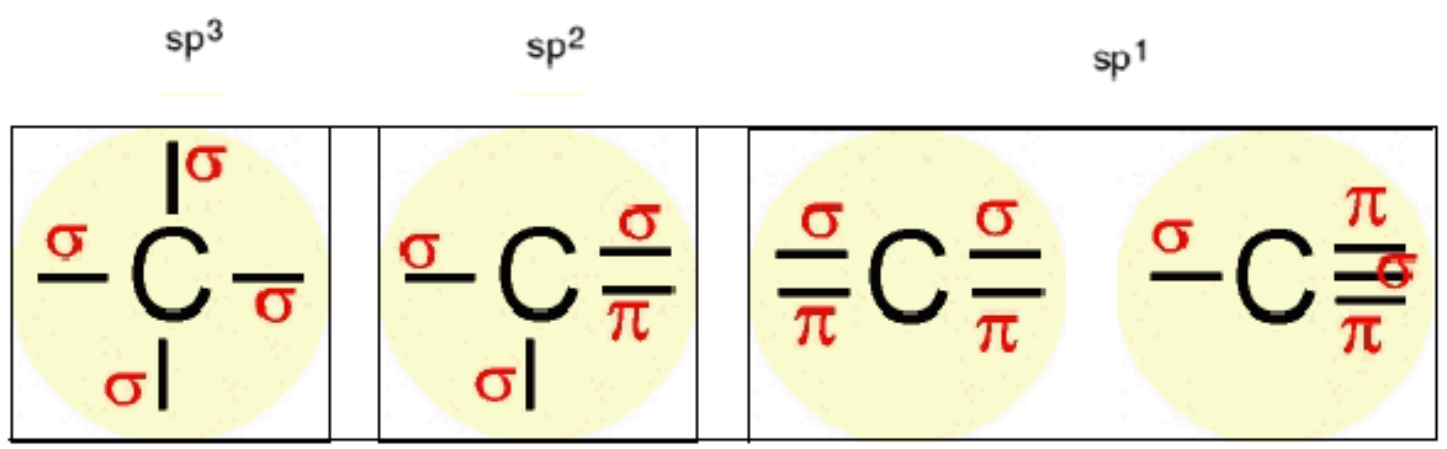

Figura 1 - Representação das três formas de hibridizações do carbono: $\mathrm{sp}^{3}, \mathrm{sp}^{2} \mathrm{e} \mathrm{sp}^{1}$.

Nesta figura, observam-se as três formas de hibridizações do carbono: $\mathrm{sp}^{3}$ com 
quatro orbitais híbridos tipos $\sigma$ (quatro ligações simples); $\mathrm{sp}^{2}$ com três orbitais híbridos do tipo $\sigma$ e uma do tipo $\pi$ sendo uma dupla ligação e duas ligações simples; $\mathrm{sp}^{1}$ com dois orbitais híbridos, com duas ligações duplas ou com uma ligação tripla e uma simples (duas ligações do tipo $\sigma$ e duas do tipo $\pi$ ).

O diamante possui apenas ligações $\mathrm{sp}^{3}$, onde cada um dos quatro elétrons da camada de valência tende a formar ligações tetraédricas, saturadas, tipo sigma $(\sigma)$ com $\mathrm{o}$ átomo de carbono vizinho. A grafite possui ligação $\mathrm{sp}^{2}$ onde três dos quatro elétrons da camada de valência estão em orbitais $\mathrm{sp}^{2}$ trigonalmente direcionados formando ligações $\sigma$ com os átomos de carbono no plano. $\mathrm{O}$ quarto elétron se situa em um orbital pi $(\pi)$ normal ao plano das ligações $\sigma$. As ligações insaturadas $\pi$ formadas com um ou mais orbitais $\pi$ dos vizinhos são mais fracas que as ligações $\sigma$. Na configuração $\mathrm{sp}^{1}$, dois elétrons de valência estão em orbitais $\sigma$, cada um formando ligações direcionadas ao longo do mesmo eixo, enquanto que os outros dois elétrons formam ligações $\pi$. Este tipo de hibridação ocorre em compostos carbono-carbono, cuja geometria é linear.

Um diagrama de fase ternária das ligações dos filmes de a-C:H e ligas de carbono-hidrogênio foi mostrado pela primeira vez por Jacob (JACOB, 1998) e Moller (MOLLER, 1993) apresentando as várias formas possíveis de mistura amorfas do carbono. Na figura 2, pode-se observar esse diagrama.

Nos vértices do diagrama ternário encontram-se os pontos para $100 \%$ de ligações $\mathrm{sp}^{2}$ (grafite), $\mathrm{sp}^{3}$ (diamante) e para hidrogênio. As concentrações de estados $\mathrm{sp}^{2}, \mathrm{sp}^{3}$ e hidrogênio são responsáveis pela estrutura e propriedades físicas e químicas dos filmes de a-C:H.

Algumas regiões do diagrama definem grupos específicos de carbonos, tais como: os carbonos amorfos (a-C) que apresentam estruturas de grafite desordenadas (máximo $80 \%$ de ligações $\mathrm{C}=\mathrm{C}$ com hibridização $\mathrm{sp}^{2}$ ), os carbonos amorfos tetraédricos (ta-C) com no máximo $85 \%$ de ligações C-C $\mathrm{sp}^{3}$, assim como suas fases hidrogenadas, representadas pelo carbono amorfo hidrogenado tetraédrico (ta-C:H) com concentração atômica de hidrogênio em torno de 25 e $30 \%$ e ligações $\mathrm{C}-\mathrm{C}\left(\mathrm{sp}^{3}\right)$ e carbono amorfo hidrogenado $(\mathrm{a}-\mathrm{C}: \mathrm{H})$. Na parte inferior direita do diagrama estão as estruturas poliméricas e macromoléculas. 


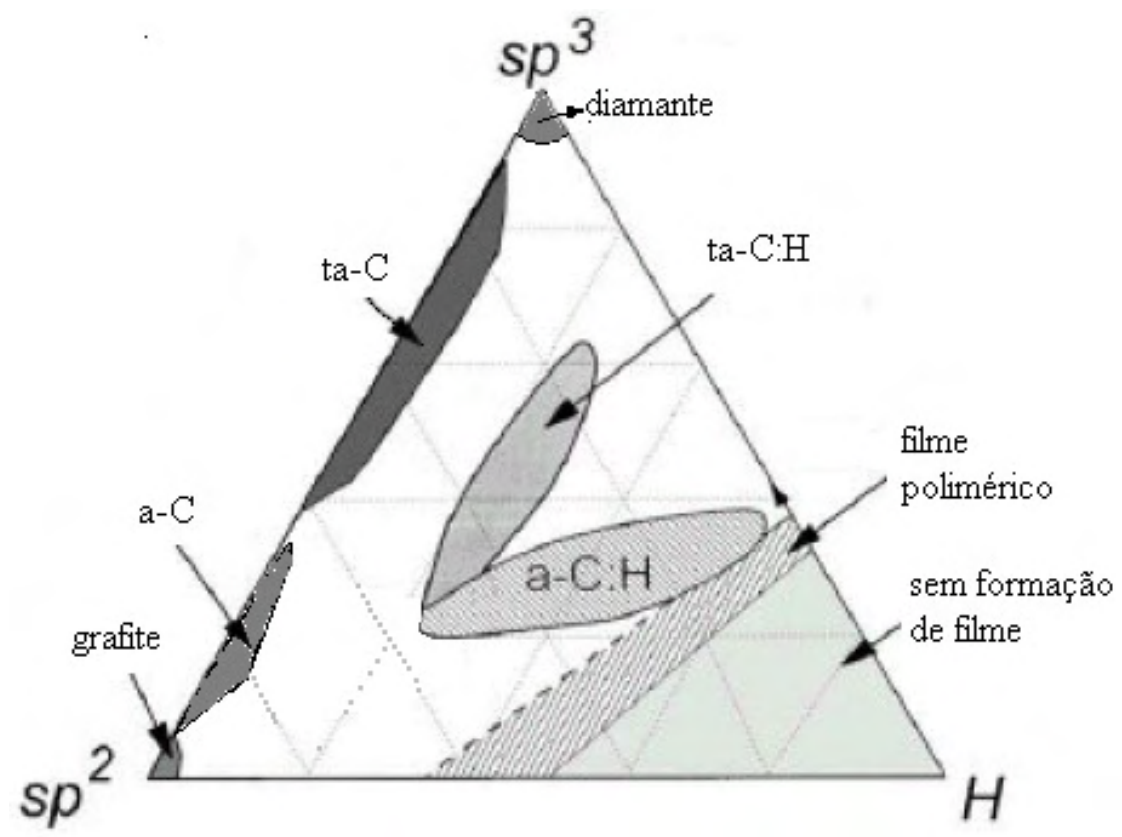

Figura 2 - Diagrama de fase ternária das ligações nos possíveis tipos de carbono amorfo em função das concentrações de ligações $\mathrm{sp}^{3}, \mathrm{sp}^{2}$ e hidrogênio (FERRARI, 2000).

Os filmes de a-C:H encontram-se no centro do diagrama de fase ternária com uma fração de átomos de carbono distribuída entre hibridizações $\mathrm{sp}^{2}, \mathrm{sp}^{3}$ e hidrogênio ligado. Quando os filmes de a-C:H apresentam concentrações atômicas de hidrogênio entre 40 e $60 \%$ e mais de $70 \%$ de ligações $\mathrm{C}-\mathrm{H}\left(\mathrm{sp}^{3}\right)$ são caracterizados como tipo polimérico; se apresentam concentrações atômicas de hidrogênio entre 20 e $40 \%$ e ligações C-C $\left(\mathrm{sp}^{3}\right)$ são denominados como tipo diamante e se apresentam percentual de hidrogênio menor que $20 \%$ at. e ligações $\mathrm{C}=\mathrm{C}\left(\mathrm{sp}^{2}\right)$ são denominados tipo grafitico (FERRARI, 2000).

\subsection{MECANISMOS DE DEPOSIÇÃO DOS FILMES a-C:H}

Várias técnicas de deposição de filmes de a-C:H foram desenvolvidos para obtenção de filmes com maior conteúdo de hibridizações sp $^{3}$ (ROBERTSON, 2002). 
Neste trabalho, foi utilizado o processo de Deposição Química na fase Vapor Assistido por Plasma - PECVD. Esta técnica consiste na formação de um plasma a partir de um gás de hidrocarboneto, tais como o metano $\left(\mathrm{CH}_{4}\right)$, acetileno $\left(\mathrm{C}_{2} \mathrm{H}_{2}\right)$, etileno $\left(\mathrm{C}_{2} \mathrm{H}_{4}\right)$, benzeno $\left(\mathrm{C}_{6} \mathrm{H}_{6}\right)$, etc. excitado por uma fonte de rádiofrequência com acoplamento capacitivo. Existem três estágios gerais para os processos de deposição de filmes de a-C:H por plasma: as reações no plasma (dissociação, ionização, etc.), a interação plasma-superfície e as reações de sub-superficies no filme. As reações no plasma são descritas pelos elétrons energéticos (distribuição eletrônica de energia). Além dessas reações, podem ocorrer reações secundárias no plasma, tais como a polimerização dos filmes.

As espécies incidentes no plasma durante o processo de crescimento dos filmes de a-C:H consistem de íons, radicais livres, partículas neutras, átomos e moléculas em estados excitados (YASUDA, 1985). Os íons e os radicais livres podem formar moléculas, tais como um precursor gasoso não dissociado, monos-radicais (como por exemplo, $\left.\mathrm{CH}_{3}\right)$ e outras espécies insaturadas $\left(\mathrm{C}_{2} \mathrm{H}_{4}\right.$ ou $\left.\mathrm{C}_{2} \mathrm{H}_{2}\right)$. O plasma também contém uma quantidade significativa de átomos de hidrogênio.

Materiais depositados por PECVD podem ser orgânicos ou inorgânicos, dependendo da composição química do plasma (MOROSOFF, 1990). Entretanto, partindo-se de um mesmo composto, pode-se obter, por exemplo, filmes poliméricos (amorfos de baixa densidade e moles) (NOVIKOV et al., 1997), carbonos amorfos hidrogenados (moderam entre densos e duros) (FREIRE, 2002) e carbono grafíticos (com estrutura altamente ordenada, alta proporção de hibridizações $\mathrm{sp}^{2}$ e baixas durezas) (LEE, 1996).

Tais resultados são devidos ao diferente grau de interação entre o plasma e a superfície (MOROSOFF, 1990), e podem ser controlado pelos parâmetros experimentais (como potência, pressão e fluxo de gases, frequência de excitação e temperatura do substrato durante o processo) (YASUDA, 1995). Variações nestes parâmetros afetam diretamente as características "intrínsecas" do plasma, isto é, a densidade eletrônica e iônica, a função distribuição de energia dos elétrons, o potencial de plasma, entre outros (BITTENCOURT, 1986). 
Durante o processo de deposição de filmes de a-C:H, atuam diversos processos físicos e químicos que irão definir as características do filme obtido. A figura 3 mostra vários desses processos.

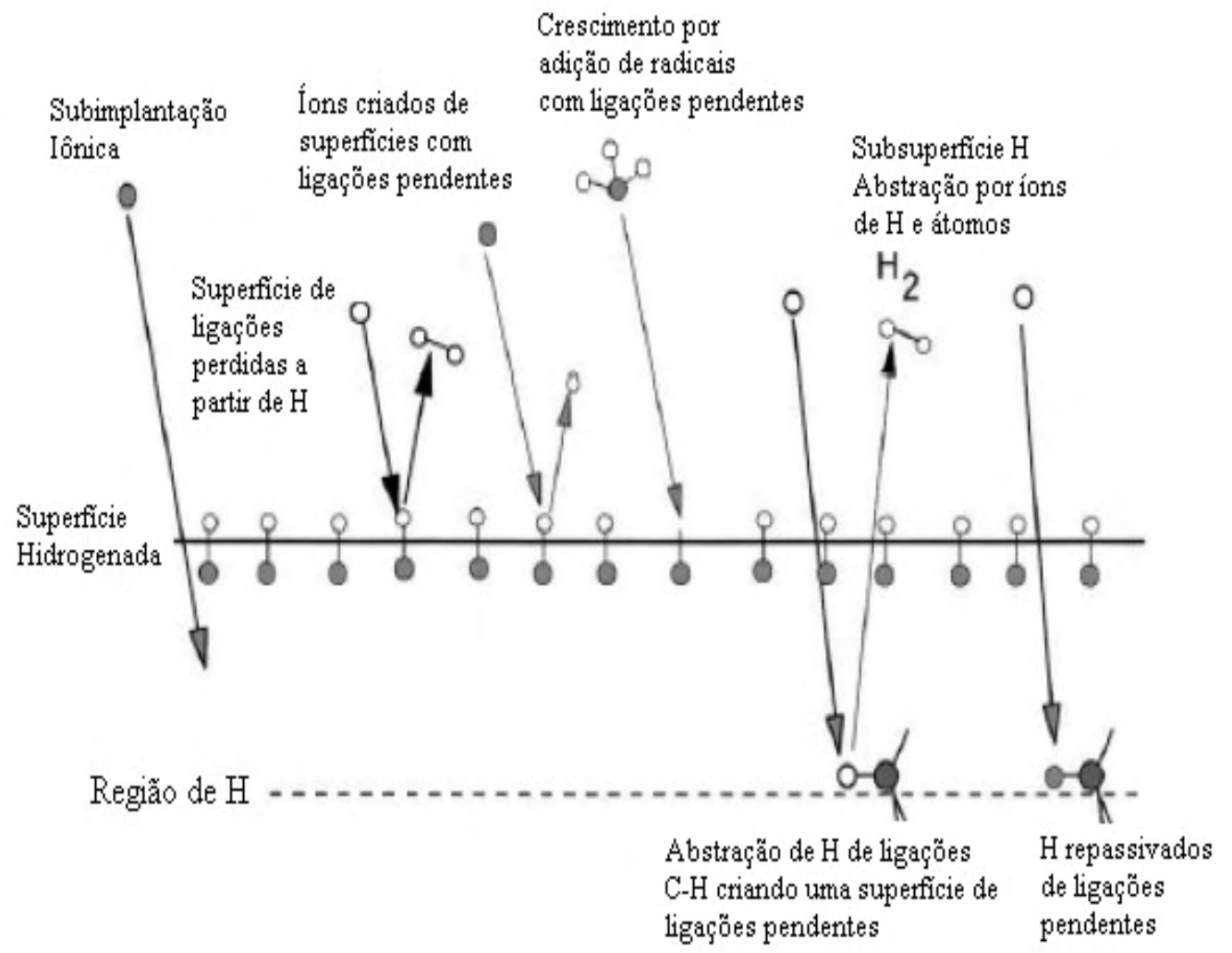

Figura 3 - Processos envolvidos no mecanismo de crescimento dos filmes de a-C:H (ROBERTSON, 2002).

Na deposição por PECVD existe uma dependência bastante clara com a energia de bombardeio dos íons e a mistura gasosa precursora. Para o entendimento do crescimento dos filmes de a-C:H, são fundamentais dois processos que ocorrem simultaneamente na deposição por PECVD: o processo físico de sub-implantação iônica e o processo químico envolvendo espécies neutras e desidrogenação chamado de mecanismo de camada adsorvida.

No mecanismo de camada adsorvida tem-se a adsorção de radicais neutros produzidos pelas reações que ocorrem no plasma (dissociação, ionização, etc.) (JACOB, 1998; MOLLER, 1993). O radical formado pode ser adsorvido com maior ou menor probabilidade dependendo do seu coeficiente de adesão nas ligações 
pendentes na superfície do material. Essas ligações pendentes são criadas pela remoção de um átomo na superfície do filme. Essa remoção pode ocorrer por erosão química ou pelo processo de bombardeio ao qual a amostra se encontra submetido durante a deposição.

As espécies neutras de hidrocarbonetos podem reagir somente na superfície, não podendo penetrar dentro do filme. Os átomos de hidrogênio são muito pequenos e podem penetrar aproximadamente $2 \mathrm{~nm}$ (KEUDELL, 2001). Dentro do filme, eles podem interagir com hidrogênio das ligações $\mathrm{C}-\mathrm{H}$ e criar ligações pendentes e moléculas de hidrogênio. Por outro lado, algumas destas ligações pendentes podem ser saturadas pelo hidrogênio atômico.

Nos filmes de a-C:H, o hidrogênio cria ligações terminais já que possui a possibilidade de realizar só uma ligação química, portanto as ligações pendentes estão correlacionadas a átomos de carbono. Em uma atmosfera precursora rica em hidrogênio a quantidade de ligações pendentes na superfície do filme em crescimento será reduzida, uma vez que o hidrogênio irá passivar estas ligações. O bombardeamento iônico gera a quebra de ligações químicas e provoca a formação de novos sítios para a absorção de radicais (JACOB, 1998).

Os mecanismos de adsorção e subimplantação ocorrem simultaneamente durante a deposição dos filmes e um auxilia o outro. No caso do mecanismo de camada adsorvida, o bombardeio iônico, também responsável pela subimplantação, provoca o aparecimento de ligações pendentes. Para a subimplantação iônica, o mecanismo de adsorção forma camadas menos densas de filmes facilitando a penetração dos íons e levando à posterior densificação da estrutura.

O mecanismo de subimplantação iônica está associado ao bombardeamento da superfície do substrato e/ou do filme pelos íons gerados no plasma. Dessa forma, os íons colidem com a superfície do filme transferindo momento. Após essa primeira colisão podem ocorrer novas colisões binárias entre os átomos do filme desencadeando um rearranjo estrutural ou provocando um processo de erosão (sputtering) da superfície. O processo de sputtering auxilia na formação de ligações pendentes (dangling bonds) que por sua vez irá auxiliar na adsorção de radicais neutros. 
As mudanças estruturais nos filmes ocorrem com a penetração dos íons até umas poucas camadas atômicas abaixo da superfície, criando uma região de alta pressão localizada (DAVIS, 1993), favorecendo a formação de ligações $\mathrm{sp}^{3}$ (ROBERTSON, 1993; ROBERTSON, 1994; GRILL, 1993). Um crescimento subsuperficial da densidade seria necessário para a formação de ligações $\mathrm{sp}^{3}$ como ocorre na formação de diamantes.

Na figura 4 está mostrado esquematicamente o processo de densificação pelo mecanismo de subimplantação iônica.

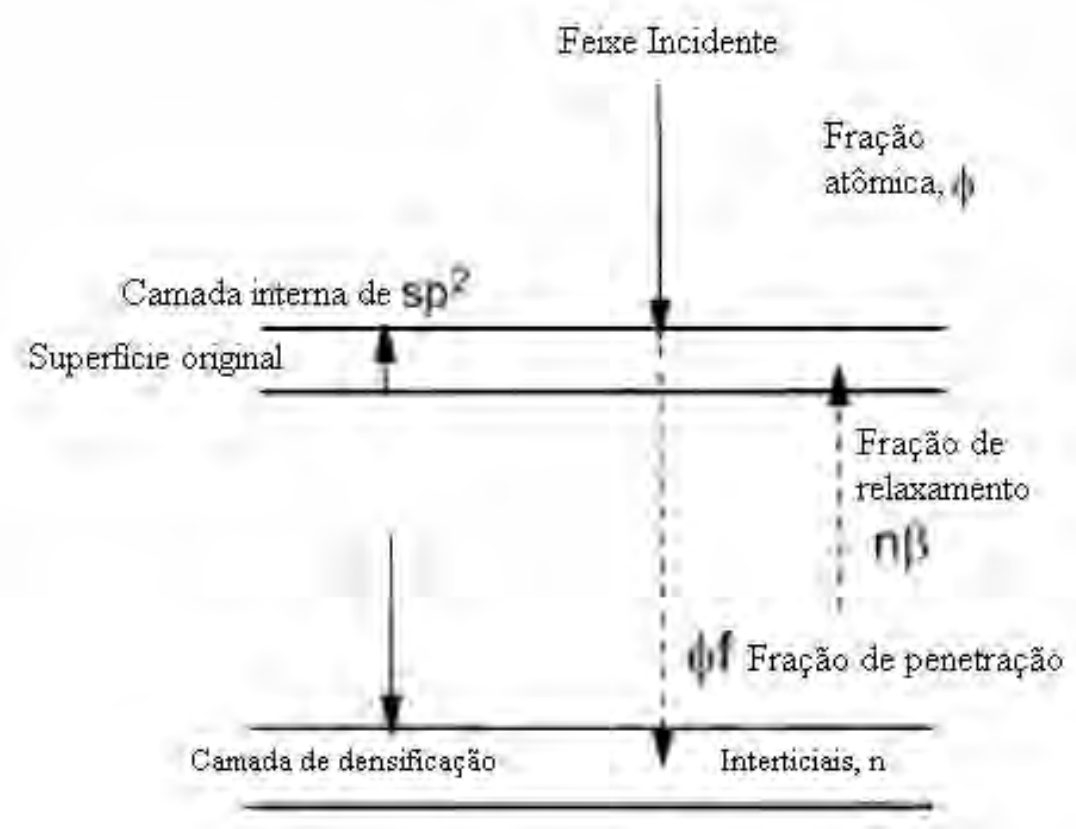

Figura 4 - Esquema do processo de densificação por subimplantação (ROBERTON, 2002).

Os íons que atingem a superfície do filme podem ou não ter energia suficiente para penetrar a superfície. Os que têm energia superior ao limiar de penetração podem penetrar diretamente ou forçar uma penetração indireta pela colisão com os átomos da superfície nos espaços intersticiais, aumentando a densidade atômica local e favorecendo a formação de ligações $\mathrm{sp}^{3}$. Os íons que não tem energia suficientemente alta para penetrar no filme, ficam na superfície formando hibridizações $\mathrm{sp}^{2} \mathrm{e}$ contribuem para o crescimento do filme mediante um processo de relaxação (ROBERTSON, 2002). 
$\mathrm{Na}$ figura 5 estão esquematizadas as bases do modelo de subimplantação através da penetração direta, da penetração indireta ou por colisão com recuo ("knock-on") dos átomos da superfície e a relaxação da região densificada. Nesse processo a energia dos íons é crítica, pois caso os íons não tenham energia suficiente para penetrar na estrutura não ocorrerá a densificação e haverá a formação de filmes com uma menor fração de átomos de carbono com hibridização $\mathrm{sp}^{3}$ e menor densidade.

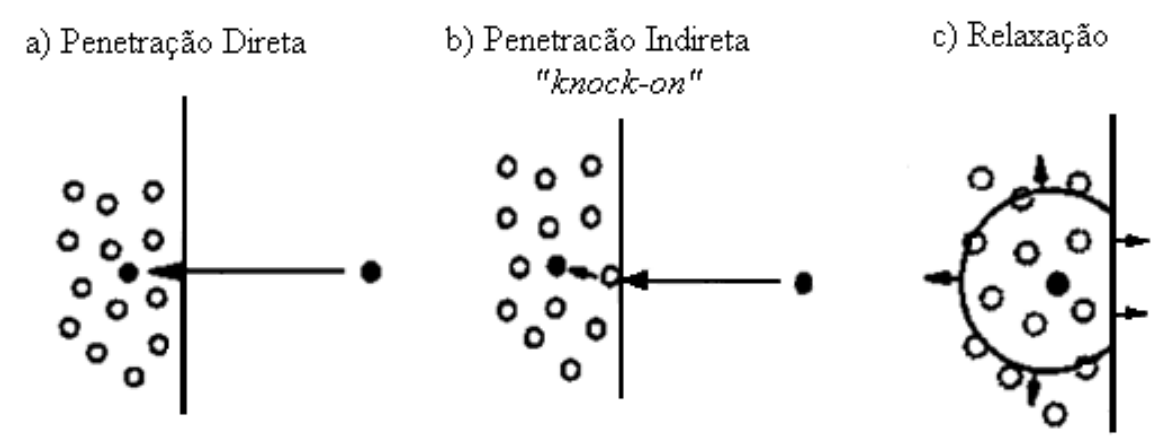

Figura 5. Esquema dos processos de subimplantação iônica: a) a penetração direta, b) indireta e c) a relaxação da região densificada (ROBERTSON, 2002).

Em trabalhos apresentados na literatura foi constatado que íons $\mathrm{C}_{2} \mathrm{H}_{2}{ }^{+}$são os mais prováveis em plasmas de misturas de acetileno e argônio, empregados na deposição de filmes do tipo diamante (WEILER, 1994; LEE, 1996; RANGEL et al., 2004). A predominância de íons $\mathrm{C}_{2} \mathrm{H}_{2}{ }^{+}$em plasmas de baixa pressão é devido à menor energia exigida para a ionização direta do acetileno comparada com sua ionização dissociativa. Nos plasmas empregados neste trabalho, entretanto, o grau de decomposição do composto orgânico é maior, visto que a pressão utilizada é de, no mínimo, uma ordem de grandeza maior $(9,5 \mathrm{~Pa})$. Assim, sucessivas fragmentações e

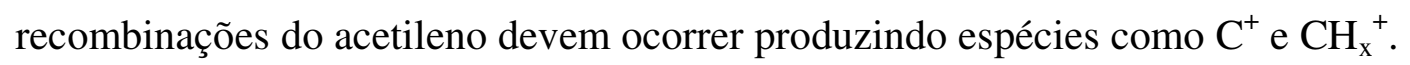

Por uma perspectiva de massa, íons gerados a partir do acetileno são mais leves e consequentemente mais móveis que íons $\mathrm{Ar}^{+}$. Além disso, a grande diferença na reatividade do $\mathrm{Ar}^{+}$e dos íons radicais $\left(\mathrm{CH}_{\mathrm{x}}^{+}, \mathrm{C}^{+}\right)$faz com que o tempo de vida destes últimos seja muito menor. Radicais ionizados podem contribuir mais efetivamente para o bombardeamento de superfícies devido a sua maior mobilidade e para o 
processo de deposição devido à sua maior reatividade. Pode também haver recombinação entre íons radicais no próprio plasma. Grandes proporções dessas espécies são então perdidas, reduzindo a densidade de íons no plasma. Considerandose a condição de neutralidade de cargas, elétrons respondem prontamente a essa variação, difundindo-se para as superfícies expostas ao plasma. Este fenômeno tende a equilibrar a proporção de espécies carregadas positiva e negativamente.

Com o aumento de potência, a fração de íons radicais e consequentemente de elétrons perdidos devem aumentar como conseqüência da maior taxa de crescimento do filme. Argônio torna-se a espécie ionizada predominante, e a energia média dos elétrons maior.

O aumento da potência torna o plasma mais reativo e, portanto, os processos de excitação e fragmentação de ligações químicas bastante efetivas. A ionização do argônio deve ocorrer por colisões com espécies com energias maiores que $16 \mathrm{eV}$, cuja densidade na descarga é mais baixa que a de elétrons menos energéticos (BIERDERMAN ，1992; DAVIS，1993; ROBERTSON, 1993; GRANIER, 1994; RANGEL et al., 2004). Espécies provenientes do acetileno, tais como $\mathrm{C}, \mathrm{CH}, \mathrm{CH}_{2}$, etc., possuem energias de ionização menores que a necessária para ionizar o argônio. Portanto, acredita-se que o processo mais favorecido nesses plasmas seja a ionização dissociativa da molécula de acetileno.

\subsection{ESTRUTURA ATÔMICA DOS FILMES a-C:H}

As ligações $\sigma$ em C-C e C-H forma estados $\sigma$ preenchidos na banda de valência e estados vazios $\sigma^{*}$ na banda de condução, separados pelo gap de distância larga $\sigma$ $\sigma^{*}$. As ligações $\pi$ em $\mathrm{sp}^{2} \mathrm{e} \mathrm{sp}^{1}$ formam estados preenchidos $\pi$ e estados vazios $\pi^{*} \operatorname{com}$ um gap muito estreito $\pi-\pi^{*}$ (ROBERTSON, 2002). A banda gap é determinada pela configuração de estados nos sítios $\mathrm{sp}^{2}$ (grafite). Numa estrutura cristalina, como do diamante, a banda gap é definida como a mínima energia entre um estado preenchido e 
um estado vazio. A figura 6 apresenta um diagrama esquemático da estrutura de bandas do carbono amorfo.

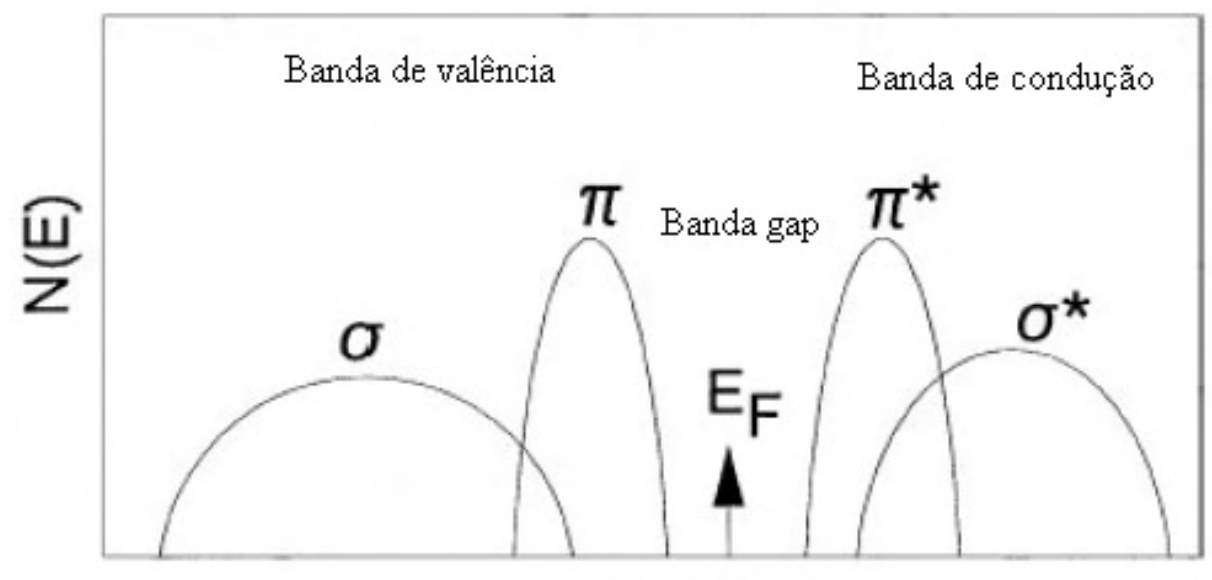

\section{Energia}

Figura 6 - Diagrama esquemático da estrutura de bandas do carbono amorfo (ROBERTSON, 1987).

Com base nas propriedades das ligações do tipo $\sigma$ e $\pi$, Robertson propôs um modelo para explicar a estrutura molecular dos filmes de a-C:H. O modelo é conhecido como modelo de aglomerados ("clusters") e permite explicar as relevantes propriedades dos filmes de a-C:H. Segundo este modelo, a estrutura dos filmes pode ser descrita como uma matriz inicial de carbonos com hibridização $\mathrm{sp}^{3}$ formando elos de ligação entre aglomerados de carbono com hibridização $\mathrm{sp}^{2}$, anéis grafiticos e/ou aromáticos distorcidos. Também se pode falar do arranjo estrutural como um composto bifásico, onde os aglomerados de carbono $\mathrm{sp}^{2}$ estão imersos em uma matriz de carbono $\mathrm{sp}^{3}$. As dimensões desses aglomerados de carbono $\mathrm{sp}^{2}$ determinariam a largura da banda $\pi-\pi^{*}$.

A quantidade desses carbonos com hibridização $\mathrm{sp}^{3}$ seria responsável pela dureza dos filmes, ou seja, com um aumento de domínios $\mathrm{sp}^{3}$ em relação aos domínios $\mathrm{sp}^{2}$ seria possível a obtenção de filmes mais duros. A formação das ligações $\mathrm{sp}^{3}$ está relacionada à energia de bombardeio dos íons. Existe uma energia onde é maximizada a formação de carbono com hibridização $\mathrm{sp}^{3}$, tipicamente $100 \mathrm{eV}$. No caso de um 
bombardeio pouco intenso são obtidos filmes poliméricos, pela dificuldade de criação dessa matriz de carbono $\mathrm{sp}^{3}$ (ROBERTSON, 1994).

Os filmes de a-C:H possuem estrutura amorfa composta por carbonos

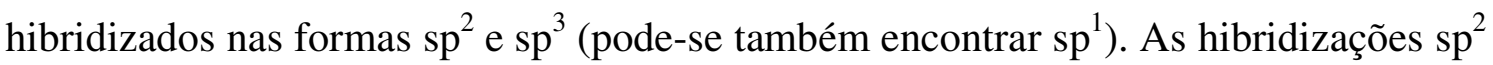
podem formar anéis grafiticos/aromáticos e/ou cadeias olefinicas, enquanto as hibridizações $\mathrm{sp}^{3}$ formam tetraedros e ligações terminais $-\mathrm{CH}_{\mathrm{n}}(\mathrm{n}=1,2,3)$. Portanto, nos filmes de a-C:H existe uma grande variedade de tipos estruturais que podem se arranjar geometricamente de diversas formas: anéis, cadeias, tetraedros, etc. Na figura 7 mostra-se um esquema da estrutura molecular tipo polímero e tipo grafite presentes nos filmes de a-C:H. Essa diversidade de estruturas é a que dificulta sua completa caracterização. Daí a necessidade da utilização de diversas técnicas de análise, quando se estuda esse tipo de material.

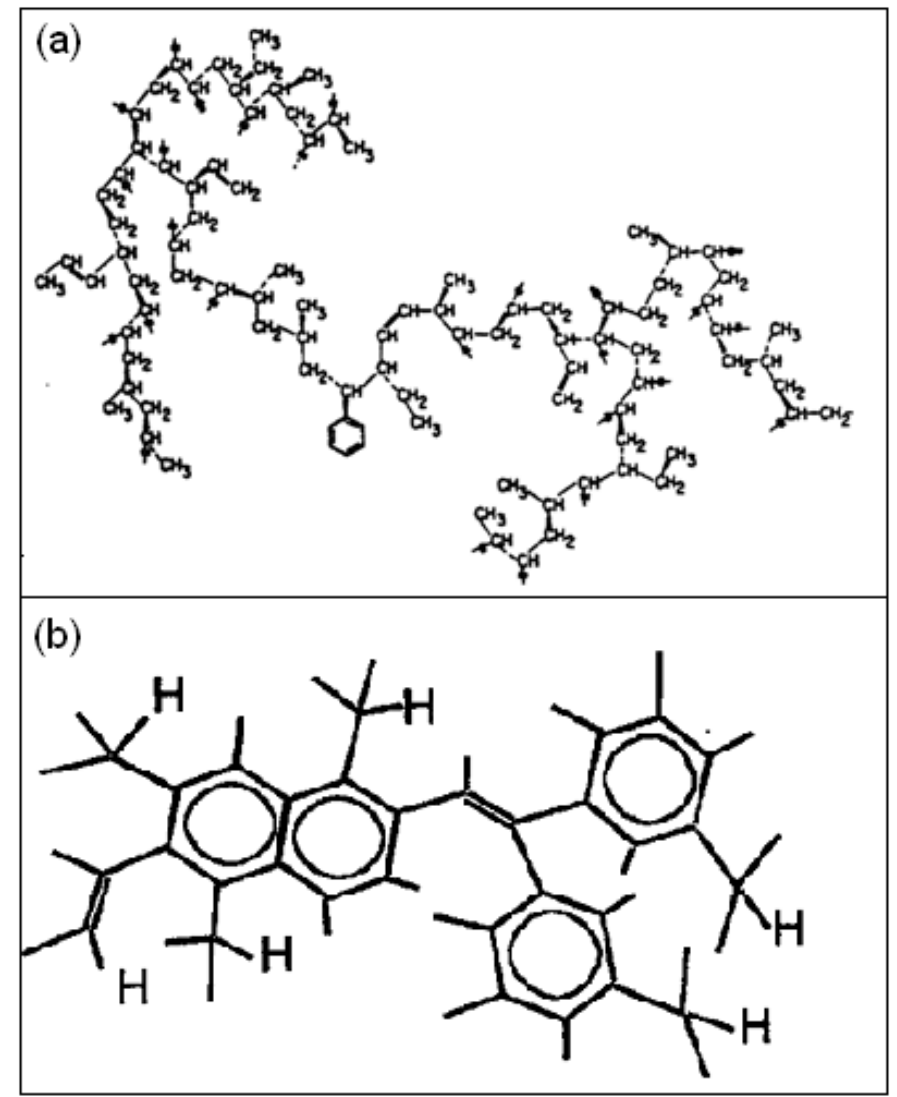

Figura 7 - Esquema da estrutura molecular dos filmes de a-C:H, (a) tipo polímero depositado a plasma (YASUDA, 1985) e (b) tipo grafite (cluster sp²) (ROBERTSON, 2002). 


\subsection{PROCESSOS DE INCORPORAÇÃO DE FLÚOR NOS FILMES a-} $\mathbf{C : H}$

O mecanismo de fluoração nos filmes de a-C:H promove a substituição dos átomos de hidrogênio pelos átomos de flúor na rede estrutural desse material (BUTTER et al., 1997). Esse fenômeno foi evidenciado através das análises de espectroscopia Raman e XPS nos filmes de a-C:H fluorados, que revelou a ocorrência de um aumento na intensidade da banda C-F e uma diminuição na intensidade da banda C-H nos espectros desse material (SAH, 1985).

Em termos de processo de deposição, a liberação do hidrogênio da rede estrutural dos filmes de a-C:H é facilitada pelo uso de uma alta energia de bombardeamento, em virtude da ligação $\mathrm{C}-\mathrm{H}$ ser mais fraca do que a ligação $\mathrm{C}-\mathrm{F}$ (VIVENSANG et al., 1994), entretanto, é provável que os átomos de flúor também sejam expelidos se estiverem fracamente ligados (YI, 2000). A substituição do hidrogênio pelo flúor na estrutura molecular dos filmes de a-C:H causa um aumento na quantidade de defeitos de coordenação, porque o diâmetro atômico do flúor é maior que do hidrogênio e causa também um aumento no gap, pelo fato da energia de ligação entre C-F (5,4 eV) ser maior do que a energia de ligação entre C-C (3,6 eV) (YANG et al., 1998; YASUDA, 1985).

\subsubsection{O Efeito do Flúor nas Propriedades Estruturais dos Filmes de a-C:H}

A incorporação de flúor nos filmes de a-C:H modifica fortemente a estrutura das ligações químicas desse material. Estudos revelam que, caso a quantidade de flúor exceda a quantidade de 10 at\% na composição química dos filmes de a-C:H, a banda D (desordem) desse material se torna mais intensa e mais larga. Esse aumento na intensidade da banda $\mathrm{D}$ ocorre devido às hibridizações $\mathrm{sp}^{2}$ formarem clusters aromáticos (ENDO, 1995). Portanto, o filme a-C:H se torna mais grafítico com a presença de altas quantidades de flúor em sua composição química. Se a quantidade de flúor exceder 25 at\% haverá a ocorrência de um aumento na intensidade da banda 
luminescente, causando uma transição entre a estrutura molecular tipo diamante para tipo polimérico (FREIRE, 2001). Já o alargamento da banda D, é resultado da alteração do comprimento e do ângulo das ligações C-C nos anéis hexagonais que compõem o cluster (FERRARI, 1999).

A rede estrutural dos filmes de a-C:H fluorado é constituída por estruturas em anéis de ligações $\mathrm{C}-\mathrm{C}, \mathrm{C}-\mathrm{H}$ e $\mathrm{C}-\mathrm{F}$, conectadas pelo grupo $\mathrm{C}-\mathrm{F}_{2}$ e terminadas pelo grupo $\mathrm{C}-\mathrm{F}_{3}$ em uma matriz de hibridizações $\mathrm{sp}^{3}$ (MA et al., 1998). Além dessas ligações, podem também existir terminações com o grupo $\mathrm{C}-\mathrm{F}_{2}\left(\mathrm{~F}_{2} \mathrm{C}=\mathrm{C}\right)$, caso o flúor se ligue nas estruturas olefínicas do carbono (WANG, 2000).

Estudos revelam também, que os átomos de flúor "preferem" se ligar a hibridização do tipo $\mathrm{sp}^{3}$ ao invés de se ligarem a hibridização $\mathrm{sp}^{2}$, de maneira que $75 \%$ das hibridizações do tipo $\mathrm{sp}^{3}$ são fluoradas, enquanto que somente $30 \%$ das hibridizações do tipo $\mathrm{sp}^{2}$ apresentam essa fluoração (HAMAGAWA, 1989; BUTTER et al., 1997; FINK et al., 1987). 


\section{MÉTODOS DE CARACTERIZAÇÃO DOS FILMES DE a-C:H e a-C:H} FLUORADO

\subsection{ESPECTROSCOPIA RAMAN}

A espectroscopia Raman é uma técnica não destrutiva amplamente aplicada para a análise de materiais a base de carbono (WILLIAMS, 1996). Através dela podem-se obter informações sobre os estados vibracionais das moléculas além da hibridização da ligação. Sabe-se que as propriedades mecânicas e tribológicas de filmes de a-C:H, é definido pela proporção de átomos de carbono com hibridização $\mathrm{sp}^{2}$

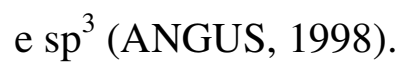

A espectroscopia Raman é baseada no espalhamento inelástico de uma radiação monocromática devido a mudança de polarização pelas vibrações na rede estrutural dos materiais. A polarização pode ocorrer devido à excitação de estados eletrônicos, estados virtuais ou estados reais de energia (ELLIS, 2004; SANTOS L, 2004).

No espalhamento Raman ocorre uma colisão inelástica entre um fóton e uma molécula num determinado estado inicial de energia, no qual a frequência da luz espalhada difere daquela incidente.

As energias dos fótons espalhados são menores, maiores ou iguais em relação à energia dos fótons incidentes através de incrementos quantizados, os quais correspondem às diferenças de energia entre os níveis de energia inicial e final, seja vibracional, eletrônico, ou entre níveis rotacionais da molécula em um gás, líquido ou sólido. Na figura 8 estão representadas estas três situações: as linhas designadas $\mathrm{v}=\mathrm{n}$ e v $=\mathrm{n}+1$ representam, por exemplo, os níveis de energia vibracional da molécula. Se o fóton espalhado tem a mesma frequência que o fóton incidente, a esse efeito dá-se o nome de espalhamento Rayleigh. 


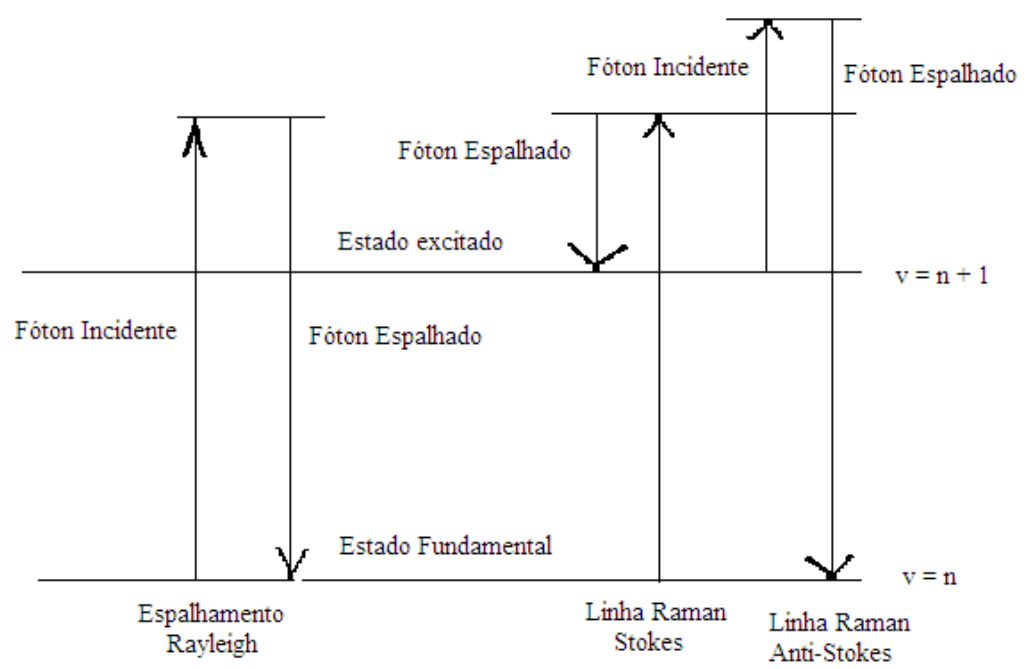

Figura 8 - Espalhamento Rayleigh, Linha Raman Stokes e anti-stockes (SANTOS L, 2004).

Quando a energia do fóton espalhado é maior que a energia do fóton incidente há um espalhamento cuja linha é denominada de linha anti-Stokes, a molécula é de excitada de $v=n+1$ para $v=n$. Se a frequência da radiação espalhada for menor que a incidente, então há um espalhamento Raman de linha espectral, chamada Stokes, a molécula é excitada do nível $\mathrm{v}=\mathrm{n}$ para o nível $\mathrm{v}=\mathrm{n}+1$. O deslocamento Raman é a diferença entre a energia de radiação incidente e a radiação espalhada, portanto o método da espectroscopia de espalhamento Raman consiste na diferença destas energias.

A luz do laser de argônio passa por um microscópio óptico, sendo dirigida ao longo do sistema e interage com a amostra, com uma resolução espacial menor que $5 \mu \mathrm{m}$. A luz espalhada, coletada pela mesma lente ótica do microscópio é separada da radiação incidente por meio de um divisor de feixe dicróico, enviada ao monocromador e em seguida para o fotodetector e para o amplificador. O sinal detectado tratado é armazenado em um computador para processamento de dados.

Em filmes de a-C:H, duas bandas características são ativas para espectroscopia Raman, uma em torno de $1360 \mathrm{~cm}^{-1}$ denominada de banda D (“disordered") e outra em $1580 \mathrm{~cm}^{-1}$ denominada de banda $\mathrm{G}$ (de grafite). A banda $\mathrm{G}$ é atribuída às redes estruturais com hibridização $\mathrm{sp}^{2}$ típicas da grafite. A banda $\mathrm{D}$ é característica ao modo 
de desordem dos cristais da grafite devido à possibilidade de existência das hibridizações $\mathrm{sp}^{3}, \mathrm{sp}^{2}$ e $\mathrm{sp}^{1}$.

Um aumento da hibridização $\mathrm{sp}^{2}$, por exemplo, pode causar aumento da desordem e com isso um aumento da banda $\mathrm{D}$, pois a energia de polarização dos estados $\pi$ (pi) presentes nas hibridizações $\mathrm{sp}^{2}$ é da ordem de 50 a 130 vezes maior do que a energia de polarização dos estados $\sigma$ (sigma) presentes nas hibridizações $\mathrm{sp}^{3}$ (ROBERTSON, 2002).

A figura 9 mostra um espectro típico de deslocamento Raman de um filme de aC:H, depositado a plasma, com a deconvolução das bandas D e G. destacando os fatores que afetam as mudanças nas posições e nas intensidades dessas bandas.

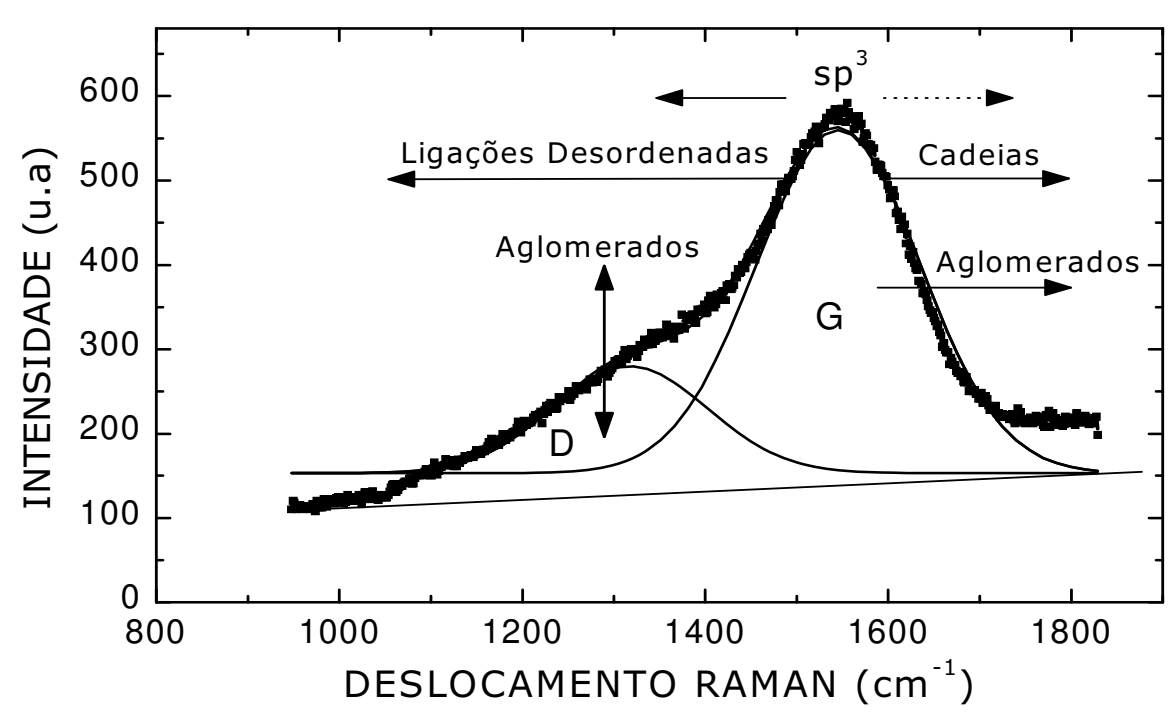

Figura 9 - Espectro Raman característico de um filme de a-C:H depositado no sistema PECVD, enfatizando os fatores que afetam a mudança nas posições e nas intensidades das bandas D e G dos filmes (ROBERTSON, 2002).

De acordo com esta figura, nota-se que a quantidade de hibridizações $\mathrm{sp}^{3}$ das ligações de carbono para os filmes de a-C:H e a quantidade de ligações desordenadas, aumenta de acordo com o deslocamento do centro da banda $G$ para a esquerda, correspondendo a filmes com maior quantidade de ligações tridimensionais e estruturas mais próximas do diamante. Se a posição central da banda $\mathrm{G}$ desloca-se para 
a direita, tem-se o aumento da formação de clusters (aglomerados de carbono) nos filmes.

A variação da posição central da banda $G$ e a razão entre as intensidades das bandas $\mathrm{D}$ e $\mathrm{G}\left(\mathrm{I}_{\mathrm{D}} / \mathrm{I}_{\mathrm{G}}\right)$ nos espectros Raman são parâmetros complementares para a determinação da estrutura molecular dos filmes obtidos. A posição central da banda $G$ também pode ser usada para quantificar as hibridizações $\mathrm{sp}^{3}$ e a forma da estrutura molecular dos filmes. A razão $\left(\mathrm{I}_{\mathrm{D}} / \mathrm{I}_{\mathrm{G}}\right)$ é usada para caracterizar o nível de ordem cristalina e o tamanho do grão nos filmes de a-C:H.

A variação dos espectros Raman dos filmes de a-C:H dependem de quatro fatores: presença de anéis ou ligações $\mathrm{sp}^{2}$, formação de aglomerados (clustering) da fase $\mathrm{sp}^{2}$, comprimento e ângulo de desordem da ligação e a razão $\mathrm{sp}^{3} / \mathrm{sp}^{2}$ (SPEAR, 1993).

A estrutura molecular dos filmes, de a-C:H e dos filmes fluorados, obtidos neste trabalho foi investigada através da espectroscopia Raman utilizando-se um equipamento Renishaw Modelo S2000, com laser de argônio iônico em 514,5 nm pertencente ao Laboratório de Sensores e Materiais (LAS) do Instituto de Pesquisa Espacial (INPE), em São José dos Campos.

O espectro Raman foi obtido entre 400 e $2200 \mathrm{~cm}^{-1}$ fazendo-se a luz monocromática do laser de argônio incidir sobre as amostras. A luz espalhada foi dispersa por uma rede de difração no espectrômetro e suas componentes foram avaliadas em um detector que converte a intensidade da luz em sinais elétricos, interpretados em um computador na forma de um espectro Raman. Para os filmes de a$\mathrm{C}: \mathrm{H}$ e para os filmes fluorados, esse espectro foi deconvoluídos em duas bandas D e G. A Figura 10 mostra as fotografias do equipamento utilizado para obtenção dos espectros Raman. 

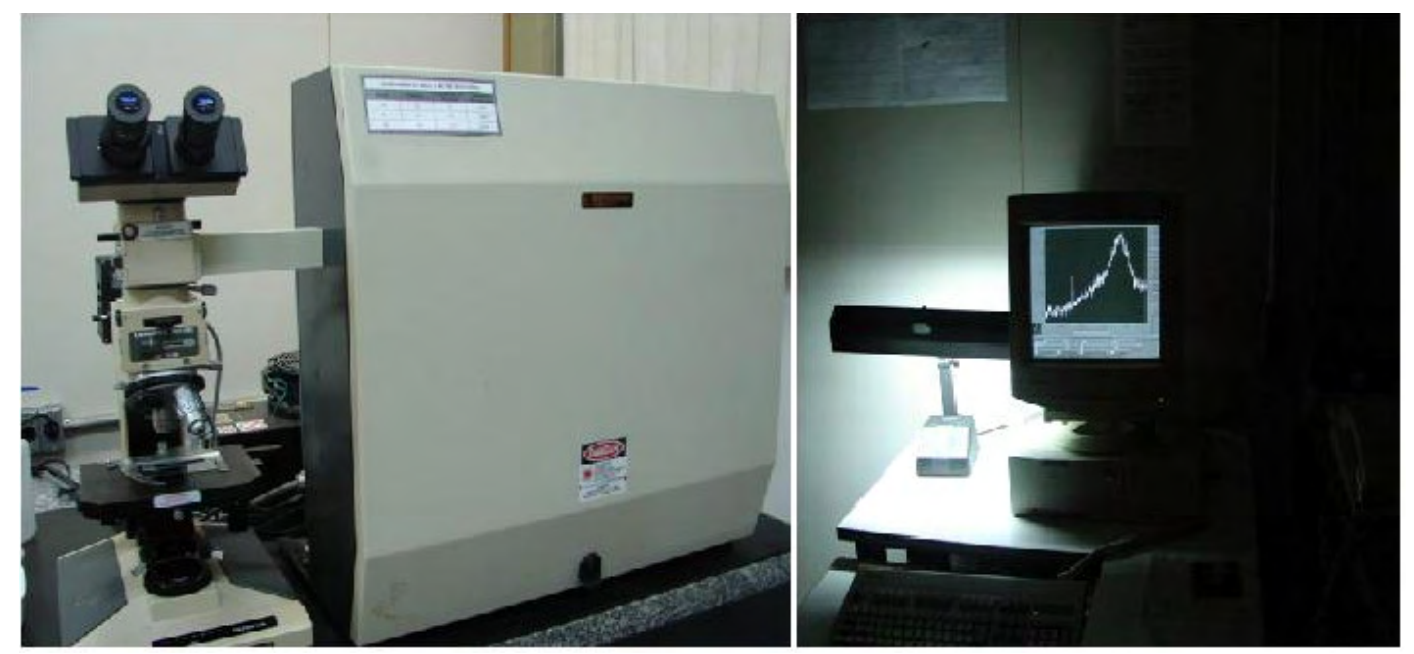

Figura 10 - Fotografias do equipamento utilizado para determinação dos espectros Raman.

A quantificação das hibridizações dessas bandas procede-se através do cálculo da razão entre a intensidade do pico referente à banda $\mathrm{D}$ e a intensidade do pico referente à banda $\mathrm{G}$ (razão $\mathrm{I}_{\mathrm{D}} / \mathrm{I}_{\mathrm{G}}$ ). Para calcular essas intensidades foram feitas as deconvoluções dos espectros Raman (curva Gaussiana), para todas as amostras, utilizando-se o programa “OriginLab 7.0". Para a análise dos filmes foram utilizados os seguintes picos característicos da região deconvoluída: $1332 \mathrm{~cm}^{-1}$, intensidade da banda D correspondente à hibridização $\mathrm{sp}^{3}$ e $1580 \mathrm{~cm}^{-1}$, intensidade da banda $\mathrm{G}$ correspondente à hibridização $\mathrm{sp}^{2}$.

Além do estudo da variação entre a banda D e G, obtidas por espectroscopia Raman, para a determinação da qualidade dos filmes depositados através do método de PECVD, foi feito também o estudo do deslocamento da banda G, pois esse deslocamento está relacionado com a mudança entre as hibridizações $\mathrm{sp}^{3}$ e $\mathrm{sp}^{2} \mathrm{e}$ também com as mudanças estruturais dos filmes de a-C:H.

\subsection{ESPECTROSCOPIA DE FOTOELÉTRONS EXCITADOS POR}

\section{RAIOS -X (XPS)}

Esta técnica é muito utilizada para análise de superfícies, sendo empregada na análise de vários tipos de amostras, tais como: metais, polímeros, cerâmicas, 
compósitos, semicondutores e amostras biológicas; na forma de lâminas, fibras, pós, partículas ou filmes (NASCENTE 2005). As informações obtidas incluem análise elementar semi-quantitativa, identificação de grupos funcionais com possibilidades de analise de perfil de profundidades. Como os filmes de a-C:H depositados a plasma são geralmente finos, XPS torna-se uma ferramenta importante para a determinação de sua composição química.

Para quantificar a composição superficial dos filmes de a-C:H, se irradia a amostra com fótons monocromáticos de raios-X, com energia $h v$, de modo de que eles ejetem elétrons dos átomos do material por efeito fotoelétrico. Os fotoelétrons possuem uma distribuição de energia cinética (Ec) que consiste de picos discretos, associados às camadas eletrônicas do átomo fotoionizado. Como os termos referentes à função trabalho $(\phi)$ podem ser compensados eletronicamente, a energia cinética do fotoelétron é dada por:

$$
\mathrm{Ec}=\mathrm{hv}-\mathrm{E}_{\mathrm{L}}
$$

sendo Ec a energia com que o elétron abandona o átomo, hv a energia do fóton incidente e $\mathrm{E}_{\mathrm{L}}$ a energia de ligação do elétron no átomo. Como se conhecem a energia do fóton incidente e a função trabalho do espectrômetro, é possível obter a energia de ligação do elétron mediante a medida de sua energia cinética após abandonar o átomo. Estas energias de ligação são características de cada elemento e permitem identificar todos os tipos de átomos existentes nos filmes, exceto hidrogênio e hélio, e também são capazes de fornecer dados sobre seu ambiente químico, já que estes podem produzir deslocamentos detectáveis que podem chegar a vários eV na energia final dos picos. Estes deslocamentos são muito úteis na hora de identificar os tipos de ligação química presentes nos filmes.

Em um espectro típico XPS aparecem três tipos básicos de picos: os devidos aos processos de fotoemissão de níveis internos, a fotoemissão de níveis de valência e os picos devidos às transições Auger excitadas por fótons de raios X. Este processo de emissão do fotoelétron é esquematizado na figura 11. 

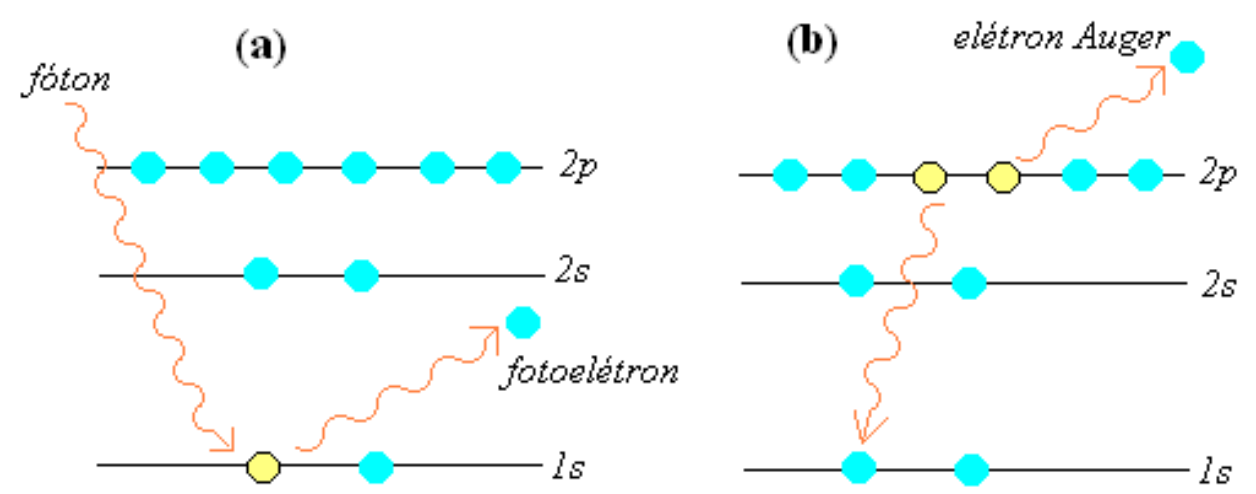

Figura 11 - (a) processo de emissão do fotoelétron e (b) processo de relaxação com emissão de elétron Auger (SANTOS, 2004).

O sistema de XPS geralmente é constituído por uma câmara de alto vácuo, um analisador de energia de elétrons de alta resolução, hemisférico e eletrostático, uma fonte de raios $\mathrm{X}$ com anodo duplo ( $\mathrm{Mg} / \mathrm{Al})$, um canhão de elétrons, um canhão de íons, um dispositivo para neutralização de cargas, um manipulador de amostra, um detector de elétrons e um computador para aquisição e tratamento dos dados. As fontes de raios $\mathrm{X}$ mais usadas são de magnésio $(\mathrm{Mg})$ e alumínio (Al), que emitem radiações com 1253,6 e 1486,6 eV, respectivamente.

A amostra é colocada na câmara de ultra-vácuo e é submetida a um feixe de raios $\mathrm{X}$ incidentes. Alguns dos fotoelétrons ejetados passam por uma fenda ajustada pela energia de passe, sendo que somente aqueles com mesma energia podem entrar no analisador de elétrons. $\mathrm{O}$ analisador é formado por duas placas polarizadas com um potencial elétrico, forçando os elétrons a viajarem com energia cinética correspondente, isto é, o analisador é um filtro de energia. Em seguida os elétrons são contados pelo detector, e num sistema de aquisição de dados é plotado um espectro do número de elétrons, por unidade de tempo, em função de suas energias de ligação. Um espectro survey típico no caso pertencente a uma amostra de a-C:H produzida neste trabalho, está ilustrado na figura 12. Ela mostra as fotoemissões de 0-1100 eV (larga varredura), suficiente para identificação de todos os elementos químicos (excetos hélio e hidrogênio), pois a maioria dos elementos possuem picos de fotoelétrons abaixo de $1100 \mathrm{eV}$. Entretanto, muitas linhas podem ser observadas neste espectro. As linhas mais intensas, relativamente simétricas e estreitas, são os fotoelétrons ou picos 
principais, tais como oxigênio (O 1s), carbono (C 1s) e nitrogênio (N 1s).

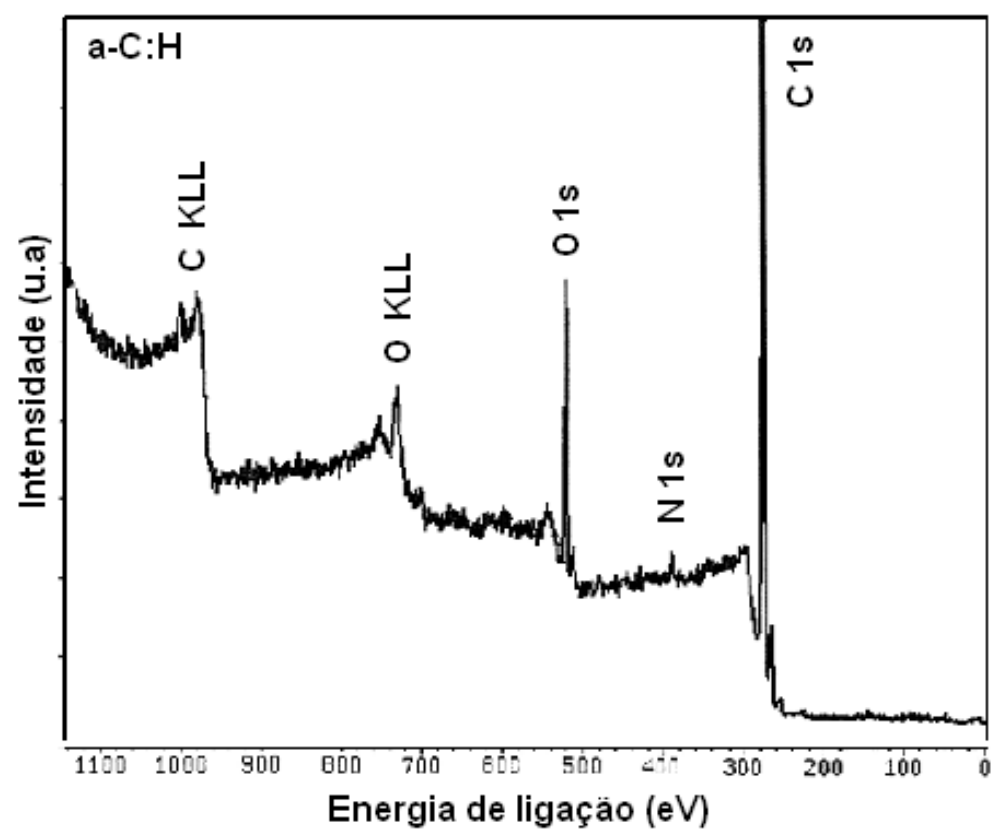

Figura 12 - Espectro de longa varredura representativo de filmes de a-C:H, obtidos neste trabalho.

A análise quantitativa, que determina as concentrações relativas dos diferentes elementos presentes na superfície de uma amostra, é realizada através de um espectro de alta resolução de energia.

A análise quantitativa é feita pela determinação das áreas sob os picos fotoelétricos (I), que são proporcionais ao número de átomos $(\mathrm{N})$ e seus fatores de sensibilidade $(S)$ (informam a taxa de geração de fotoelétrons de um determinado nível eletrônico). Assim, o número de átomos $\mathrm{N}$ de cada elemento analisado, é dado pela expressão (2):

$$
N=\frac{I}{S}
$$

sendo $S$ diretamente relacionado a função de transmissão do espectrômetro utilizado. Logo, a concentração relativa de um elemento $x$ é calculada pela expressão (3):

$$
\frac{N_{x}}{N}=\frac{I_{x} / S_{x}}{I / S}
$$

Pela deconvolução dos espectros de alta resolução de cada elemento 
(JACKSON, 1995), realizadas através de programas computacionais gráficos, pode-se então determinar os estados químicos destes elementos ou seus grupos funcionais. Para isso são utilizados valores de energias de ligação, conhecidos e tabelados, relacionadas às possíveis espécies presentes na estrutura.

As composições químicas superficiais dos filmes de a-C:H e dos filmes de a$\mathrm{C}: \mathrm{H}$ fluorados foram feitas utilizando-se um espectromicroscópio de superfícies, Kratos modelo XSAM HS, disponível no Centro de Caracterização e Desenvolvimento de Materiais (CCDM), instalado no Departamento de Engenharia de Materiais da Universidade Federal de São Carlos (UFSCar).

A identificação dos elementos presentes na superfície destes filmes foi feita diretamente pela determinação das energias de ligação dos picos fotoelétricos. A intensidade dos picos forneceu a informação quantitativa sobre a composição da superfície, enquanto que a posição exata de cada pico indicou o estado químico do átomo emissor. A análise foi realizada em ambiente de ultra-vácuo, empregando-se uma fonte de radiação de $\mathrm{K} \alpha$ do magnésio como fonte excitadora, com energia de 1253,6 eV e potência de $40 \mathrm{~W}$. O ajuste dos picos foi realizado através do programa fornecido pelo fabricante do equipamento, com curvas, subtração de background pelo método de Shirley e a rotina de mínimos quadrados (NASCENTE, 2005).

O pico fotoelétrico C 1s referente a C-C e/ou C-H, centrado em 284,8 eV, foi utilizado como referência de energia de ligação (MOULEDER et al., 1992). Os picos de alta resolução foram deconvoluídos em suas componentes usando um perfil Gaussiano com base linear.

Para os filmes de a-C:H, obtidos neste trabalho, o pico $\mathrm{C} 1 \mathrm{~s}$ foi decomposto em três componentes que correspondem às ligações de C-C e/ou C-H $(284,8$ eV), C-O $(286,4 \mathrm{eV})$ e $\mathrm{C}=\mathrm{O}(288,8 \mathrm{eV})$, conforme mostra a figura 13 e o pico $\mathrm{O}$ 1s foi decomposto em três componentes correspondentes às ligações $\mathrm{C}-\mathrm{O}(531,5 \mathrm{eV}), \mathrm{C}=\mathrm{O}$ $(532,6 \mathrm{eV})$ e $-\mathrm{OH}(534,5 \mathrm{eV})$. 


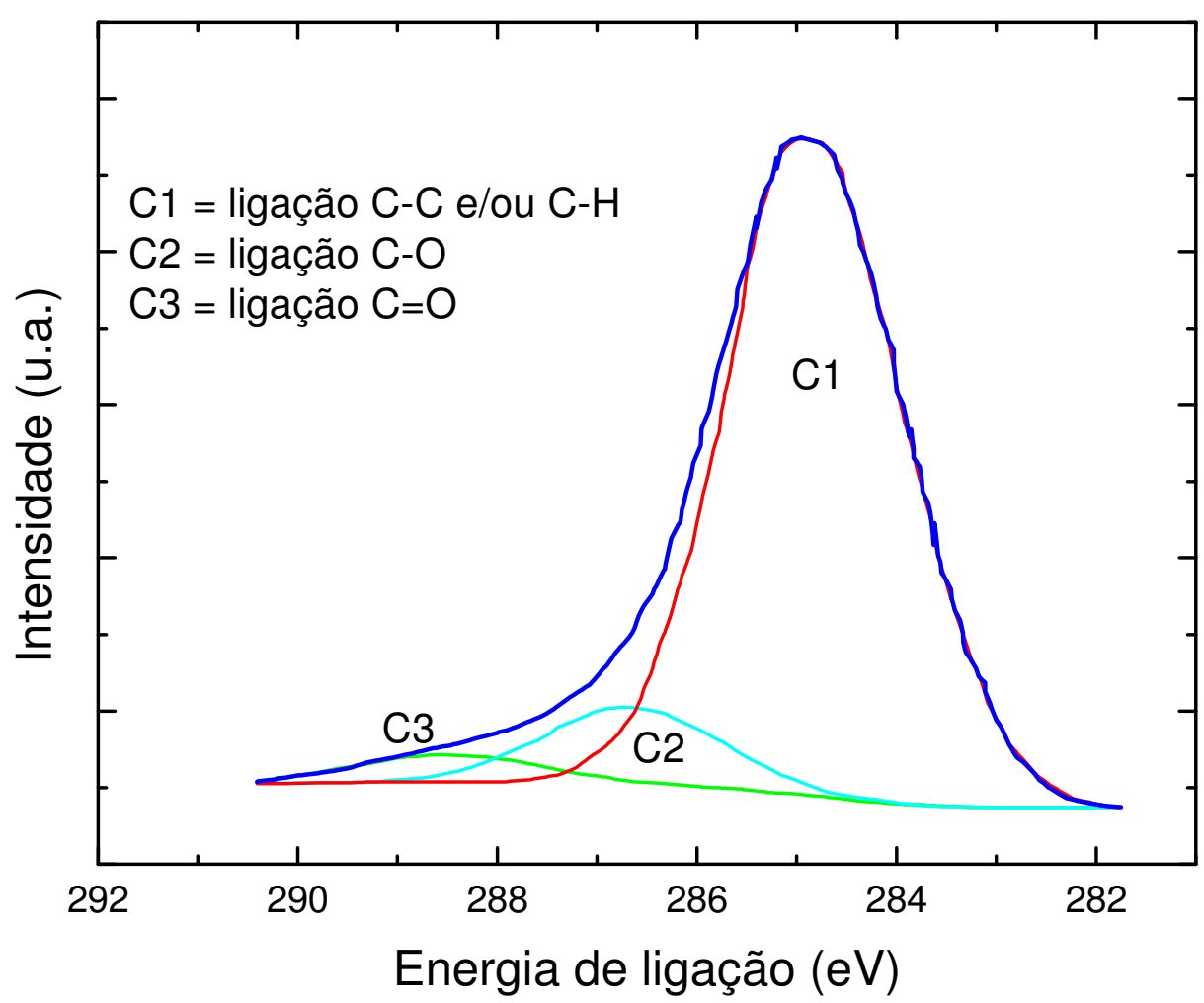

Figura 13 - Espectro C 1s característico dos filmes de a-C:H, obtido neste trabalho.

Para os filmes de a-C:H fluorados, também obtidos neste trabalho, o pico $\mathrm{C} 1 \mathrm{~s}$ foi decomposto em cinco componentes que correspondem às ligações de $\mathrm{C}-\mathrm{C}$ e/ou $\mathrm{C}-\mathrm{H}$ (284,8 eV), C-O e/ou C-CF (286,4 eV), C=O e/ou C-F (288,6 eV), C-F $2(290,6$ eV) e ${\mathrm{C}-\mathrm{F}_{3}}_{2}(292,5)$ conforme mostra a figura 14. O pico O $1 \mathrm{~s}$ foi decomposto em três componentes correspondentes às ligações $\mathrm{C}-\mathrm{O}(531,5 \mathrm{eV}), \mathrm{C}=\mathrm{O}(532,6 \mathrm{eV}) \mathrm{e}-\mathrm{OH}$ $(534,5 \mathrm{eV})$ e o pico $\mathrm{F} 1 \mathrm{~s}$, a aproximadamente $687 \mathrm{eV}$, também foi decomposto em três componentes atribuídas às ligações $\left(-\mathrm{CF}_{2} \mathrm{CH}_{2}\right)_{\mathrm{n}},\left(-\mathrm{CHFCH}_{2}-\right)_{\mathrm{n}}$ e $\left(-\mathrm{CF}_{2} \mathrm{CF}_{2^{-}}\right)_{\mathrm{n}}$, (FERRARIA, 2003). 


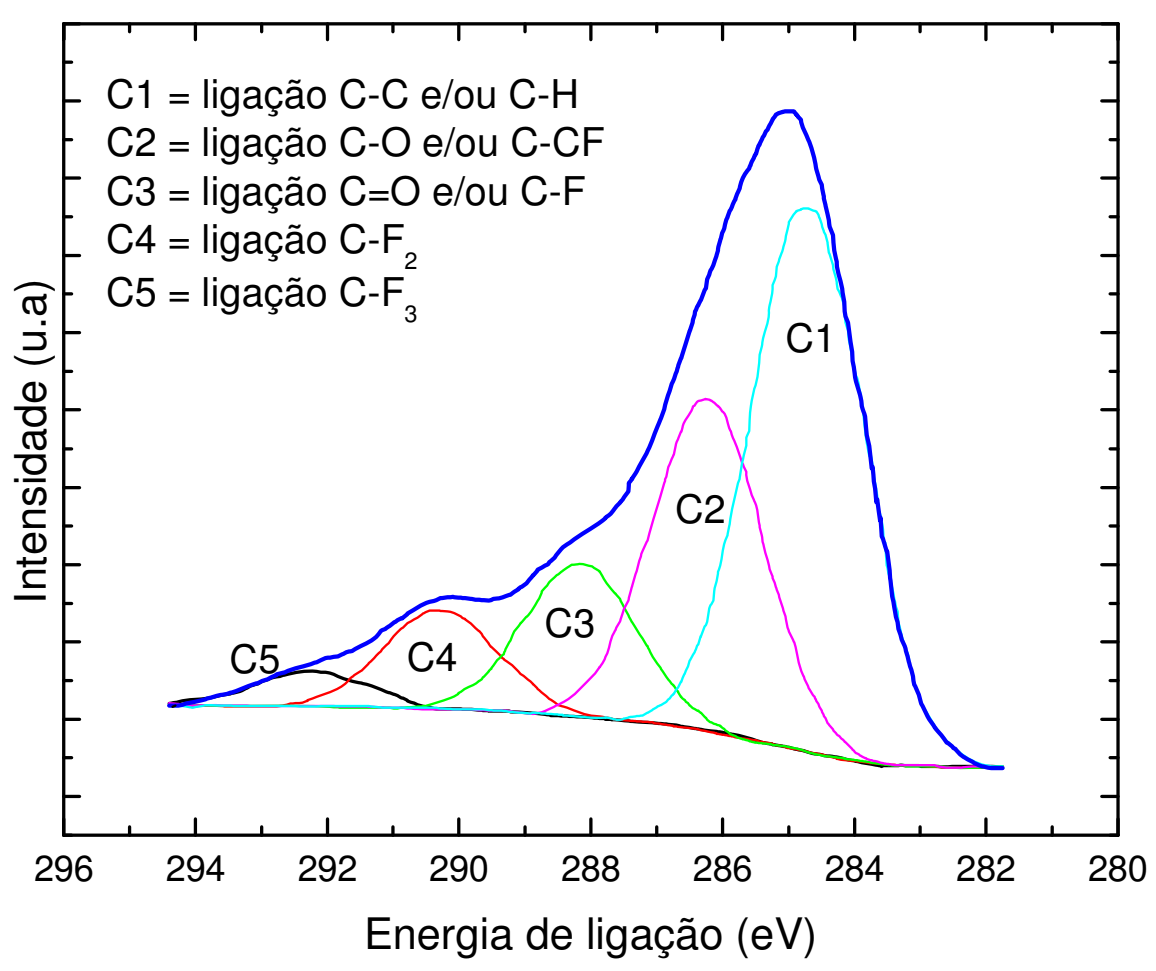

Figura 14 - Espectro C 1s característico dos filmes de a-C:H fluorados, obtido neste trabalho.

\subsection{NANOINDENTAÇÃO}

Esta técnica consiste em se aplicar uma força conhecida em uma ponta de diamante na direção normal à superfície do filme. A dureza $(\mathrm{H})$ é definida como a força máxima aplicada pela ponta em relação à área de contato da ponta na amostra (obtida pelo conhecimento da geometria da ponta e da profundidade de penetração) (LEE et al., 1993; HUTCHINGS, 1996). Assim, a dureza é calculada conforme a equação (4):

$$
H=\frac{P}{A}
$$

sendo $P$ a força proveniente da carga aplicada e $A$ a área de contato projetada do 
indentador.

Técnicas de indentação permitem que a dureza de camadas superficiais, seja medida continuamente à medida que o indentador penetra o material. Nesses equipamentos, as áreas de teste são visualizadas através de um microscópio de força atômica, as cargas utilizadas são baixas e controladas simultaneamente com a profundidade de penetração. Uma curva carga-deslocamento é construída, e com ela se pode avaliar não somente a dureza $(H)$ do material, mas também a rigidez mecânica $(S)$, o módulo elástico $(E)$, a resistência ao risco e o coeficiente de atrito $(\mu)$.

Oliver e Pharr (OLIVER, 1992) descreveram um modelo para cálculo de $H$ e $E$, que utiliza alguns parâmetros medidos experimentalmente, tais como a carga do indentador $P$, o deslocamento total $h_{T}$ no interior do filme (abaixo do ponto inicial de contato), a rigidez mecânica $S$ e a forma geométrica do indentador. Estes parâmetros podem ser visualizados na figura 15 .

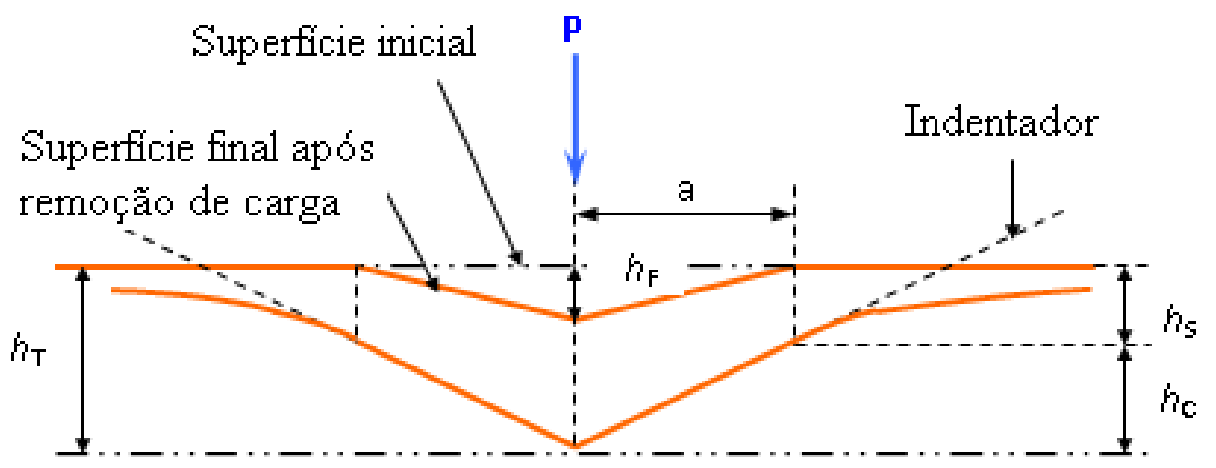

Figura 15 - Representação esquemática da geometria da superfície da amostra nas situações de carga máxima e depois de retirada do indentador (SANTOS, 2004).

Esta figura mostra a representação esquemática da geometria da superfície da amostra nas situações de carga máxima e após a retirada do indentador, onde $h_{\mathrm{T}}$ é a profundidade de deslocamento total (atingida pelo indentador durante a penetração), $h_{\mathrm{C}}$ é $a$ profundidade de contato (atingida pelo indentador a partir do deslocamento superficial), $h_{\mathrm{S}}$ deslocamento superficial (atingida pela superfície ao redor do indentador que se deforma com a penetração) e $h_{\mathrm{F}}$ profundidade final (profundidade da marca deixada pelo indentador após sua remoção). 
Num material com deformação elástica e plástica, como os metais, os polímeros e os filmes finos de carbono, a relação entre essas profundidades são dadas pelas expressões (5), (6) e (7):

$$
\begin{aligned}
& h_{T}>h_{C}>h_{F} \\
& h_{C}=h_{T}-h_{S}
\end{aligned}
$$

sendo,

$$
h_{S}=\varepsilon \frac{P}{S}
$$

O parâmetro $h_{\mathrm{C}}$ é importante para correção da área de contato $A$, que se altera devido a deformação elástica, sendo a relação entre elas dada pela expressão (8).

$$
A \propto h_{C}^{2}
$$

Todos os parâmetros de profundidade, bem como $S$, são determinados através das curvas carga-deslocamento, mostradas na figura 16.

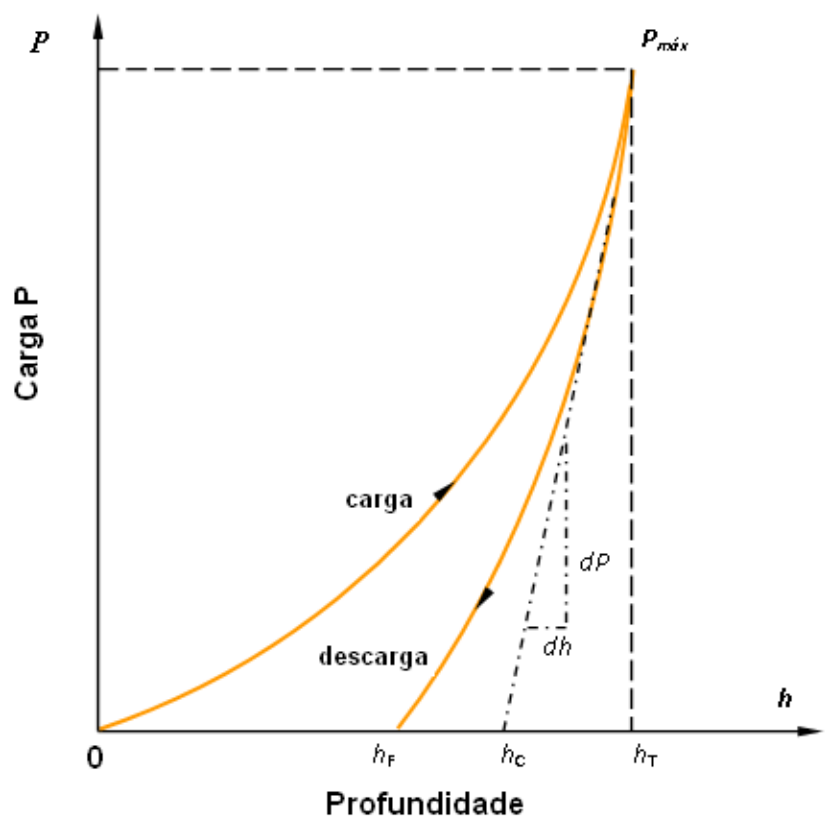

Figura 16 - Curvas características carga-deslocamento de materiais com deformação elástica e plástica.

Pelo gráfico desta figura, a grandeza $\mathrm{S}$ denominada rigidez do material é obtida a partir da inclinação da porção inicial da curva de descarga, de forma que $S$ é dada pela equação (9). 


$$
S=\frac{d P}{d h}
$$

A rigidez do material $S$ é diretamente proporcional ao módulo elástico reduzido $E_{\mathrm{R}}$, que pode ser obtido através da equação (10) (OLIVER, 1992):

$$
S=E_{R} \sqrt{\frac{\pi}{4 A}}
$$

sendo, $E_{R}$ determinado pela expressão (11) (OLIVER, 1992).

$$
E_{R}=\left[\frac{1-v_{s}^{2}}{E_{s}}+\frac{1-v_{i}^{2}}{E_{i}}\right]
$$

Sendo, $E$ o módulo de Young, $v$ a constante de Poisson e os subscritos $s$ e $i$ correspondem respectivamente à amostra e ao indentador.

A dureza foi determinada através de um nanoindentador Hysitron TriboIndenter automatizado, do Grupo de Plasmas Tecnológicos da UNESP de Sorocaba. Este equipamento é constituído por uma plataforma motorizada XYZ, um indentador de diamante de forma piramidal (tipo Berkovich), um transdutor capacitivo e um computador para controle e aquisição de dados. A Figura 17 mostra um esquema deste equipamento.

O transdutor capacitivo possui três placas e é utilizado como controlador e sensor do equipamento, permitindo que uma força seja aplicada eletrostaticamente enquanto o deslocamento é medido simultaneamente pela variação na capacitância.

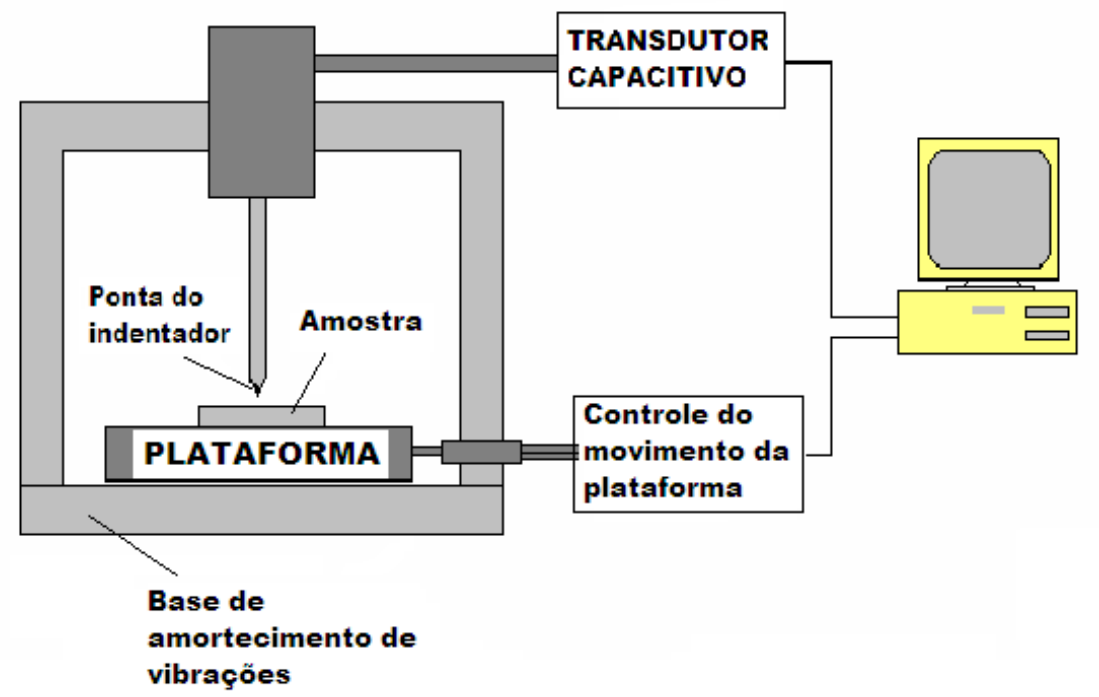

Figura 17 - Representação esquemática do equipamento de indentação (SANTOS, 2004). 
Para um penetrador ideal do tipo Berkovich (uma pirâmide de três lados com cada lado formando um ângulo de $65,3^{\circ}$ com um plano normal à base da pirâmide), a área projetada está relacionada com a profundidade de contato.

A dureza das amostras foi avaliada estatisticamente, sendo que cada amostra foi analisada em oito posições diferentes da superfície.

\section{4 ÂNGULO DE CONTATO}

As medidas de ângulo de contato $(\theta)$ podem ser feitas empregando diversos métodos, neste trabalho foi utilizado o método de gota estático (YAAKOV, 1999), que consiste em se colocar em contato com o material um pequeno volume de água deionizada formando uma gota sobre a sua superfície. Esta gota em grande parte das situações está sujeita a um equilíbrio termodinâmico que envolve três meios e fases distintas: amostra - fase sólida, água - fase liquida e ar - fase gasosa (vapor). A forma da gota na região onde ocorre a interface entre essas três fases é dada pelas energias $\left(\gamma_{S V}, \gamma_{S L}\right.$ e $\left.\gamma_{L V}\right)$ envolvidas neste sistema. Essa forma é sensível aos três meios envolvidos, porém a fase gasosa e a líquida podem ser controladas, sofrendo pouca variação, deixando como a única variável a energia superficial do sólido (SAFRAN, 1994; ADAMSON, 1997).

Quando uma gota de líquido repousa sobre uma superfície, a interface líquidovapor forma um ângulo finito a superfície sólida, denominado ângulo de contato $(\theta)$, como pode ser visto na figura 18.

Ar atmosférico (V)

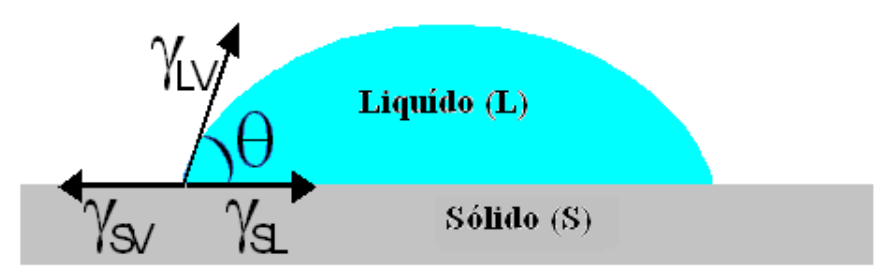

Figura 18 - Ângulo de contato entre a gota de um líquido e uma superfície sólida (ADAMSON, 1997). 
Nesta figura, verifica-se que $\theta$ está diretamente relacionado com as interações das energias superficiais das interfaces: entre o sólido e o vapor $\left(\gamma_{\mathrm{SV}}\right)$, entre a gota do líquido e o vapor $\left(\gamma_{\mathrm{LV}}\right)$ e entre o sólido e a gota do líquido $\left(\gamma_{\mathrm{SL}}\right)$.

O espalhamento da gota de um líquido $\left(\Delta V_{S}\right)$ sobre a superfície sólida pode ser calculado pela variação da energia livre da superfície (ADAMSON, 1997), dada pela equação (12):

$$
\Delta V_{S}=\left(\gamma_{S L}-\gamma_{S V}\right) \Delta A+\gamma_{L V} \cos (\theta-\Delta \theta)
$$

onde, $\Delta A$ é a variação da área coberta pela gota e $\Delta \theta$ é a variação do ângulo de contato.

No equilíbrio termodinâmico, tem-se que $\lim _{\Delta A \rightarrow 0}\left(\Delta V_{S} / \Delta A\right)=0$, logo a expressão (12) se simplifica, como mostra a equação (13):

$$
\gamma_{S V}=\gamma_{S L}+\gamma_{L V} \cos \theta
$$

Esta equação é conhecida como Lei de Young (SAFRAN, 1994; ADAMSON, 1997; YAAKOV, 1999) e é usada para a determinação do ângulo de contato $\theta$ através da expressão (14):

$$
\cos \theta=\left(\frac{\gamma_{S V}-\gamma_{S L}}{\gamma_{L V}}\right)
$$

A forma que a gota irá ter sobre um material dependerá de uma competição entre dois pares de interações. O primeiro é a interação entre a gota e o material que pode ser energeticamente favorável ao espalhamento da gota pela superfície. Esse espalhamento implica em um aumento da área de contato entre a segunda interação entre fluido e a fase gasosa. Este aumento da área de contato provoca um aumento da energia da tensão superficial entre a gota e o vapor e pode reduzir a molhabilidade do filme. Quando a interação sólido/líquido domina, tem-se uma superfície completamente molhada, porém quando o termo da tensão superficial entre a gota e o vapor é dominante a superfície é parcialmente molhada e ocorre a formação de uma gota (SAFRAN, 1994). Na Figura 19 são mostradas situações possíveis para uma gota de água deionizada ao tocar uma superfície. 


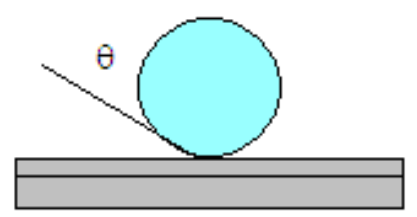

Não Molhado

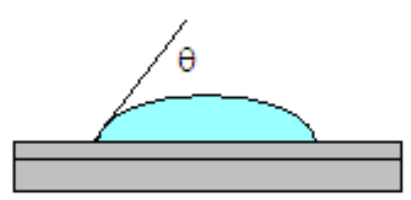

Parcialmente molhado

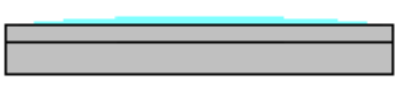

Completamente Molhado

Figura 19 - Situações para uma gota de água deionizada ao tocar uma superfície.

Verificam-se nesta figura que a superfície encontra-se completamente molhada quando $\theta=0^{\circ}$, parcialmente molhada para $\theta<90^{\circ}$ e não molhada com $\theta>90^{\circ}$, sendo que as gotas do líquido tendem a se movimentarem sobre a superfície (ADAMSON, 1997).

A tensão interfacial $\gamma_{S V}$ não é a energia de superfície do sólido, $\gamma_{S}$, pois esta é determinada no vácuo. A diferença entre estes valores é a pressão de espalhamento $\pi_{0}$ devido a adsorção de vapor saturado pela superfície sólida. A relação entre elas é dada pela equação (15):

$$
\gamma_{S}=\gamma_{S V}-\pi_{0}
$$

Entretanto, para superfícies com baixa energia, tais como os filmes finos de carbono, $\pi_{0}$ são desprezíveis, de forma que $\gamma_{S}=\gamma_{S V}$ (MA et al., 2000).

Os estudos das forças atrativas nas interfaces (OWENS, 1969) sugerem que a energia livre total numa superfície é a soma de contribuições de diferentes forças intermoleculares. Logo, a energia de superfície pode ser dada pela equação (16):

$$
\gamma=\gamma_{P}+\gamma_{D}
$$

onde, $P$ e $D$ referem-se respectivamente às componentes polar e dispersiva (não polar). A componente polar inclui todas as interações entre o sólido e o líquido, tais como dipolo-dipolo, dipolo induzido, ligações de hidrogênio, etc. A componente dispersiva refere-se a dipolos instantâneos devido ao movimento dos elétrons dentro das moléculas.

Dois métodos de cálculos são usados para determinação da energia de superfície considerando estas duas componentes, o método harmônico e o geométrico (MA et al., 2000), dados respectivamente pelas equações (17) e (18): 
Método harmônico:

$$
\gamma_{L V}(1+\cos \theta)=\frac{4 \gamma_{S}^{D} \gamma_{L V}^{D}}{\gamma_{S}^{D}+\gamma_{L V}^{D}}+\frac{4 \gamma_{S}^{P} \gamma_{L V}^{P}}{\gamma_{S}^{P}+\gamma_{L V}^{P}}
$$

Método geométrico:

$$
\gamma_{L V}(1+\cos \theta)=2\left(\gamma_{S}^{D} \gamma_{L V}^{D}\right)^{1 / 2}+2\left(\gamma_{S}^{P} \gamma_{L V}^{P}\right)^{1 / 2}
$$

Usando-se dois líquidos para a medida dos ângulos de contato, cujas componentes polar $\gamma_{L V}^{P}$ e dispersiva $\gamma_{L V}^{D}$ sejam conhecidas, pode-se determinar as componentes $\gamma_{S}^{P}$ e $\gamma_{S}^{D}$ da energia de superfície do sólido, pela solução destas equações (17) e (18). WU (1971) sugeriu que o método harmônico pode ser aplicado com exatidão entre filmes finos de carbono e um líquido qualquer.

As medidas de ângulos de contato $(\theta)$ foram realizadas utilizando um Goniômetro automatizado (Ramé-Hart - modelo F-300), pertencente ao Laboratório de Plasma e Aplicações da Faculdade de Engenharia do Campus de Guaratinguetá (FEG/UNESP), conforme mostrado na figura 20.

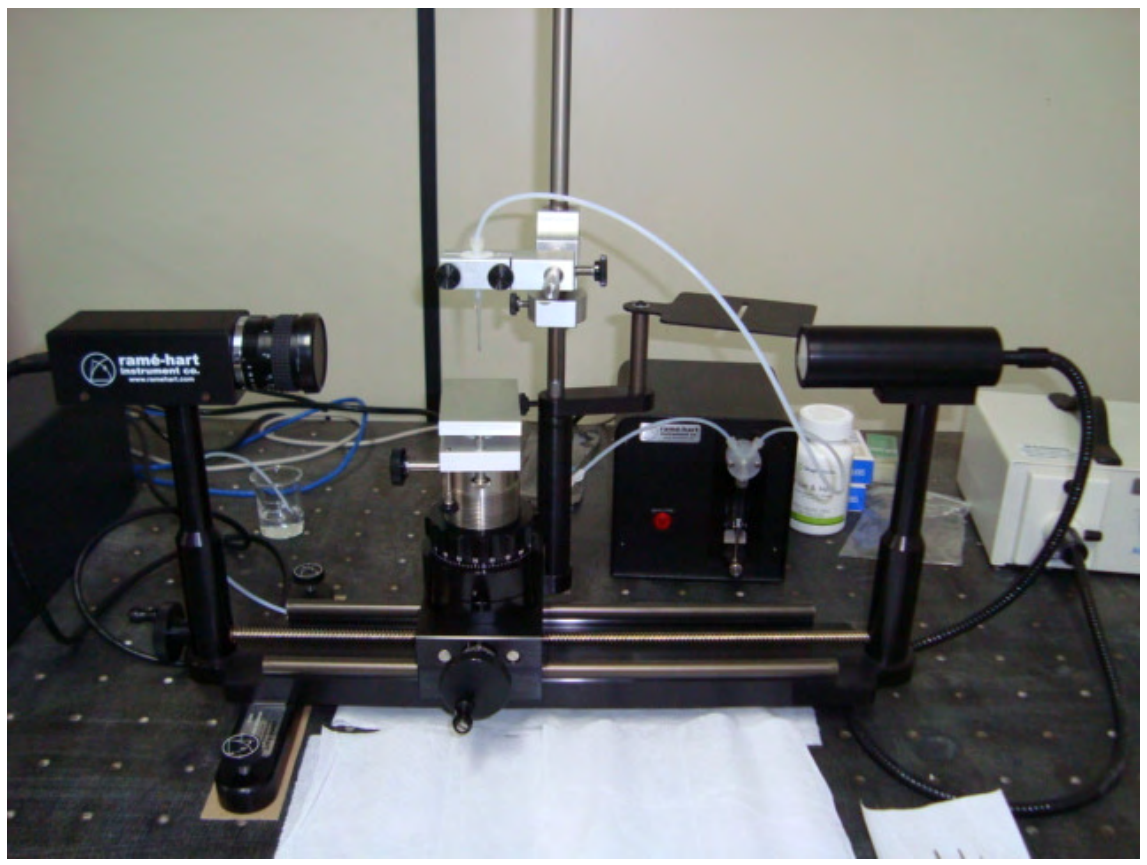

Figura 20 - Fotografia do goniômetro utilizado nas medidas de ângulo de contato e energia de superfície dos filmes. 
Este equipamento é composto por uma plataforma para colocação das amostras, um reservatório para colocação dos líquidos, uma câmera $\mathrm{CCD}$, que captura a imagem da gota depositada sobre o filme e um computador com programa de tratamento de imagens que determina o perfil desta gota e então se calcula o ângulo de contato. Para um resultado estatístico cada gota foi medida 10 vezes e as analises realizadas 30 dias após as deposições.

\subsection{TRIBÔMETRIA}

O conceito básico de medidas do coeficiente de atrito e desgaste está contido na ciência que estuda o efeito do movimento relativo entre dois corpos, ou seja, a tribologia. A técnica de caracterização tribológica é muito importante para o estudo de materiais quanto sua resistência ao desgaste, coeficiente de atrito, e mesmo da aderência.

No modo rotacional, as medidas são obtidas com o substrato em movimento giratório (fixado em um disco) na mesma trilha ou em trilha diferente, fazendo-se composição de movimento com a ponta em contato.

No modo recíproco linear, a base onde o substrato está fixado se move em ida e volta na mesma trilha ou ainda com mudança de trilha. A força é aplicada de forma ativa, através de comandos elétricos em uma rosca sem fim. A carga é medida por um sensor (conjunto de "Strain Gauge"). O sistema é composto por sensores, de diferentes cargas, dependendo do que se deseja aplicar. A medida do coeficiente de atrito e desgaste pode ser usada por qualquer um dos modos de operação. O sistema é também composto de aquisição de dados que mostra de forma gráfica o comportamento dos parâmetros como função do tempo, ciclo, etc. Todas as medidas podem ser feitas com controle da umidade e da temperatura do ambiente.

Os ensaios foram realizados através de um Tribômetro modelo UMT, CETR, pertencente ao Laboratório de Caracterização de Materiais da EMBRACO, Joinville/SC. Este equipamento é composto por unidades que podem ser classificadas 
como superiores (que ficam acima da amostra) e inferiores (que ficam abaixo da amostra).

A figura 21 mostra a fotografia do tribômetro utilizado para a determinação do coeficiente de atrito das amostras analisadas.

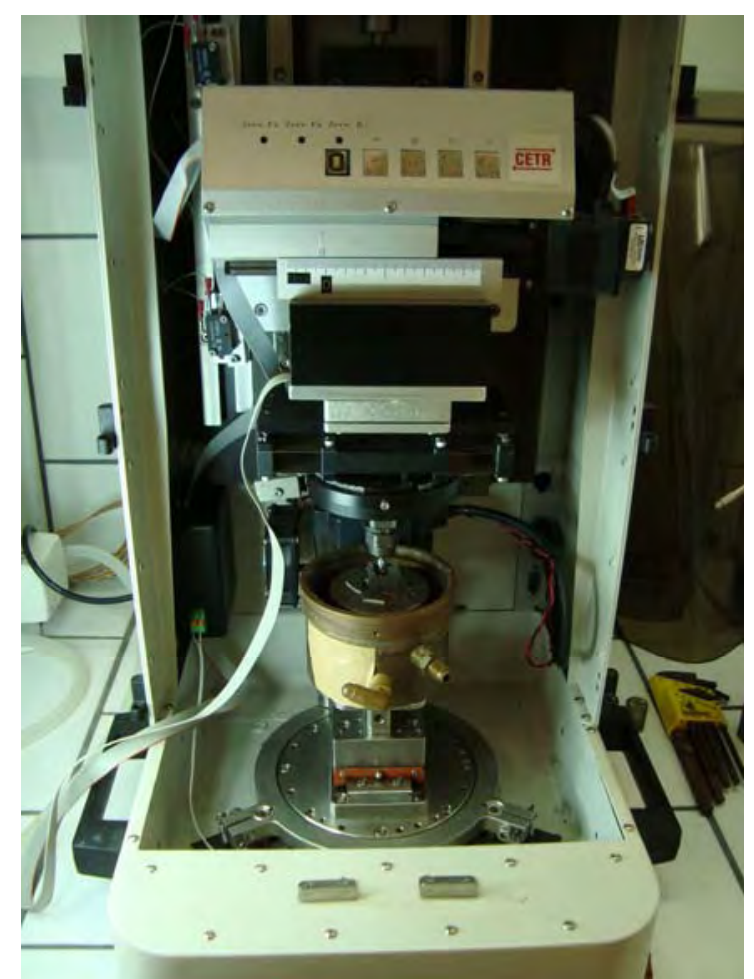

Figura 21 - Fotografia do Tribômetro modelo UMT utilizado para caracterização do coeficiente de atrito dos filmes.

Dentre as unidades superiores temos os sensores de carga e a unidade de posicionamento lateral (utilizado para posicionar a esfera que ficará em contato com a amostra). Já as unidades inferiores são divididas em unidade de movimento rotacional e unidade de movimento recíproco linear. A combinação dessas unidades permite a realização de análises em diversos modos de operação, sempre de acordo com a situação que se deseja simular.

Neste trabalho os testes tribológicos foram realizados no modo recíproco linear, esquematizado de acordo com a figura 22. 


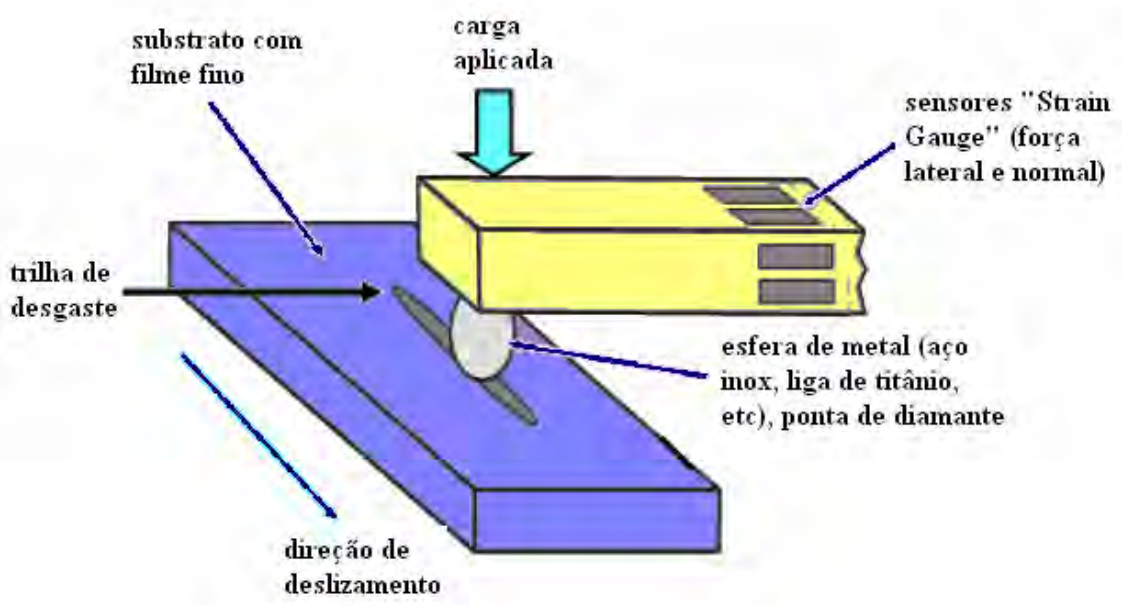

Figura 22 - Desenho esquemático do sistema utilizado para os testes tribológicos, no modo recíproco linear (BONETTI, 2006).

As condições utilizadas durante os ensaios foram: carga normal de $10 \mathrm{~N}$; amplitude de deslizamento de $2 \mathrm{~mm}$; temperatura ambiente de $20^{\circ} \mathrm{C}$; velocidade de 5 $\mathrm{cm} / \mathrm{s}$ e atmosfera ambiente com $60 \%$ de umidade relativa. Como contra-corpo, foram utilizadas esferas de aço com diâmetro de $6 \mathrm{~mm}$ em aço inox. Antes dos ensaios, as esferas foram submetidas a um processo de limpeza em banho de ultra-som com acetona.

Os resultados das curvas de atrito foram exportados diretamente em forma de banco de dados e abertos no programa específico do equipamento. Para cada amostra foram realizados 3 ensaios.

\subsection{PERFILOMETRIA}

A técnica de perfilometria foi utilizado para determinação da espessura dos filmes de a-C:H e dos filmes fluorados. Todas as medidas foram realizadas através de um perfilômetro Tencor Alfa-Step 500, cuja fotografia está mostrada na figura 23. Este equipamento pertence ao Laboratório de Análises e Sensores (LAS) do INPE, em São José dos Campos/SP. 


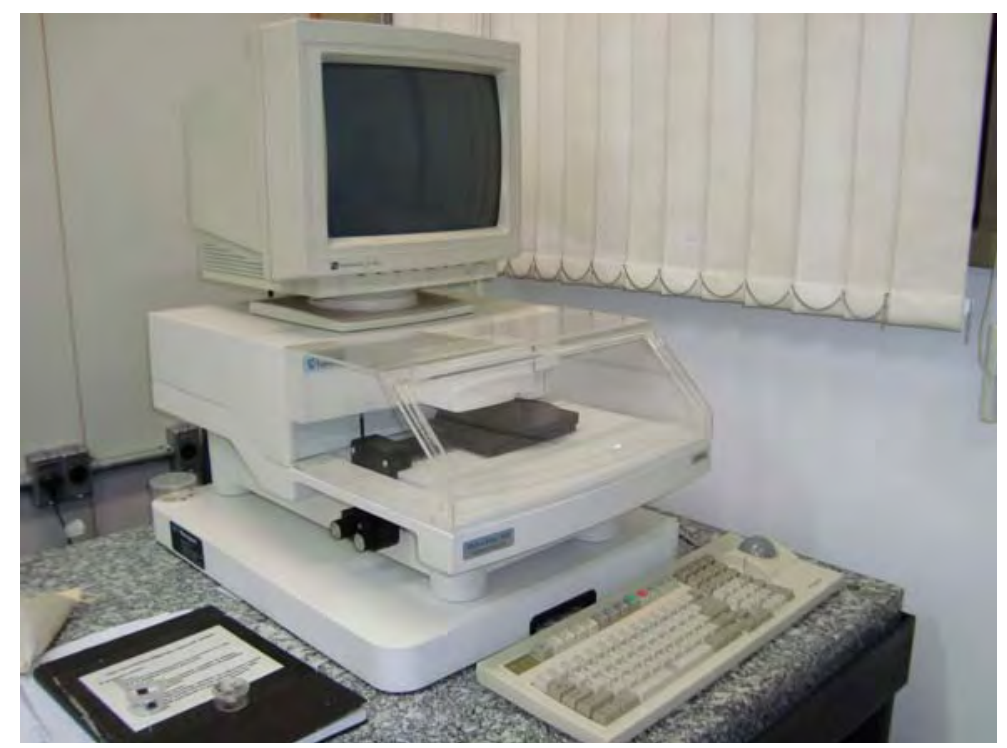

Figura 23 - Fotografia do perfilômetro utilizado nas medidas de espessura dos filmes.

Para cada amostra foram realizadas 5 medidas ao longo da interface entre o substrato e o filme.

Os filmes foram depositados sobre substratos de vidro parcialmente cobertas por uma máscara, de modo a apresentar um degrau entre a superfície do filme e a do substrato, como ilustra a figura 24. Para isso parte da superfície do substrato é coberta

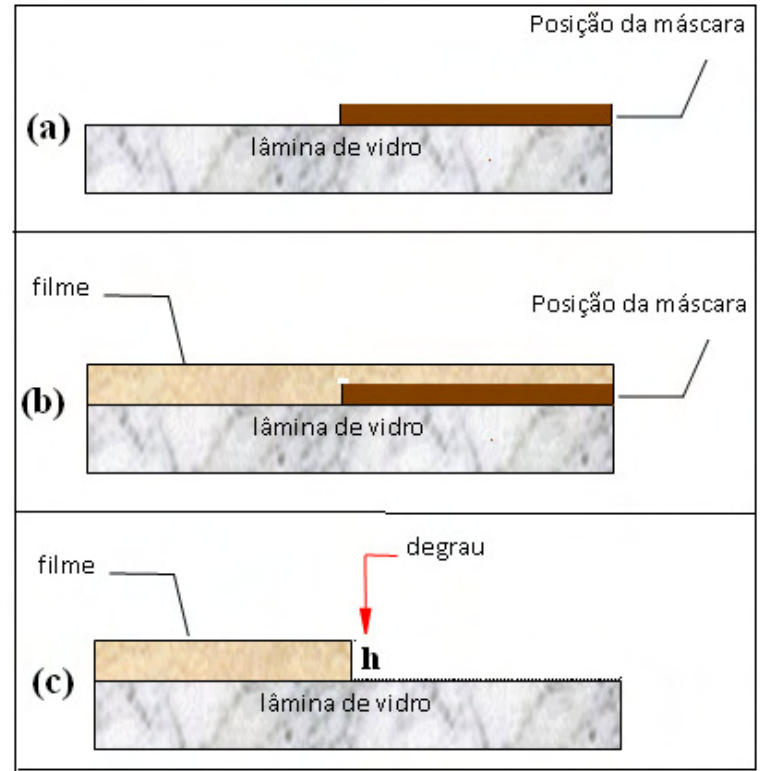

Figura 24 - Degrau para medida de espessura; (a) substrato de vidro parcialmente recoberta por uma máscara; (b) deposição do filme sobre o substrato de vidro parcialmente recoberta pela máscara e (c) substrato de vidro recoberto pelo filme depois de retirada da máscara. 
por uma máscara e o filme é então depositado. Após a obtenção do filme, a máscara é removida obtendo-se um degrau entre a parte do substrato protegida e a revestida com o filme, cuja altura "h" corresponde à espessura do filme.

\subsection{INTERFEROMETRIA ÓPTICA}

Essa técnica consiste na combinação de várias fontes de luz (LEDs verde e branca de longo tempo de vida) a partir de um instrumento óptico, com o objetivo de fazer medições precisas e é utilizada para caracterizar a topografia tri-dimensional, o perfil e rugosidade de superfície.

A rugosidade de superfície dos filmes foi avaliada a partir das imagens obtidas em um interferômetro ótico, WYKO NT1100, cuja fotografia é mostrada na figura 25, pertencente ao Laboratório de Análises e Sensores do INPE, São José dos Campos.

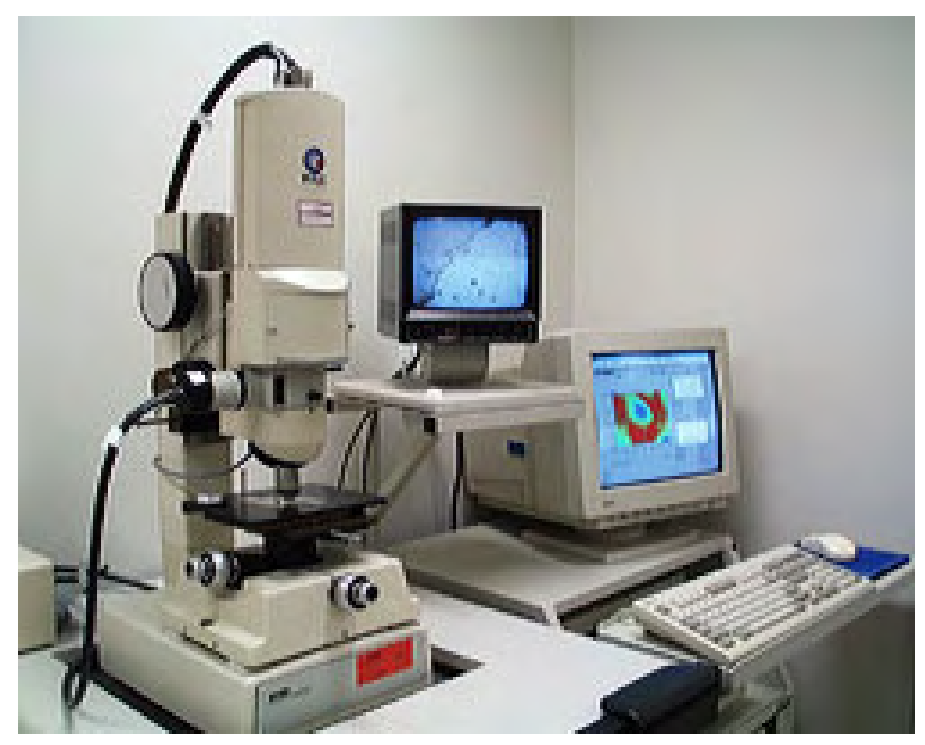

Figura 25 - Fotografia do interferômetro ótico utilizado na obtenção da rugosidade de superfícies dos filmes. 
Este equipamento compreende um sistema óptico (laser, mesa anti-vibratória, lente, etc), dispositivos de aquisição de imagem (câmera CCD e placa de captura), e um computador, podendo operar em dois modos: PSI (Phase Shifting Interferometry) que permite medir superfícies ásperas (na faixa de nanômetro a micrômetro) e VSI (Vertical Scanning Interferometry) que permite medir superfícies lisas (na faixa de angstrom).

A técnica de interferometria baseia-se no fato de ser não destrutiva e de não contato, isto é, a única interação entre a amostra a ser medida e o sistema de medição se dá através de um feixe luminoso. O efeito speckle é um dos principais fenômenos resultantes da interação de uma iluminação coerente com uma superfície opticamente rugosa. Entende-se por efeito speckle o fenômeno de interferência de ondas mutuamente coerentes com uma variação ao acaso de fase. O resultado deste tipo de interferência é uma distribuição de máximos e mínimos na intensidade da luz que é estacionaria no tempo, mas aleatória no espaço. Os picos individuais de intensidades representando pequenas manchas claras ou escuras são chamados de speckle. $\mathrm{O}$ termo superfície opticamente rugosa significa aquela que apresenta um micro-relevo tal que a altura dos picos individuais é maior ou igual do que o comprimento de onda da luz usada para iluminação da superfície.

A rugosidade superficial é uma característica essencial de cada material e quando uma superfície é iluminada com luz coerente, a informação do micro-relevo superficial é transmitida à onda espalhada (campo speckle) e depois a uma imagem formada pelo sistema óptico. O uso de câmeras CCD acopladas a um sistema de aquisição de imagens controlado por um computador permite processamento refinado das imagens, inferindo prontamente, mediante cálculos apropriados, as informações desejadas.

Os parâmetros que podem ser obtidos através dessa técnica são: rugosidade (Ra); raiz quadrática média (RMS) da rugosidade; altura máxima do pico de perfil, a uma profundidade máxima (Rp e Rv) e altura média máxima do perfil (Rz).

As análises das amostras obtidas neste trabalho, foram realizadas no modo VSI e para cada amostra, foram escolhidas cinco perfis, a partir dos quais a raiz quadrática média da rugosidade (RMS) foi calculada automaticamente pelo programa fornecido com o equipamento. 


\section{METODOLOGIA EXPERIMENTAL}

\subsection{SISTEMA EXPERIMENTAL PARA DEPOSIÇÃO E TRATAMENTO DOS FILMES de a-C:H}

A deposição dos filmes de carbono amorfo hidrogenado foi realizada no Laboratório de Plasmas e Aplicações da Faculdade de Engenharia do Campus de Guaratinguetá (FEG/UNESP), utilizando o método de deposição química por plasma de rádio frequência (Radio-Frequency Plasma-Enhanced Chemical Vapor Deposition - RF-PECVD), tendo como fonte gasosa o acetileno $\left(\mathrm{C}_{2} \mathrm{H}_{2}\right)$ e o argônio.

O sistema utilizado é constituído por uma câmara de vidro de formato cilíndrico, medindo $190 \mathrm{~mm}$ de diâmetro por $150 \mathrm{~mm}$ de altura, com eletrodos internos, circulares, planos e paralelos, em aço inoxidável, com $60 \mathrm{~mm}$ de diâmetro. $\mathrm{O}$ espaçamento entre os dois eletrodos foi de $20 \mathrm{~mm}$. Dois flanges de alumínio são utilizados na parte superior e inferior para a vedação do reator. O eletrodo inferior foi usado como porta substrato e acoplado a uma fonte de radiofrequência de $13,56 \mathrm{MHz}$ para a produção do plasma.

O reator de deposição é evacuado por um sistema constituído por uma bomba mecânica de duplo estágio, modelo E2M18, com velocidade de bombeamento de 25 $\mathrm{m}^{3} / \mathrm{h}$, atingindo a pressão nominal, de fundo de $0,5 \mathrm{~Pa}$. A bomba mecânica apresenta uma válvula solenóide modelo IPVA10EK, com tempo de resposta de $30 \mathrm{~m} / \mathrm{s}$, acoplada a saída da mesma, tendo por objetivo realizar a admissão automática de ar atmosférico quando do desligamento da bomba. Este procedimento evita o refluxo do óleo da bomba para o interior da câmara de plasma atingindo pressões até $10^{-1} \mathrm{~Pa}$.

A câmara de plasma é conectada à bomba por meio de uma válvula esférica e um tubo flexível de aço inoxidável com flange NW25. O controle da pressão no interior do reator é realizado por meio de um sensor tipo Pirani TM, operando na faixa de pressão de $10^{5}$ a $10^{-2} \mathrm{~Pa}$. A leitura do valor de pressão é feita através de uma unidade controladora de pressão, digital, provida de seis canais independentes com capacidade de efetuar leituras de pressão na faixa de 2 × $10^{5}$ a 2 × $10^{-9} \mathrm{~Pa}$. Uma fotografia do sistema experimental está mostrada na figura 26. 


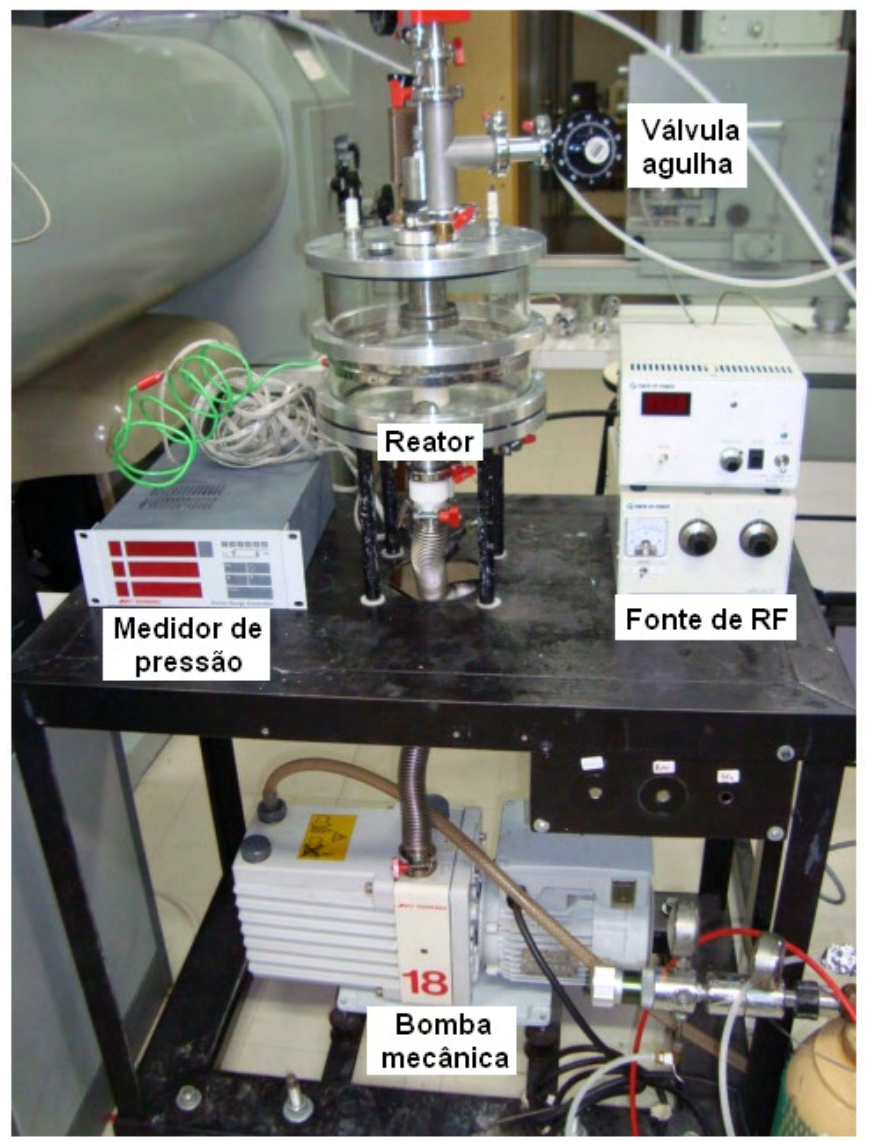

Figura 26 - Fotografia do sistema utilizado na deposição e tratamento dos filmes.

Os plasmas foram excitados por meio de uma fonte de radiofrequência, Tokyo HY-Power, modelo RF-300, operando na frequência de 13,56 MHz com a potência podendo ser variada na faixa de 0 a $300 \mathrm{~W}$.

A fonte de RF foi acoplada ao reator através de cabos coaxiais e um sistema casador de impedância, Tokyo HY-Power, modelo MB-300, permitindo uma eficiência de acoplamento na faixa de $90 \%$ a $100 \%$ para a maioria das situações experimentais.

\subsection{PROCEDIMENTOS PRÉ-DEPOSIÇÃO}

Antes da deposição dos filmes, alguns procedimentos foram adotados com relação ao sistema de deposição e com os substratos utilizados. 


\subsubsection{Preparação dos Substratos}

Para a deposição dos filmes foram usados substratos de vidro, com dimensões de 2,0 cm de comprimento, 1,0 $\mathrm{cm}$ de largura e $0,1 \mathrm{~cm}$ de espessura e substratos de silício amorfo, medindo 1,0 x 1,0 cm de largura, com uma das faces polida.

O procedimento de limpeza das lâminas de vidro e do silício consiste em várias etapas. As amostras foram mergulhadas em uma solução com detergente especial para vidros e deixadas por 15 minutos em uma cuba ultra-sônica. Em seguida enxaguadas em água corrente e água destilada e retornando ao ultra-som submerso em água destilada. Após 15 minutos, a água destilada foi substituída por álcool isopropílico e depois por acetona, mantidas em banho ultra-sônico por 20 minutos para cada solução. Após a limpeza dos substratos, eles foram secados em estufa numa temperatura de aproximadamente $250{ }^{\circ} \mathrm{C}$ por 20 minutos. Os substratos de vidro foram usados para caracterizar a composição química, a molhabilidade e a espessura dos filmes. Os de silício foram usados para determinação da estrutura molecular, rugosidade, dureza e atrito.

\subsubsection{Limpeza das Tubulações dos Gases}

A limpeza foi feita abrindo-se as válvulas das tubulações dos gases, mantendose fechado apenas a válvula dos cilindros de gás. Na sequência, as tubulações foram purgadas antes do inicio das deposições dos filmes.

\subsubsection{Limpeza a Plasma}

O processo de limpeza a plasma consistiu em bombardear a superfície dos substratos com íons de argônio, gerados em pressões de 1,33 Pa, utilizando-se a fonte de rádiofrequência operando na potência de $50 \mathrm{~W}$ por 20 minutos. 


\subsection{PARÂMETROS DAS DEPOSIÇÕES}

\subsubsection{Deposição de filme de carbono amorfo hidrogenado (a-C:H)}

Os parâmetros de deposição dos filmes de a-C:H, a partir de acetileno e argônio, foram determinados a partir da otimização do processo PECVD em trabalhos anteriores (MARINS, 2003). Onde foram realizados experimentos com variação da proporção dos monômeros (acetileno e argônio) e variação na pressão total dos gases. Após a realização dos experimentos variando-se a pressão e a proporção de gases, verificou-se que a melhor condição para obtenção de filmes de a-C:H foi a de $30 \%$ de acetileno e $70 \%$ de argônio com pressão total entre 9,0 - $10 \mathrm{~Pa}$. Os filmes de a-C:H foram depositados a partir de uma mistura de gases compostos de $30 \%$ de acetileno $\left(\mathrm{C}_{2} \mathrm{H}_{2}\right)$ e $70 \%$ de argônio (Ar) numa pressão total de 9,5 Pa. A potência de rádiofrequência foi variada de 5 a 125 Watts (W) e o tempo de deposição de 5 e 10 minutos. O sinal de rádiofrequência $(13,56 \mathrm{MHz})$ foi aplicado no eletrodo inferior. Os parâmetros do plasma adotados em cada deposição são mostrados na tabela 1 .

Tabela 1- Parâmetros das deposições dos filmes de a-C:H, sendo $\mathrm{P}_{\mathrm{t}}=\mathrm{P}_{\mathrm{b}}+\mathrm{P}_{\mathrm{T}}$ e $\mathrm{P}_{\mathrm{T}}=\left(\mathrm{P}_{\mathrm{a}}+\right.$ $\mathrm{P}_{\mathrm{Ar}}$ ), onde $\mathrm{P}_{\mathrm{T}}=$ Pressão total dos gases (acetileno e argônio).

\begin{tabular}{|l|c|c|c|c|c|c|c|c|c|c|c|c|}
\hline Amostras & 1 & 2 & 3 & 4 & 5 & 6 & 7 & 8 & 9 & 10 & 11 & 12 \\
\hline Monômeros & $\begin{array}{l}\mathrm{C}_{2} \mathrm{H}_{2} \\
+\mathrm{Ar}\end{array}$ & $\begin{array}{l}\mathrm{C}_{2} \mathrm{H}_{2} \\
+\mathrm{Ar}\end{array}$ & $\begin{array}{l}\mathrm{C}_{2} \mathrm{H}_{2} \\
+\mathrm{Ar}\end{array}$ & $\begin{array}{l}\mathrm{C}_{2} \mathrm{H}_{2} \\
+\mathrm{Ar}\end{array}$ & $\begin{array}{l}\mathrm{C}_{2} \mathrm{H}_{2} \\
+\mathrm{Ar}\end{array}$ & $\begin{array}{l}\mathrm{C}_{2} \mathrm{H}_{2} \\
+\mathrm{Ar}\end{array}$ & $\begin{array}{l}\mathrm{C}_{2} \mathrm{H}_{2} \\
+\mathrm{Ar}\end{array}$ & $\begin{array}{l}\mathrm{C}_{2} \mathrm{H}_{2} \\
+\mathrm{Ar}\end{array}$ & $\begin{array}{l}\mathrm{C}_{2} \mathrm{H}_{2} \\
+\mathrm{Ar}\end{array}$ & $\begin{array}{l}\mathrm{C}_{2} \mathrm{H}_{2} \\
+\mathrm{Ar}\end{array}$ & $\begin{array}{l}\mathrm{C}_{2} \mathrm{H}_{2} \\
+\mathrm{Ar}\end{array}$ & $\begin{array}{c}\mathrm{C}_{2} \mathrm{H}_{2} \\
+\mathrm{Ar}\end{array}$ \\
\hline $\begin{array}{l}\mathrm{P}_{\mathrm{b}}-\text { Pressão } \\
\text { base (Pa) }\end{array}$ & 1,10 & 1,30 & 1,20 & 1,10 & 1,00 & 1,20 & 1,10 & 1,10 & 1,10 & 1,00 & 1,00 & 1,20 \\
\hline $\begin{array}{l}\mathrm{P}_{\mathrm{a}}-\text { Pressão } \\
\text { parcial de } \mathrm{C}_{2} \mathrm{H}_{2} \\
\text { (Pa) }\end{array}$ & 2,85 & 2,85 & 2,85 & 2,85 & 2,85 & 2,85 & 2,85 & 2,85 & 2,85 & 2,85 & 2,85 & 2,85 \\
\hline $\begin{array}{l}\mathrm{P}_{\mathrm{Ar}} \text { - Pressão } \\
\text { parcial de } \\
\text { argônio (Pa) }\end{array}$ & 6,65 & 6,65 & 6,65 & 6,65 & 6,65 & 6,65 & 6,65 & 6,65 & 6,65 & 6,65 & 6,65 & 6,65 \\
\hline $\begin{array}{l}\mathrm{P}_{\mathrm{t}}-\text { Pressão de } \\
\text { trabalho (Pa) }\end{array}$ & 10,60 & 10,80 & 10,70 & 10,60 & 10,50 & 10,70 & 10,60 & 10,60 & 10,70 & 10,50 & 10,50 & 10,70 \\
\hline $\begin{array}{l}\mathrm{P}_{\mathrm{T}} \text { dos gases } \\
\text { (Pa) }\end{array}$ & 9,50 & 9,50 & 9,50 & 9,50 & 9,50 & 9,50 & 9,50 & 9,50 & 9,50 & 9,50 & 9,50 & 9,50 \\
\hline $\begin{array}{l}\text { Potência (W) } \\
\text { Tempo de } \\
\text { deposição (min) }\end{array}$ & 5 & 25 & 50 & 75 & 100 & 125 & 5 & 25 & 50 & 75 & 100 & 125 \\
\hline
\end{tabular}




\subsubsection{Tratamento a plasma com hexafluoreto de enxofre $\left(\mathrm{SF}_{6}\right)$}

Após a deposição, os filmes de a-C:H foram tratados com $\mathrm{SF}_{6}$, via plasma. $\mathrm{O}$ tratamento foi realizado no mesmo reator de vidro, logo após a deposição dos filmes, numa pressão total de $13,33 \mathrm{~Pa}$. A potência de rádiofrequência foi de $70 \mathrm{~W}$ e o tempo de tratamento de 5 minutos. $\mathrm{O}$ sinal de rádiofrequência $(13,56 \mathrm{MHz})$ foi aplicado no eletrodo superior, enquanto que o eletrodo inferior permaneceu aterrado. Os filmes obtidos após o tratamento foram aqui denominados de a-C:H(F). Os parâmetros do tratamento a plasma de $\mathrm{SF}_{6}$ adotados são mostrados na tabela 2.

Tabela 2- Parâmetro do tratamento a plasma de $\mathrm{SF}_{6}$ dos filmes de a-C:H, sendo $\mathrm{P}_{\mathrm{t}}=\mathrm{P}_{\mathrm{b}}+\mathrm{P}_{\mathrm{SF} 6}$.

\begin{tabular}{|l|c|c|c|c|c|c|c|c|c|c|c|c|}
\hline Amostras & $1^{*}$ & $2^{*}$ & $3^{*}$ & $4^{*}$ & $5^{*}$ & $6^{*}$ & $7^{*}$ & $8^{*}$ & $9^{*}$ & $10^{*}$ & $11^{*}$ & $12^{*}$ \\
\hline Monômero & $\mathrm{SF}_{6}$ & $\mathrm{SF}_{6}$ & $\mathrm{SF}_{6}$ & $\mathrm{SF}_{6}$ & $\mathrm{SF}_{6}$ & $\mathrm{SF}_{6}$ & $\mathrm{SF}_{6}$ & $\mathrm{SF}_{6}$ & $\mathrm{SF}_{6}$ & $\mathrm{SF}_{6}$ & $\mathrm{SF}_{6}$ & $\mathrm{SF}_{6}$ \\
\hline $\begin{array}{l}\mathrm{P}_{\mathrm{b}}-\text { Pressão } \\
\text { base (Pa) }\end{array}$ & 1,60 & 1,50 & 1,40 & 1,30 & 1,20 & 1,20 & 1,60 & 1,50 & 1,50 & 1,30 & 1,10 & 1,10 \\
\hline $\begin{array}{l}\mathrm{P}_{\text {SF6 }}- \\
\text { Pressão de } \\
\mathrm{SF}_{6}(\mathrm{~Pa})\end{array}$ & 13,33 & 13,33 & 13,33 & 13,33 & 13,33 & 13,33 & 13,33 & 13,33 & 13,33 & 13,33 & 13,33 & 13,33 \\
\hline $\begin{array}{l}\mathrm{P}_{\mathrm{t}}-\text { Pressão } \\
\text { de trabalho } \\
\text { (Pa) }\end{array}$ & 14,93 & 14,83 & 14,73 & 14,63 & 14,53 & 14,53 & 14,93 & 14,83 & 14,83 & 14,63 & 14,43 & 14,43 \\
\hline $\begin{array}{l}\text { Tempo de } \\
\text { tratamento } \\
\text { (min) }\end{array}$ & 5 & 5 & 5 & 5 & 5 & 5 & 5 & 5 & 5 & 5 & 5 & 5 \\
\hline $\begin{array}{l}\text { Potência de } \\
\text { RF (W) }\end{array}$ & 70 & 70 & 70 & 70 & 70 & 70 & 70 & 70 & 70 & 70 & 70 & 70 \\
\hline
\end{tabular}

\subsubsection{Deposição de filme de carbono amorfo hidrogenado fluorado (a-}

\section{C:H:F)}

Os filmes de a-C:H:F foram depositados a partir de uma mistura de gases compostos de $30 \%$ de acetileno $\left(\mathrm{C}_{2} \mathrm{H}_{2}\right), 65 \%$ de argônio (Ar) e $5 \%$ de $\mathrm{SF}_{6}$ numa pressão total de $9,5 \mathrm{~Pa}$. A potência de rádiofrequência foi variada de 5 a 125 Watts (W) e o tempo de deposição foi de 5 minutos. O sinal de rádiofrequência $(13,56 \mathrm{MHz})$ foi aplicado no eletrodo inferior. Os filmes foram depositados sobre substratos de 
vidro e silício, montados sobre o eletrodo inferior do reator, logo após a limpeza a plasma, enquanto que o eletrodo superior permaneceu aterrado. Os parâmetros do plasma adotados em cada deposição são mostrados na tabela 3 .

Tabela 3- Parâmetros das deposições dos filmes de a-C:H:F, sendo $\mathrm{P}_{t}=\mathrm{P}_{\mathrm{b}}+\mathrm{P}_{\mathrm{T}}$ e $\mathrm{P}_{\mathrm{T}}=\left(\mathrm{P}_{\mathrm{a}}+\right.$ $\left.\mathrm{P}_{\mathrm{Ar}}+\mathrm{P}_{\mathrm{SF} 6}\right)$, onde $\mathrm{P}_{\mathrm{T}}=$ Pressão total dos gases $\left(\mathrm{C}_{2} \mathrm{H}_{2}+\mathrm{Ar}+\mathrm{SF}_{6}\right)$.

\begin{tabular}{|c|c|c|c|c|c|c|}
\hline Amostras & 13 & 14 & 15 & 16 & 17 & 18 \\
\hline Monômeros & $\begin{array}{c}\mathrm{C}_{2} \mathrm{H}_{2}+ \\
\mathrm{Ar}+\mathrm{SF}_{6}\end{array}$ & $\begin{array}{c}\mathrm{C}_{2} \mathrm{H}_{2}+ \\
\mathrm{Ar}+\mathrm{SF}_{6}\end{array}$ & $\begin{array}{c}\mathrm{C}_{2} \mathrm{H}_{2}+ \\
\mathrm{Ar}+\mathrm{SF}_{6}\end{array}$ & $\begin{array}{c}\mathrm{C}_{2} \mathrm{H}_{2}+ \\
\mathrm{Ar}+\mathrm{SF}_{6}\end{array}$ & $\begin{array}{c}\mathrm{C}_{2} \mathrm{H}_{2}+ \\
\mathrm{Ar}+\mathrm{SF}_{6}\end{array}$ & $\begin{array}{c}\mathrm{C}_{2} \mathrm{H}_{2}+ \\
\mathrm{Ar}+\mathrm{SF}_{6}\end{array}$ \\
\hline $\mathrm{P}_{\mathrm{b}}-$ Pressão base $(\mathrm{Pa})$ & 1,20 & 1,30 & 1,20 & 1,00 & 1,10 & 1,10 \\
\hline $\mathrm{P}_{\mathrm{a}}-$ Pressão parcial de $\mathrm{C}_{2} \mathrm{H}_{2}(\mathrm{~Pa})$ & 2,85 & 2,85 & 2,85 & 2,85 & 2,85 & 2,85 \\
\hline $\mathrm{P}_{\mathrm{Ar}}-$ Pressão parcial de argônio $(\mathrm{Pa})$ & 6,15 & 6,15 & 6,15 & 6,15 & 6,15 & 6,15 \\
\hline $\mathrm{P}_{\mathrm{SF} 6}-$ Pressão parcial de $\mathrm{SF}_{6}(\mathrm{~Pa})$ & 0,50 & 0,50 & 0,50 & 0,50 & 0,50 & 0,50 \\
\hline $\mathrm{P}_{\mathrm{t}}-$ Pressão de trabalho $(\mathrm{Pa})$ & 10,70 & 10,80 & 10,70 & 10,50 & 10,60 & 10,60 \\
\hline $\mathrm{P}_{\mathrm{T}}$ dos gases $(\mathrm{Pa})$ & 9,50 & 9,50 & 9,50 & 9,50 & 9,50 & 9,50 \\
\hline Potência de RF (W) & 5 & 25 & 50 & 75 & 100 & 125 \\
\hline Tempo de deposição (min) & 5 & 5 & 5 & 5 & 5 & 5 \\
\hline
\end{tabular}




\section{RESULTADOS E DISCUSSÕES}

\subsection{EFEITOS DA POTÊNCIA DE EXCITAÇÃO DO PLASMA NAS PROPRIEDADES DOS FILMES DE a-C:H}

Nesta seção são apresentados os resultados das propriedades de filmes finos depositados a partir de plasmas de misturas de acetileno e argônio. Os plasmas foram estabelecidos pela aplicação de radiofrequiência ao porta-amostras, enquanto o eletrodo superior foi aterrado. As proporções de argônio e acetileno foram de 70 e 30\%, respectivamente, mantendo-se a pressão total dos gases constante em 9,5 Pa. A pressão de base do sistema foi de 1,3 Pa, o tempo de deposição foram de 5 e 10 minutos e a potência do sinal de excitação, entre 5 e 125 W. O efeito destes parâmetros nas propriedades dos filmes foi investigado, conforme resultados a seguir apresentados.

\subsubsection{Estrutura Molecular e Composição Química dos Filmes de a-C:H}

A Figura 27 apresenta os espectros Raman dos filmes depositados por 5 e 10 minutos, em plasmas de diferentes potências. Para os filmes depositados em 5 minutos, observa-se o surgimento de uma componente em torno de $1360 \mathrm{~cm}^{-1}$, denominada banda $\mathrm{D}$, e outra mais intensa centrada em $1548 \mathrm{~cm}^{-1}$ denominada banda G. Enquanto a banda $\mathrm{G}$ relaciona-se com vibrações de ligações de carbono duplas no plano basal da grafite, tipo $\mathrm{sp}^{2}$, a banda $\mathrm{D}$ está associada à desordem no ângulo de ligações de carbono nos contornos grafíticos pela formação de ligações tetragonais, $\mathrm{sp}^{3}$.

Observa-se também deslocamento da banda $G$ para a esquerda, nos espectros dos filmes depositados em plasmas de 5, 25 e $50 \mathrm{~W}$, indicando que as proporções de hibridizações $\mathrm{sp}^{3}$ das ligações de carbono e de ligações desordenadas aumentam. Os filmes depositados em plasmas de 5 e $25 \mathrm{~W}$ apresentaram luminescência, que foram corrigidas descontando-se o sinal de fundo. Para os filmes depositados em plasmas de 
potência acima de $50 \mathrm{~W}$, a posição central da banda $\mathrm{G}$ desloca-se para a direita, indicando aumento na formação de aglomerados de carbono.

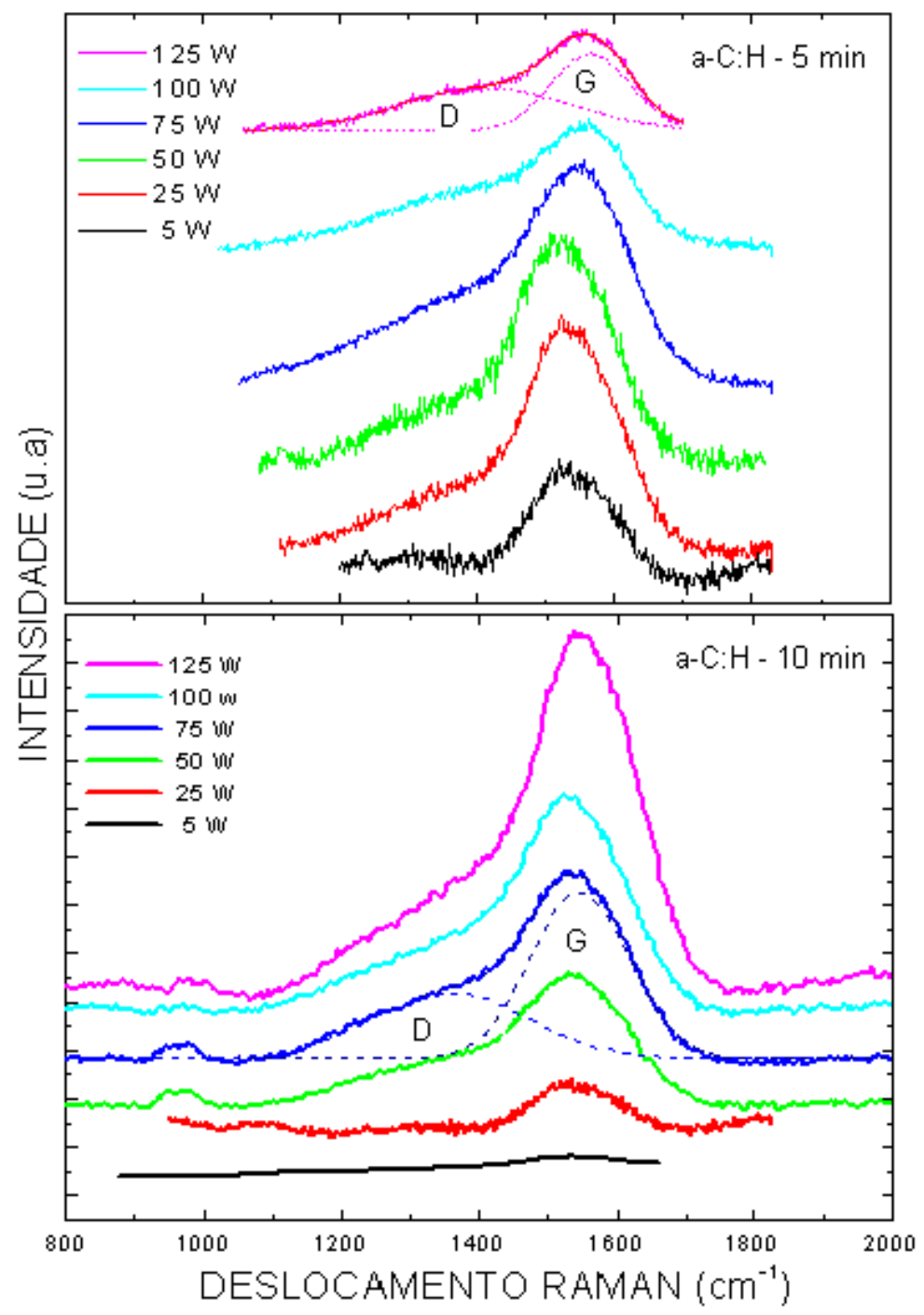

Figura 27 - Espectros Raman dos filmes de a-C:H depositados por 5 e 10 minutos, em plasmas de diferentes potências. A linha pontilhada é representativa das deconvoluções das bandas D e G.

Para os filmes depositados por 10 minutos, observa-se que a banda D está centrada em $1352 \mathrm{~cm}^{-1}$ e a banda $\mathrm{G}$ em $1541 \mathrm{~cm}^{-1}$. Observa-se também deslocamento da banda $\mathrm{G}$ para a esquerda, nos espectros dos filmes depositados até $50 \mathrm{~W}$, indicando que as proporções de hibridizações $\mathrm{sp}^{3}$ das ligações de carbono e de ligações 
desordenadas aumentam. Os filmes depositados em 5 e $25 \mathrm{~W}$ apresentaram acentuadas luminescências que também foram corrigidas.

Para quantificar as alterações apresentadas nos espectros, a posição, a largura e a intensidade das bandas foram determinadas e são apresentadas na tabela 4 .

Tabela 4 - Posição, largura e intensidade das bandas D e G dos espectros dos filmes depositados em 5 e 10 minutos, em plasmas de potências entre 5 e 125 W.

\begin{tabular}{|c|c|c|c|c|c|c|c|c|c|c|c|c|}
\hline & \multicolumn{4}{|c|}{5 minutos de deposição } & \multicolumn{5}{c|}{10 minutos de deposição } \\
\cline { 2 - 13 } & $\begin{array}{c}\text { Posição } \\
\left(\mathrm{cm}^{-1}\right)\end{array}$ & $\begin{array}{c}\text { Largura } \\
\left(\mathrm{cm}^{-1}\right)\end{array}$ & \multicolumn{2}{|c|}{ Intensidade } & \multicolumn{2}{c|}{$\begin{array}{c}\text { Posição } \\
\left(\mathrm{cm}^{-1}\right)\end{array}$} & \multicolumn{2}{|c|}{$\begin{array}{c}\text { Largura } \\
\left(\mathrm{cm}^{-1}\right)\end{array}$} & \multicolumn{2}{|c|}{ Intensidade } \\
\cline { 2 - 14 } & $\mathrm{D}$ & $\mathrm{G}$ & $\mathrm{D}$ & $\mathrm{G}$ & $\mathrm{D}$ & $\mathrm{G}$ & $\mathrm{D}$ & $\mathrm{G}$ & $\mathrm{D}$ & $\mathrm{G}$ & $\mathrm{D}$ & $\mathrm{G}$ \\
\hline 5 & 1298 & 1536 & 145 & 115 & 32 & 192 & 1362 & 1539 & 389 & 106 & 42 & 205 \\
\hline 25 & 1354 & 1541 & 133 & 207 & 101 & 387 & 1351 & 1543 & 262 & 174 & 187 & 783 \\
\hline 50 & 1324 & 1527 & 183 & 143 & 100 & 404 & 1345 & 1536 & 204 & 140 & 390 & 1379 \\
\hline 75 & 1393 & 1554 & 293 & 133 & 161 & 308 & 1353 & 1540 & 228 & 144 & 264 & 798 \\
\hline 100 & 1417 & 1564 & 295 & 115 & 110 & 156 & 1346 & 1543 & 217 & 145 & 176 & 494 \\
\hline 125 & 1411 & 1565 & 244 & 116 & 77 & 142 & 1356 & 1545 & 215 & 139 & 263 & 700 \\
\hline
\end{tabular}

Observam-se variações sucessivas nas intensidades das bandas D e G com o aumento da potência. Muito embora as intensidades destas bandas não possam ser comparadas diretamente, devido às diferenças nas sensibilidades, sabe-se que a razão entre as intensidades das bandas $\mathrm{D}$ e $\mathrm{G},\left(\mathrm{I}_{\mathrm{D}} / \mathrm{I}_{\mathrm{G}}\right)$ é proporcional ao tamanho dos centros grafíticos no filme (ROBERTSON, 2002). Este parâmetro foi calculado e os resultados obtidos são apresentados na figura 28 , juntamente com os valores da largura $(\Delta \mathrm{G})$ e da posição da banda $\mathrm{G}\left(\omega_{\mathrm{G}}\right)$, para os filmes depositados por 5 e 10 minutos em plasmas de diferentes potências.

De uma forma geral, $\mathrm{I}_{\mathrm{D}} / \mathrm{I}_{\mathrm{G}}$ cresce com o aumento da potência, para os filmes depositados por 5 e 10 minutos, refletindo crescimento nas dimensões dos centros grafíticos presentes na estrutura e, desta forma, na proporção de estados $\mathrm{sp}^{2}$. 


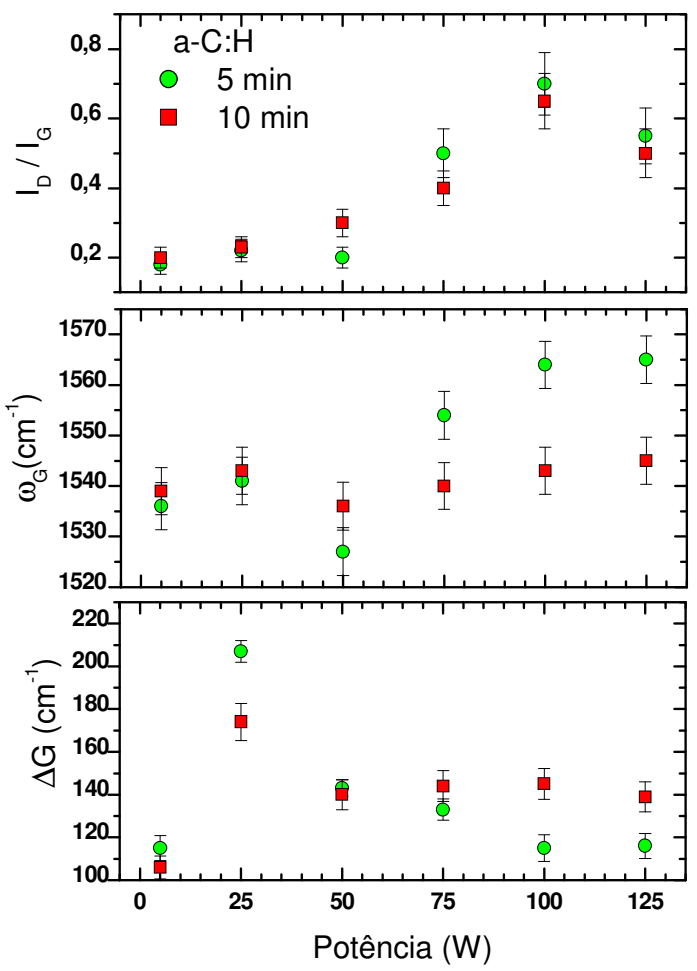

Figura 28 - Razão $I_{D} / I_{G}$, posição $\left(\omega_{G}\right)$ e largura $(\Delta G)$ da banda $G$ dos filmes de a-C:H, depositados por 5 e 10 minutos em função da potência.

$\mathrm{O}$ crescimento de $\mathrm{I}_{\mathrm{D}} / \mathrm{I}_{\mathrm{G}}$ sugere também que há diminuição na proporção de hidrogênio nos filmes (FERRARI, 2000). Nota-se ainda que as duas curvas nesta figura coincidem em baixas potências e separam-se para as altas potências. Para interpretar tal resultado, deve-se considerar que o aumento na potência de excitação do plasma induz aumento na tensão de autopolarização das amostras (TAKAI, 2001; TAJIMA, 2000). Por sua vez, tal fenômeno aumenta a intensidade de bombardeamento iônico durante o crescimento do filme induzindo fragmentações de ligações químicas, excitações e ionizações. O rompimento de ligações químicas geralmente ocorre para espécies mais fracamente ligadas à estrutura. Como energeticamente o rompimento de ligações C-H é mais provável que o de ligações C-C, há dehidrogenação da camada em crescimento, favorecendo a formação de uma estrutura rica em carbono.

Além da modificação na composição química, o bombardeamento iônico altera a estrutura molecular do material. O modelo de subimplantação (DAVIS, 1993; 
ROBERTSON, 1993) para a obtenção de filmes de carbono amorfo hidrogenado a partir de processos de plasma, pressupõe a deposição de energia em regiões próximas da superfície do sólido por radicais ionizados $\left(\mathrm{C}_{\mathrm{x}} \mathrm{H}_{\mathrm{y}}^{+}, \mathrm{CH}_{\mathrm{x}}^{+} \mathrm{e}_{\mathrm{x}}^{+}\right)$. De acordo com este modelo, a formação de núcleos $\mathrm{sp}^{3}$ ocorre quando a energia da espécie iônica incidente é suficiente para mover átomos com baixas energias de deslocamento, isto é, átomos de carbono com hibridização $\mathrm{sp}^{2}$, mas é insuficiente para remover átomos com hibridização $\mathrm{sp}^{3}$. Nestes casos, o aumento na densidade estabiliza a configuração $\mathrm{sp}^{3}$ com relação à $\operatorname{sp}^{2}$ (LIFSHITZ, 1999). Logo, a energia das espécies iônicas que são subimplantadas é de fundamental importância para a formação de estados $\mathrm{sp}^{3}$. Este modelo também propõe que íons de menor energia se liguem na superfície do filme $\left(\right.$ sítios $\mathrm{sp}^{2}$ ) e aqueles com maior energia troquem calor com a rede, por um processo de relaxação, favorecendo a configuração $\mathrm{sp}^{2}$. Assim, apenas em uma faixa determinada de energia, os íons de carbono se ligam na forma $\mathrm{sp}^{3}$ e esta energia depende intrinsecamente de cada sistema e condição de deposição utilizada (LACERDA, 1998).

Como os filmes depositados com 5 e $25 \mathrm{~W}$ de potência apresentaram luminescência nos espectros, estes podem ser caracterizados como filmes poliméricos. Então, pode-se dizer que há diminuição na proporção de grupos $\mathrm{sp}^{3}$ nos filmes (CAPOTE et al., 2006) quando a potência é variada de 50 a $125 \mathrm{~W}$, como conseqüência da dehidrogenação e grafitização da estrutura. Além disto, constata-se que a amostra depositada a $50 \mathrm{~W}$ apresenta maior proporção de sítios com hibridização $\mathrm{sp}^{3}$

Já a largura da banda cresce para valores de potência entre 5 e $25 \mathrm{~W}$ e diminui para maiores potências tanto para as deposições com 5 quanto 10 minutos. Desconsiderando os dois primeiros pontos ( 5 e $25 \mathrm{~W}$ ), que representam carbono tipo polimérico, verifica-se que as amostras preparadas com $50 \mathrm{~W}$ foram as que apresentaram as maiores concentrações de ligação $\mathrm{C}-\mathrm{C} \mathrm{sp}^{3}$, ou tipo diamante, comparada às demais.

Considerando-se os resultados obtidos pela análise dos espectros de espalhamento Raman, pode-se sugerir que a reorganização das ligações $\mathrm{sp}^{3}$ em centros grafíticos ocorre com o aumento da potência além de $50 \mathrm{~W}$. O deslocamento da banda 
G, para maiores números de onda, a variação de sua largura, assim como o aumento da razão $I_{D} / I_{G}$ são os indicadores dessa grafitização.

A figura 29 mostra os espectros XPS de longa varredura dos filmes depositados em plasmas de diferentes potências por 5 min. Surgem, nestes espectros, contribuições relacionadas ao carbono (aproximadamente a $285 \mathrm{eV}$ ), oxigênio (aproximadamente a 533,0 eV), nitrogênio (aproximadamente a 400,0 eV) e silício (aproximadamente a 103,0 eV). Estas mesmas contribuições foram encontradas nos espectros dos filmes depositados por 10 minutos (não apresentados).

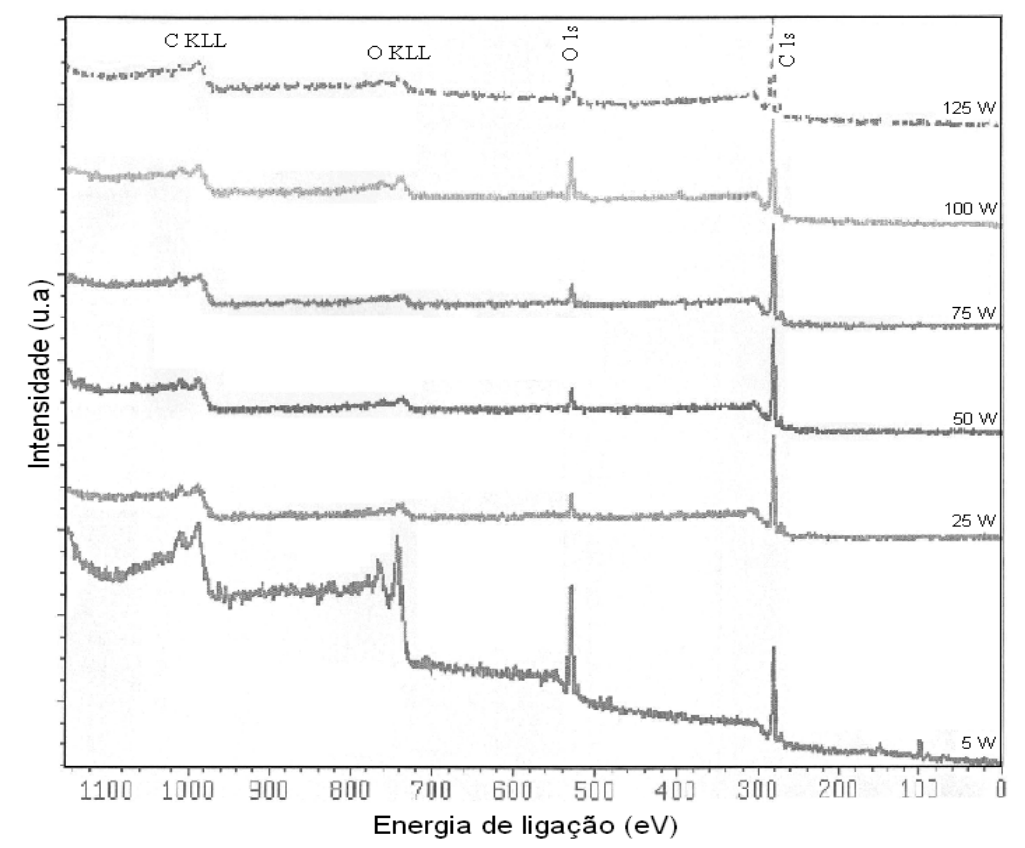

Figura 29 - Espectros de longa varredura dos filmes de a-C:H depositados em plasmas de diferentes potências.

As presenças de nitrogênio e oxigênio podem ser atribuídas à atmosfera residual no reator durante os processos de deposição, às reações pós-deposição entre radicais livres residuais, mantidos na estrutura dos filmes, e espécies atmosféricas, como também ao substrato utilizado para as deposições. Como o mecanismo de crescimento dos filmes é baseado na interação de radicais livres com superfícies, estes podem ser incorporados na estrutura do filme, devido a não saturação do radical. Como tais espécies podem apresentar longos tempos de vida (YASUDA, 1985), elas são ávidas pela captura de grupos atmosféricos quando as amostras são expostas ao ar, 
incorporando grupos contendo oxigênio e nitrogênio nos filmes. Muitos autores observaram a presença destas espécies químicas em filmes depositados a partir de plasmas de hidrocarbonetos, assim como a presença de oxigênio e nitrogênio em processos de implantação iônica de materiais poliméricos oriundos de hidrocarbonetos (MOTA, 1995; DURRANT, 1999; BORUCKI, 2001; SANTOS, 2004).

Espectros de alta resolução do pico de carbono foram também obtidos e suas deconvoluções resultaram em componentes centradas em 284,8; 286,5 e 288,0 eV. Enquanto o primeiro é devido à presença de ligações C-H e/ou C-C (MOULEDER et al., 1992), os dois últimos são atribuídos, respectivamente, a grupos C-O e C=O (TRUSSO, 1999; JIANG, 2000). Na tabela 5 são listadas as espécies detectadas com suas hibridizações, energias de ligação e respectivas proporções em cada uma das amostras investigadas neste trabalho. É interessante notar que somente a amostra depositada em $25 \mathrm{~W}$, por 5 minutos, não apresentou a componente relacionada a grupos $\mathrm{C}=\mathrm{O}(288,0 \mathrm{eV})$.

Tabela 5 - Ligações químicas, energias de ligação e proporções relativas, derivadas dos componentes do pico do C 1s dos filmes preparados com diferentes potências.

\begin{tabular}{|c|c|c|c|c|c|}
\hline \multirow[b]{2}{*}{$\begin{array}{l}\text { Potência } \\
\text { (W) }\end{array}$} & \multirow[b]{2}{*}{$\begin{array}{c}\text { Ligação } \\
\text { de carbono }\end{array}$} & \multicolumn{2}{|c|}{5 minutos de deposição } & \multicolumn{2}{|c|}{10 minutos de deposição } \\
\hline & & $\begin{array}{c}\text { Energia } \\
\text { de ligação }(\mathrm{eV}) \\
\end{array}$ & $\begin{array}{c}\text { Proporção } \\
(\%)\end{array}$ & $\begin{array}{c}\text { Energia de } \\
\text { ligação }(\mathrm{eV})\end{array}$ & $\begin{array}{c}\text { Proporção } \\
(\%)\end{array}$ \\
\hline \multirow{3}{*}{5} & C-C e/ou C-H & 284,8 & 83 & 284,8 & 76 \\
\hline & $\mathrm{C}-\mathrm{O}$ & 286,7 & 13 & 286,6 & 20 \\
\hline & $\mathrm{C}=\mathrm{O}$ & 288,4 & 4 & 288,3 & 4 \\
\hline \multirow{3}{*}{25} & $\mathrm{C}-\mathrm{C}$ e/ou C-H & 284,8 & 91 & 284,8 & 78 \\
\hline & $\mathrm{C}-\mathrm{O}$ & 287,0 & 9 & 286,5 & 19 \\
\hline & $\mathrm{C}=\mathrm{O}$ & - & - & 288,5 & 3 \\
\hline \multirow{3}{*}{50} & $\mathrm{C}-\mathrm{C}$ e/ou C-H & 284,8 & 86 & 284,8 & 77 \\
\hline & $\mathrm{C}-\mathrm{O}$ & 286,7 & 10 & 286,5 & 19 \\
\hline & $\mathrm{C}=\mathrm{O}$ & 288,4 & 4 & 288,3 & 4 \\
\hline \multirow{3}{*}{75} & $\mathrm{C}-\mathrm{C}$ e/ou C-H & 284,8 & 71 & 284,8 & 80 \\
\hline & $\mathrm{C}-\mathrm{O}$ & 286,0 & 25 & 286,4 & 17 \\
\hline & $\mathrm{C}=\mathrm{O}$ & 287,9 & 4 & 288,3 & 3 \\
\hline \multirow{3}{*}{100} & C-C e/ou C-H & 284,8 & 77 & 284,8 & 75 \\
\hline & $\mathrm{C}-\mathrm{O}$ & 286,3 & 18 & 286,4 & 21 \\
\hline & $\mathrm{C}=\mathrm{O}$ & 288,1 & 5 & 288,2 & 4 \\
\hline \multirow{3}{*}{125} & $\mathrm{C}-\mathrm{C}$ e/ou C-H & 284,8 & 79 & 284,8 & 77 \\
\hline & $\mathrm{C}-\mathrm{O}$ & 286,4 & 17 & 286,5 & 20 \\
\hline & $\mathrm{C}=\mathrm{O}$ & 288,4 & 4 & 288,4 & 3 \\
\hline
\end{tabular}


Para analisar os resultados apresentados nesta tabela, construiu-se o gráfico da figura 30 que mostra as concentrações relativas das espécies presentes nas amostras em função de potência em que foram preparadas.

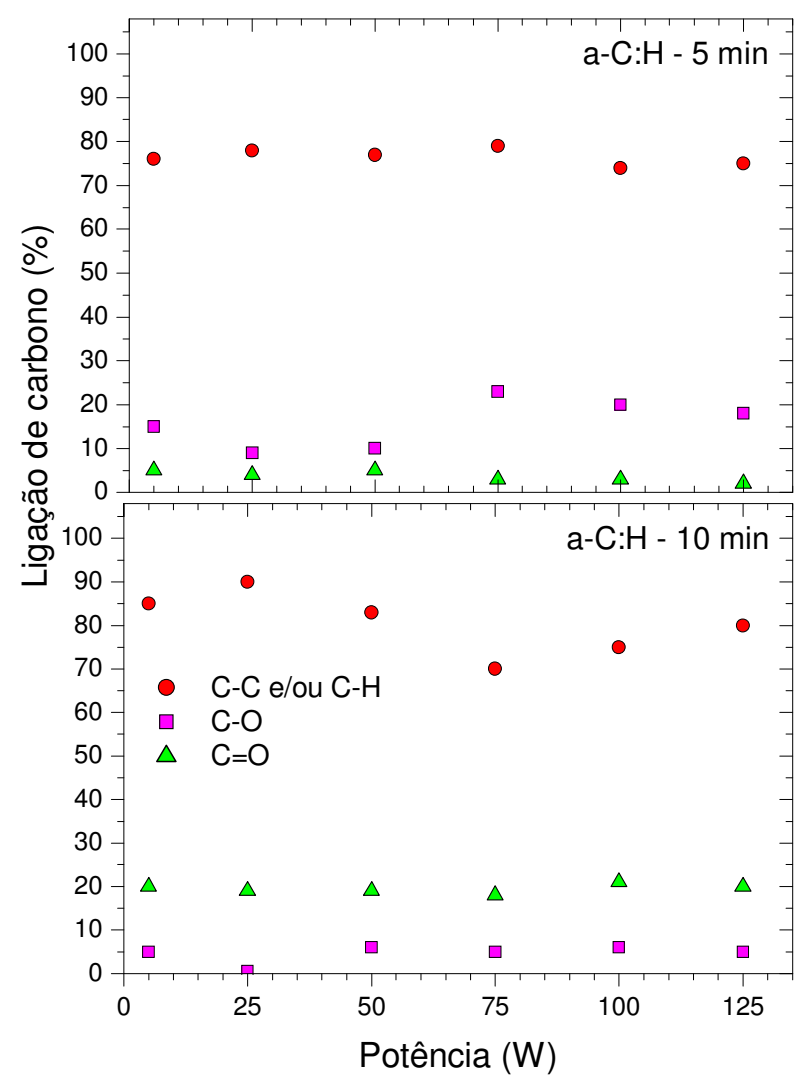

Figura 30 - Proporções relativas das espécies presentes nas amostras depositadas por 5 e 10 minutos, em função da potência, resultados obtidos a partir da deconvolução do pico fotoelétrico $\mathrm{C} 1 \mathrm{~s}$ $(284,8 \mathrm{eV})$.

Observando-se as proporções de cada componente, percebe-se que as ligações C-C e/ou C-H são predominantes, o que é característico de filmes de carbono amorfo hidrogenado. A concentração destas espécies, para os filmes depositados por 5 minutos, encontra-se entre 80 e $90 \%$ do total de espécies com a variação da potência entre 5 e $50 \mathrm{~W}$, observando-se ligeira queda, para valores de potência acima de $50 \mathrm{~W}$. Para os filmes depositados durante 10 minutos, a concentração de ligações C-H e/ou C-C permanece praticamente constante entre 70 e $80 \%$ do total de espécies em toda a faixa de potência. 
Para os filmes depositados por 5 minutos a concentração de grupos C-O segue o comportamento oposto ao dos grupos C-C e C-H: maiores proporções são observadas em potências acima de $50 \mathrm{~W}$, compensando a queda na proporção de grupos C-C e/ou C-H. Nos filmes preparados por 10 minutos a concentração destas espécies mantém-se constante em torno de $20 \%$. A mesma constância é observada na proporção de grupos $\mathrm{C}=\mathrm{O}$ que permanece praticamente constante em torno de $5 \%$ para ambos os tempos de deposição. A partir destes resultados pode-se afirmar que há aumento na incorporação de oxigênio atmosférico nos filmes com o aumento da potência em baixos tempos de deposição. O aumento no tempo de deposição também eleva a incorporação de grupos $\mathrm{C}-\mathrm{O}$ nos filmes. $\mathrm{O}$ aumento da energia proveniente do bombardeamento iônico com $\mathrm{P}$ produz crescimento na proporção de hidrogênio liberado, criando radicais livres na estrutura do material. Este processo contribui para aumentar a proporção de centros absorvedores de oxigênio nas amostras. Como a proporção de espécies $\mathrm{C}=\mathrm{O}$ é praticamente constante com a potência, é provável que a incorporação de grupos atmosféricos ocorra mediante ligações saturadas. A incorporação de grupos insaturados pode ocorrer durante o processo de deposição em que há transferência de energia pelo bombardeamento iônico.

Os espectros de alta resolução do pico de oxigênio também foram obtidos (não apresentados) e deconvoluídos em três componentes. O componente mais intenso, que surgiu por volta de 533,0 eV, é atribuído a grupos $\mathrm{SiO}_{2}$ e/ou C=O. Já o componente em aproximadamente 531,5 eV está associado a ligações C-O e o componente de mais alta energia $(535 \mathrm{eV})$, revela a presença de hidroxila $-\mathrm{OH}$ nos filmes.

Na tabela 6 são apresentadas os tipos de ligações químicas, suas energias e proporções em cada uma das amostras investigadas.

Os filmes depositados durante 5 minutos em plasmas de 100 e $125 \mathrm{~W}$, apresentaram o pico $\mathrm{N}$ 1s, além dos picos C 1s e $\mathrm{O} 1 \mathrm{~s}$, revelando a presença de ligações C-N (399,0 eV) e C=N (400,1 eV) . O filme depositado durante 10 minutos com $5 \mathrm{~W}$ de potência, também apresentou o pico $\mathrm{N}$ 1s com contribuições de ligações $\mathrm{C}-\mathrm{N}(399,0 \mathrm{eV})$ e $\mathrm{N}=\mathrm{O}(401,9 \mathrm{eV})$ enquanto o filme depositado com $25 \mathrm{~W}$ evidenciou a presença de ligações C-N (399,2 eV). 
Tabela 6 - Tipo de ligação química, suas energias e proporções relativas, derivadas dos componentes do pico $\mathrm{O} 1 \mathrm{~s}$ dos filmes de a-C:H depositados por 5 e 10 minutos, em plasmas de diferentes potências.

\begin{tabular}{|c|c|c|c|c|c|}
\hline \multirow{3}{*}{ Potência (W) } & & \multicolumn{2}{|c|}{5 minutos de deposição } & \multicolumn{2}{c|}{$\begin{array}{c}10 \text { minutos de } \\
\text { deposição }\end{array}$} \\
\cline { 3 - 6 } & $\begin{array}{c}\text { Tipo de } \\
\text { Ligação }\end{array}$ & $\begin{array}{c}\text { Energia de } \\
\text { Ligação } \\
(\mathrm{eV})\end{array}$ & $\begin{array}{c}\text { Proporção } \\
(\%)\end{array}$ & $\begin{array}{c}\text { Energia de } \\
\text { Ligação } \\
(\mathrm{eV})\end{array}$ & $\begin{array}{c}\text { Proporção } \\
(\%)\end{array}$ \\
\hline \multirow{3}{*}{5} & $\mathrm{C}-\mathrm{O}$ & 531,8 & 22 & 531,4 & 26 \\
& $\mathrm{C}=\mathrm{O}$ & 533,2 & 78 & 532,6 & 62 \\
& $-\mathrm{OH}$ & - & - & 534,4 & 12 \\
\hline \multirow{3}{*}{25} & $\mathrm{C}-\mathrm{O}$ & 531,6 & 39 & 532,4 & 83 \\
& $\mathrm{C}=\mathrm{O}$ & 532,8 & 54 & - & - \\
& $-\mathrm{OH}$ & 534,6 & 7 & 534,4 & 17 \\
\hline \multirow{3}{*}{50} & $\mathrm{C}-\mathrm{O}$ & 531,4 & 15 & 532,3 & 77 \\
& $\mathrm{C}=\mathrm{O}$ & 532,6 & 79 & - & - \\
& $-\mathrm{OH}$ & 535,1 & 6 & 534,0 & 23 \\
\hline \multirow{3}{*}{15} & $\mathrm{C}-\mathrm{O}$ & - & - & 531,5 & 19 \\
& $\mathrm{C}=\mathrm{O}$ & 532,5 & 85 & 532,7 & 67 \\
& $-\mathrm{OH}$ & 534,3 & 14 & 534,5 & 14 \\
\hline \multirow{3}{*}{100} & $\mathrm{C}-\mathrm{O}$ & 531,4 & 41 & 532,4 & 81 \\
& $\mathrm{C}=\mathrm{O}$ & 532,6 & 51 & - & - \\
& $-\mathrm{OH}$ & 534,5 & 8 & 534,2 & 19 \\
\hline \multirow{3}{*}{125} & $\mathrm{C}-\mathrm{O}$ & 531,2 & 23 & 530,9 & 5 \\
& $\mathrm{C}=\mathrm{O}$ & 532,5 & 64 & 532,5 & 81 \\
& $-\mathrm{OH}$ & 534,5 & 13 & 534,5 & 14 \\
\hline
\end{tabular}

Alguns autores associam o componente de menor energia ao nitrogênio ligado ao carbono com hibridização $\mathrm{sp}^{3}$, enquanto o componente em aproximadamente 400 eV é atribuído à grupos com hibridização sp² (TRUSSO, 1999; JIANG, 2000).

A partir das informações obtidas nestas análises, foram calculadas as concentrações atômicas das espécies presentes nos filmes. Os resultados são apresentados na figura 31 .

Observa-se, para os filmes preparados por 5 minutos, tendência de crescimento na proporção de carbono, [C], quando a potência é aumentada de 5 para $25 \mathrm{~W}$. Para a faixa de potência entre 25 e $75 \mathrm{~W},[\mathrm{C}]$, permanece praticamente constante e apresenta nova tendência de queda para potências maiores que $75 \mathrm{~W}$. É interessante notar que a 
proporção atômica de oxigênio [O] segue exatamente a tendência oposta. As contaminações com nitrogênio surgiram somente para os filmes depositados com as duas maiores potências, sugerindo que a proporção de radicais livres residuais nestas amostras é consideravelmente maior que nas demais. Os filmes depositados em plasmas de 5 e $125 \mathrm{~W}$ de potência também apresentaram pequena proporção de silício, em suas estruturas, provavelmente devido ao bombardeamento do substrato de vidro.

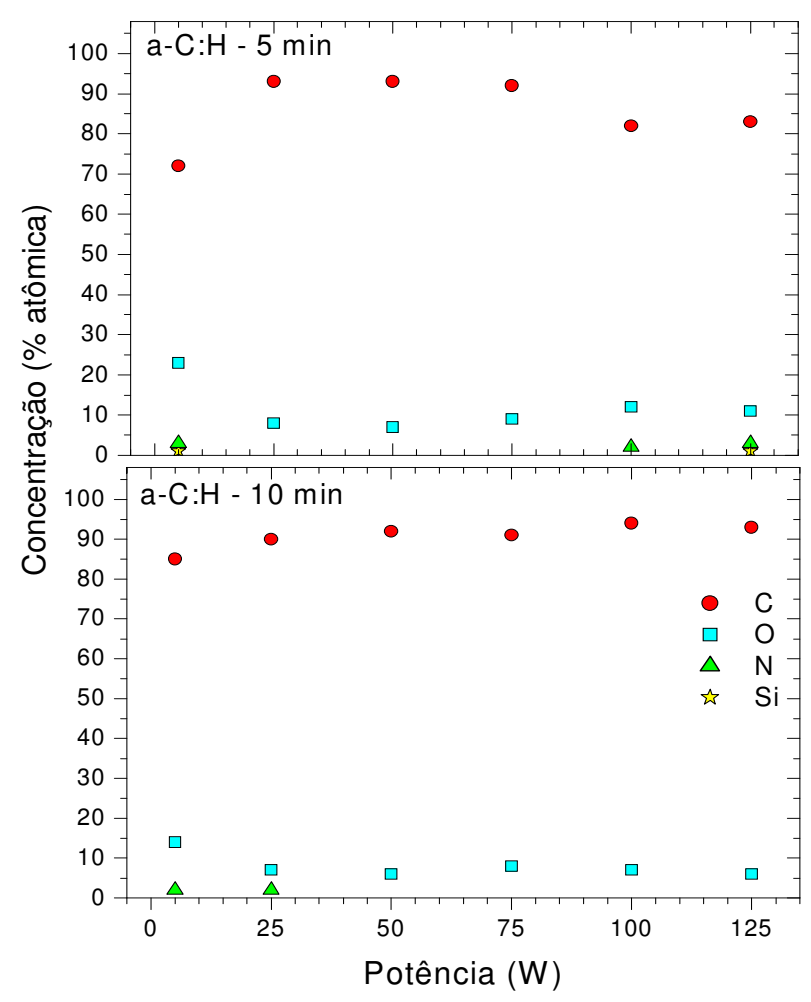

Figura 31 - Concentração em percentagem atômica das espécies presentes nos filmes depositados durante 5 e 10 minutos, em função da potência.

Nos filmes preparados por 10 minutos nota-se que a potência de excitação do plasma não afeta de forma significativa [C] e [O] e que resíduos de $\mathrm{N}$ foram encontrados somente nos filme tipo poliméricos (5 e $25 \mathrm{~W})$.

Através dos resultados discutidos nesta seção pode-se dizer que os filmes são carbonos amorfos hidrogenados (a-C:H) com grande quantidade de oxigênio na superfície e elevadas proporções de estados $\mathrm{sp}^{2}$, principalmente quando mais altas 
potências são empregadas. O filme preparado com $50 \mathrm{~W}$ foi o que apresentou a maior proporção de carbono com hibridização $\mathrm{sp}^{3}$ independente do tempo de deposição. As amostras preparadas com baixas potências, 5 e $25 \mathrm{~W}$, também apresentaram elevada proporção de carbono $\mathrm{sp}^{3}$, no entanto, a estrutura tem maior caráter polimérico em virtude da presença de hidrogênio. Maiores proporções de radicais residuais são deixados ativos na estrutura do filme com maior caráter polimérico (depositados com 5 e $25 \mathrm{~W}$ ) e grafítico (depositados com 100 e $125 \mathrm{~W}$ ), conforme constatado pela maior incorporação de oxigênio e nitrogênio nestas amostras.

\subsubsection{Espessura e Molhabilidade dos Filmes}

A figura 32 apresenta os resultados das medidas de espessura h, em função da potência para os filmes depositados por 5 e 10 minutos. Além da reduzida espessura apresentada por estas camadas, nota-se queda expressiva na mesma com o aumento da potência. Este resultado pode ser atribuído à alteração da cinética do plasma com o aumento da potência do sinal de excitação.

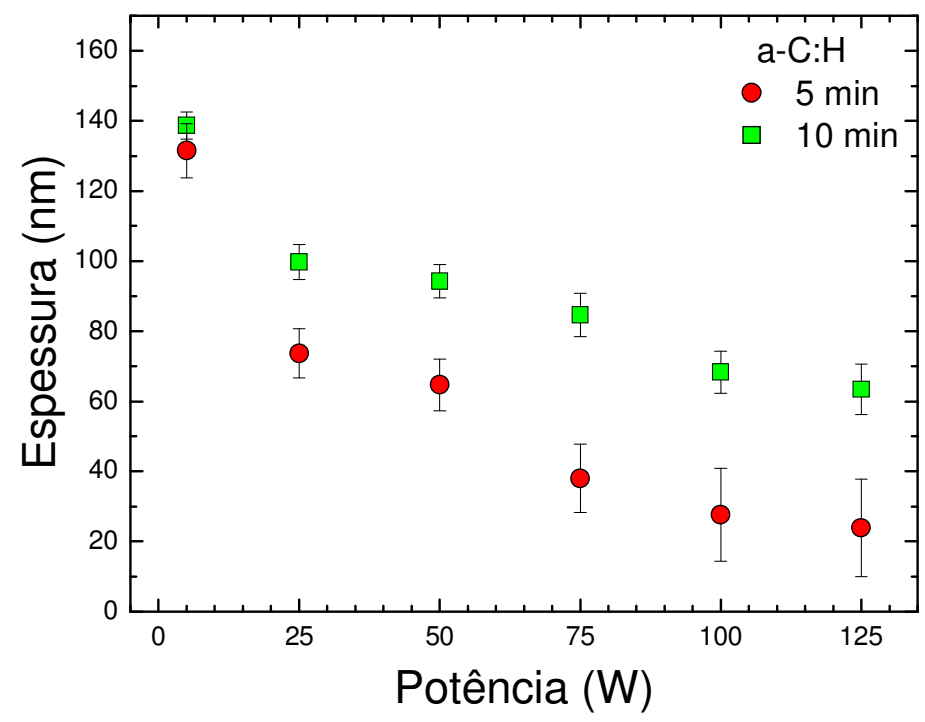

Figura 32 - Espessura dos filmes depositados durante 5 e 10 minutos, em função da potência. 
A deposição de energia pelo bombardeamento iônico também produz aquecimento nas amostras durante a deposição, contribuindo com o aumento da ablação da camada em crescimento. Portanto, a taxa de deposição dos filmes é um balanço entre a quantidade de material depositado e o removido por estes três processos distintos.

Os resultados das medidas de ângulo de contato $(\theta)$ são apresentados na figura 33 para os filmes depositados durante 5 e 10 minutos com diferentes potências.

Considerando-se as dimensões das barras de erro nos pontos pode-se afirmar que $\theta$ mantém-se praticamente constante em torno de $75^{\circ}$ com o aumento da potência. Portanto, pode-se dizer que os filmes são hidrofílicos. Este resultado está associado à presença de espécies como oxigênio e nitrogênio, que ligados ao carbono geram dipolos na superfície. Como as medidas foram realizadas 30 dias após a deposição, radicais livres contidos nos filmes provavelmente já sofreram as recombinações com átomos de oxigênio e nitrogênio, formando grupos polares nas superfícies então saturadas. O tempo de deposição, assim como a variação da potência pouco influenciaram na molhabilidade dos filmes após envelhecimento.

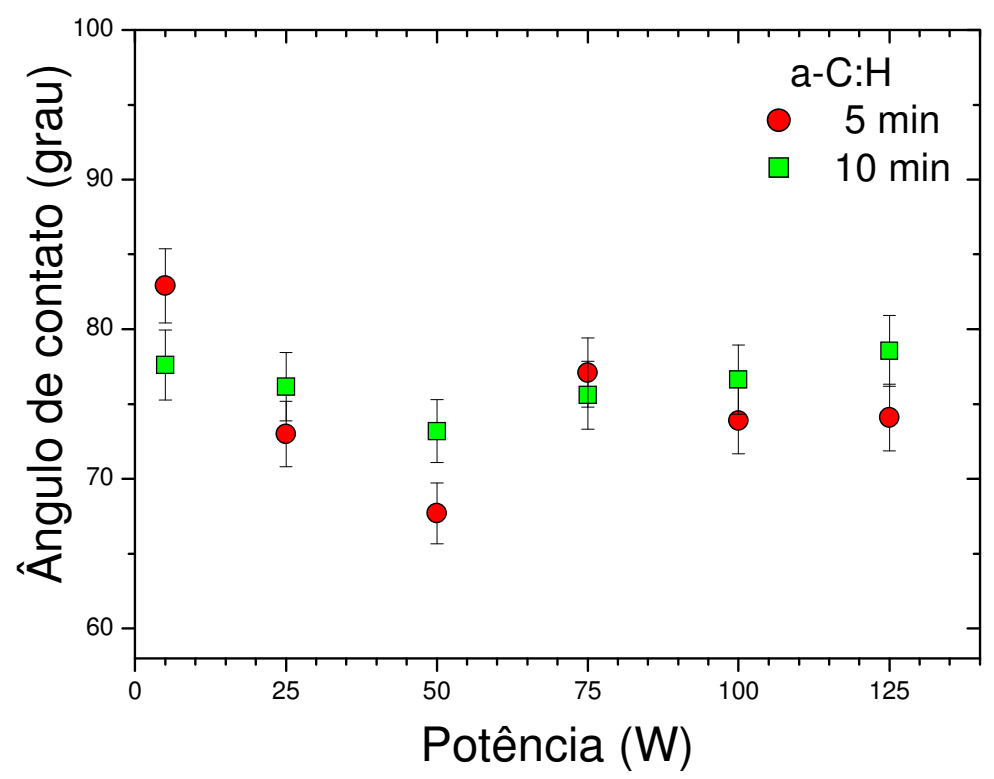

Figura 33 - Ângulo de contato dos filmes depositados durante 5 e 10 minutos em função da potência. 


\subsubsection{Propriedades Mecânicas e Tribológicas dos Filmes}

A figura 34 apresenta o comportamento da dureza das amostras em função da potência de deposição. Os valores apresentados nesta figura foram obtidos em $20 \%$ de profundidade em relação à espessura total dos filmes.

Nota-se, nesta figura, que a dureza assume valores entre 5 e $19 \mathrm{GPa}$. Os filmes depositados com 5 e $25 \mathrm{~W}$ de potência apresentaram durezas de 5 e $6 \mathrm{GPa}$, respectivamente. Estes valores de dureza associados aos resultados obtidos por espectroscopia Raman, que revelam maiores proporções de hidrogênio e de sítios $\mathrm{sp}^{3} \mathrm{e}$ menores dimensões dos núcleos grafíticos, concordam com a interpretação de uma estrutura do tipo polimérica. Os filmes depositados em plasmas de 50 e $75 \mathrm{~W}$ foram os que apresentaram maiores valores de dureza, corroborando os resultados da espectroscopia Raman, que apresentaram maiores proporções de hibridizações $\mathrm{sp}^{3}$ (C-C). Para os filmes depositados em plasmas de maiores potências, 100 e 125 W, os valores de dureza de 8 e $10 \mathrm{GPa}$ respectivamente, se aproximam à dureza do silício, decorrente da profundidade indentada. Deve-se ressaltar que estes filmes apresentaram as menores espessuras (23,9 e 27,6 nm). Caso tal interferência pudesse ser evitada, valores mais baixos de dureza deveriam ser encontrados nestes filmes.

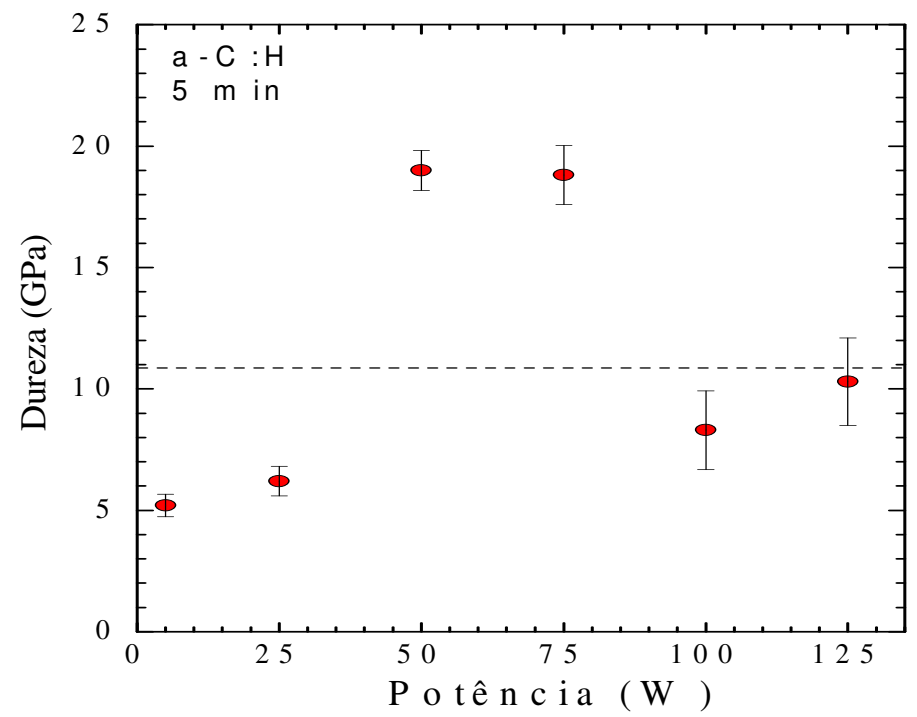

Figura 34 - Comportamento da dureza dos filmes em função da potência de deposição. A linha pontilhada representa a dureza do substrato de silício. 
O coeficiente de atrito, $\mu$, medido para as amostras depositadas durante 5 e 10 minutos em diferentes potências é apresentado na figura 35.

Observa-se que os filmes apresentaram valores de $\mu$ entre 0,13 e 0,27. Estes valores estão de acordo com os resultados encontrados na literatura para filmes de aC:H (KIM, 1999; TANAKA, 2004; BONETTI, 2008). Ressalta-se, que a deposição de filmes de a-C:H, independentemente da potência e do tempo utilizado, reduziu o coeficiente de atrito do silício como-recebido $(0,35)$. Todavia, os melhores resultados foram obtidos em plasmas de $50 \mathrm{~W}$ de potência.

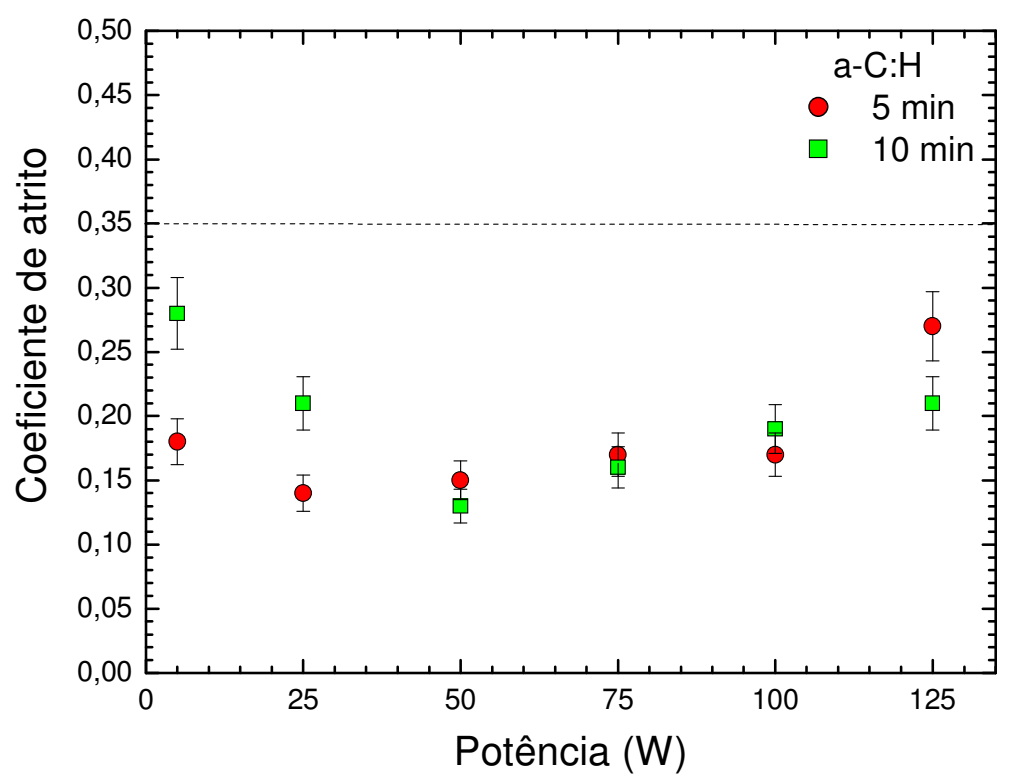

Figura 35 - Coeficiente de atrito dos filmes de a-C:H depositados em 5 e 10 minutos, em função da potência. A linha pontilhada representa o valor do coeficiente de atrito do substrato de silício.

Quando se avalia o coeficiente de atrito dos filmes, nota-se que os resultados agrupam-se de acordo com a estrutura dos filmes, ou seja, tendências similares são observadas para grupos de mesmas características. Os filmes com caráter polimérico $(5$ e $25 \mathrm{~W})$ apresentaram maiores coeficientes de atrito quando depositados por maiores tempos. Esta tendência inverte-se para os filmes com caráter grafítico (100 e 
125 W). Já os filmes com maiores proporções de hibridização $\mathrm{sp}^{3}$ (C-C) apresentaram menores coeficientes de atrito, independentemente do tempo de deposição. Quando há contato entre um material revestido por um filme de a-C:H com outro não revestido, ocorre transferência de parte do filme para a outra superfície. O contato é basicamente similar entre superfícies com o mesmo tipo de filme, explicando a invariância em $\mu$ com o tempo de deposição. A camada grafitica formada na superfície dos substratos também pode ser transferida e age como lubrificante sólido. Portanto, para uma maior camada grafitica, menor o coeficiente de atrito.

\subsubsection{Rugosidade dos Filmes}

A figura 36 mostra a raiz quadrática média (RMS) da rugosidade em função da potência para os filmes depositados por 5 e 10 minutos.

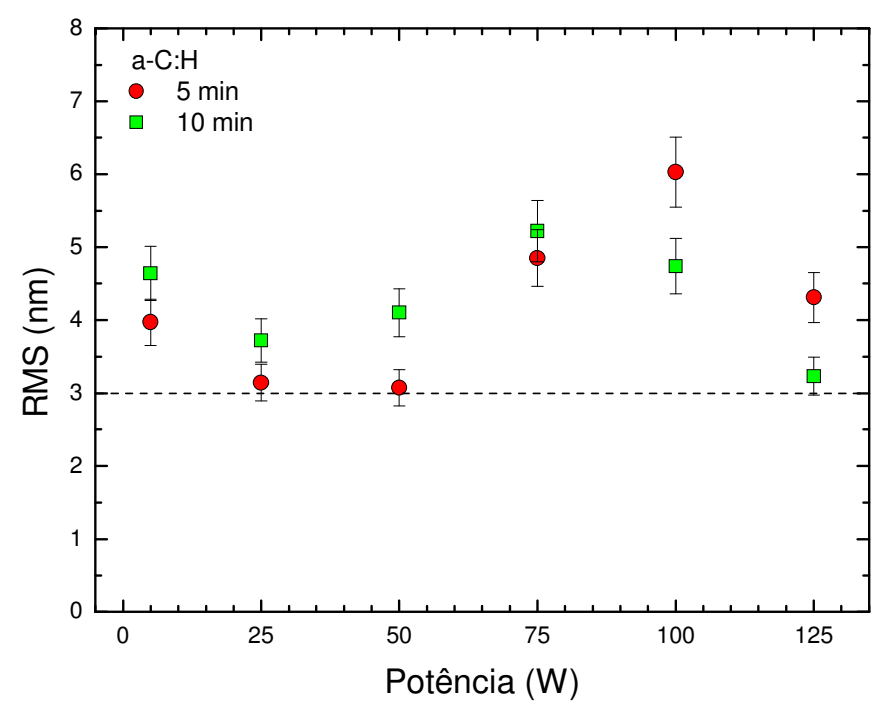

Figura 36 - Raiz quadrática média (RMS) da rugosidade dos filmes de a-C:H em função da potência de deposição. A linha pontilhada representa o valor da RMS do substrato de silício.

Observa-se, em ambos os tempos, tendência inicial de queda seguida por um crescimento em RMS. Para potências maiores que $100 \mathrm{~W}$ uma nova inversão é observada nas curvas. Enquanto a redução reflete a diminuição na proporção de 
ligações $\mathrm{sp}^{2}$ na estrutura polimérica o aumento em RMS é conseqüência do crescimento na concentração desta hibridização na estrutura grafitica. De acordo com Robertson (2002), ligações $\mathrm{C}-\mathrm{H}_{\mathrm{x}}$ ocupam espaço consideravelmente maior que ligações C-C, ou seja, a perda de hidrogênio com o aumento da potência torna a estrutura mais bem organizada e densa. Mas as ligações C-C com hibridização sp $^{2}$ ocupam mais espaço que as ligações $\mathrm{C}$-C com hibridização $\mathrm{sp}^{3}$. Portanto, uma maior transformação de carbono $\mathrm{sp}^{3} \mathrm{em} \mathrm{sp}^{2}$ favorece o aumento na rugosidade do material.

A partir destes resultados pode-se afirmar que a potência afeta o coeficiente de atrito (DONNET, 2000), pelo fato de alterar a composição química e microestrutura do material. Muito embora a rugosidade dos filmes seja maior que a do substrato, o coeficiente de atrito é menor, indicando que a natureza química do material é de fundamental importância para as propriedades tribológicas.

\subsection{PROPRIEDADES DE FILMES DE a-C:H TRATADOS EM} PLASMAS DE HEXAFLUORETO DE ENXOFRE (SF 6

Nesta seção são apresentados os resultados das propriedades dos filmes de carbono amorfo hidrogenado que foram fluorados, após o processo de deposição, em plasmas de $\mathrm{SF}_{6}$. Após o processo de deposição, realizado por 5 ou 10 minutos, os fluxos dos gases foram interrompidos e hexafluoreto de enxofre foi admitido no reator a uma pressão total de $13,3 \mathrm{~Pa}$. O plasma foi estabelecido pela aplicação de rádiofrequência $(13,56 \mathrm{MHz}, 70 \mathrm{~W})$ ao eletrodo superior aterrando-se o porta-amostra. Todos os filmes foram expostos por 5 minutos a este tratamento. Investigou-se o efeito do tratamento pós-deposição nas propriedades dos filmes, depositados durante 5 e 10 minutos em diferentes potências, conforme detalhado nas seções a seguir.

\subsubsection{Estrutura Molecular e Composição Química dos Filmes}

A figura 37 mostra os espectros Raman dos filmes de a-C:H tratados em plasmas de $\mathrm{SF}_{6}$. A deconvolução das bandas foi feita através da aproximação com 
número de gaussianas igual ao número de bandas associadas às ligações com hibridizações $\mathrm{sp}^{3}$ e $\mathrm{sp}^{2}$. Observam-se nestes espectros os componentes referentes às bandas D e G.

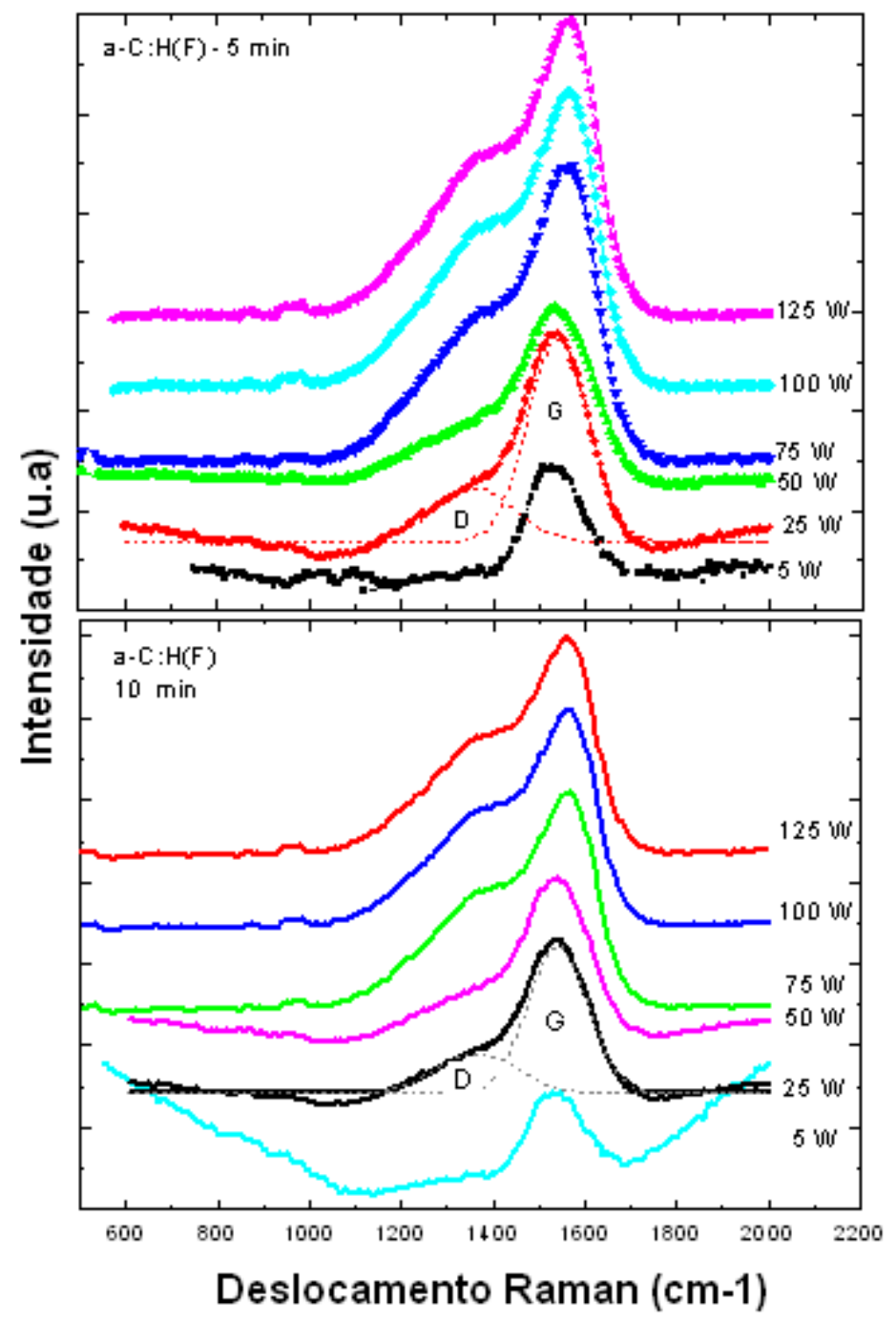

Figura 37 - Espectros Raman dos filmes a-C:H após tratamento em plasmas de $\mathrm{SF}_{6}$.

Comparando-se os espectros Raman obtidos nesta seção e na 5.1 nota-se que o tratamento em plasma de $\mathrm{SF}_{6}$ tornou a banda $\mathrm{D}$ mais intensa e mais larga indicando que houve incorporação de flúor na superfície dos filmes (ENDO, 1995). Observa-se também que após tratamento com $\mathrm{SF}_{6}$ ocorreu deslocamento das bandas $\mathrm{D}$ e $\mathrm{G}$ para maiores números de onda nos espectros dos filmes depositados com as maiores potências. Para quantificar tais alterações, a posição, a largura e a intensidade das bandas foram determinadas e são apresentadas na tabela 7 . 
Tabela 7 - Posição, largura e intensidade das bandas dos espectros dos filmes preparados durante 5 e 10 minutos em plasmas de diferentes potências e tratados em plasmas de $\mathrm{SF}_{6}$.

\begin{tabular}{|c|c|c|c|c|c|c|c|c|c|c|c|c|}
\hline \multirow{3}{*}{$\begin{array}{l}\text { Potência } \\
\text { (W) }\end{array}$} & \multicolumn{6}{|c|}{5 minutos de deposição } & \multicolumn{6}{|c|}{10 minutos de deposição } \\
\hline & \multicolumn{2}{|c|}{$\begin{array}{c}\text { Posição } \\
\left(\mathrm{cm}^{-1}\right)\end{array}$} & \multicolumn{2}{|c|}{$\begin{array}{c}\begin{array}{c}\text { Largura } \\
\left(\mathrm{cm}^{-1}\right)\end{array}\end{array}$} & \multicolumn{2}{|c|}{ Intensidade } & \multicolumn{2}{|c|}{$\begin{array}{c}\text { Posição } \\
\left(\mathrm{cm}^{-1}\right)\end{array}$} & \multicolumn{2}{|c|}{$\begin{array}{c}\begin{array}{c}\text { Largura } \\
\left(\mathrm{cm}^{-1}\right)\end{array}\end{array}$} & \multicolumn{2}{|c|}{ Intensidade } \\
\hline & $\mathrm{D}$ & $\mathrm{G}$ & $\mathrm{D}$ & $\mathrm{G}$ & $\mathrm{D}$ & G & $\mathrm{D}$ & $\mathrm{G}$ & $\mathrm{D}$ & G & $\mathrm{D}$ & G \\
\hline 5 & 1387 & 1549 & 109 & 116 & 148 & 2225 & 1226 & 1540 & 268 & 120 & 439 & 2154 \\
\hline 25 & 1360 & 1545 & 149 & 133 & 1105 & 4206 & 1223 & 1538 & 194 & 146 & 520 & 2004 \\
\hline 50 & 1440 & 1625 & 224 & 140 & 1098 & 3162 & 1328 & 1595 & 181 & 138 & 514 & 1631 \\
\hline 75 & 1478 & 1653 & 237 & 117 & 2899 & 4922 & 1351 & 1639 & 227 & 140 & 1065 & 3132 \\
\hline 100 & 1475 & 1650 & 252 & 112 & 3213 & 4606 & 1364 & 1659 & 203 & 111 & 2195 & 3092 \\
\hline 125 & 1498 & 1668 & 245 & 103 & 686 & 1014 & 1415 & 1665 & 276 & 108 & 1416 & 1967 \\
\hline
\end{tabular}

Através dos dados desta tabela foram calculadas as razões entre as intensidades das bandas $\mathrm{D}$ e $\mathrm{G}\left(\mathrm{I}_{\mathrm{D}} / \mathrm{I}_{\mathrm{G}}\right)$, mostradas na figura 38 em função da potência de deposição dos filmes. Os valores obtidos para os filmes de a-C:H que não foram fluorados (seção 5.1) também são apresentados para comparação.

Observa-se, tanto para os filmes depositados com 5 quanto com 10 minutos, aumento progressivo em $\mathrm{I}_{\mathrm{D}} / \mathrm{I}_{\mathrm{G}}$ com o aumento da potência de forma muito similar à obtida para os filmes não fluorados. Desvios deste comportamento foram evidenciados somente nas amostras preparadas por 10 minutos com as maiores potências (100 e 125 W). Este fenômeno pode ser explicado pelo fato da substituição de átomos de hidrogênio por átomos de flúor provocar diminuição na proporção das ligações $\mathrm{sp}^{3}$ (BUTTER et al., 1997) fazendo com que $\mathrm{I}_{\mathrm{D}} / \mathrm{I}_{\mathrm{G}}$ aumente nestas amostras. Para as demais, o tratamento pós-deposição não afeta significativamente a microestrutura dos filmes. 


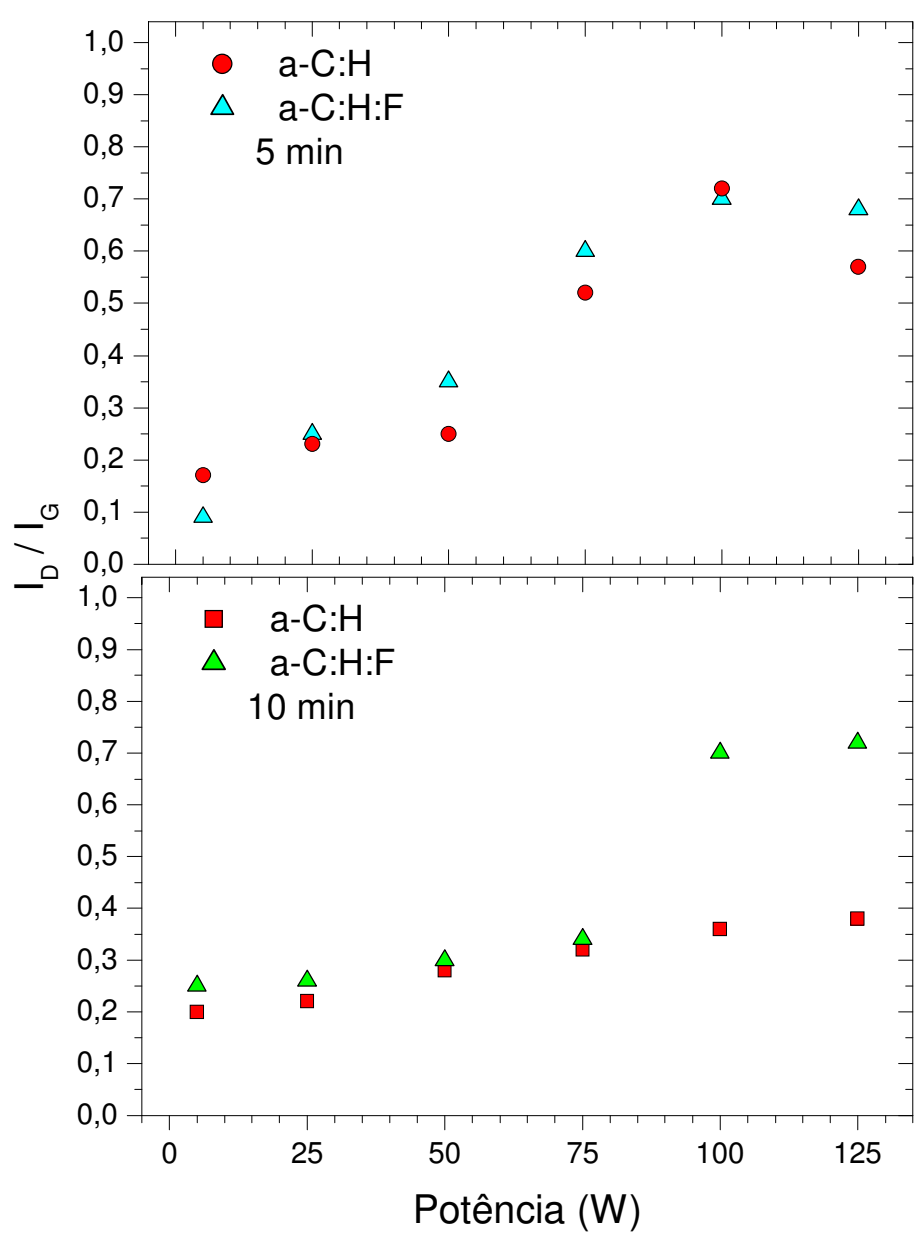

Figura 38 - Razão $\mathrm{I}_{\mathrm{D}} / \mathrm{I}_{\mathrm{G}}$ em função da potência para os filmes de a-C:H, depositados durante 5 e 10 minutos e tratados em plasmas de $\mathrm{SF}_{6}$.

A figura 39 mostra a posição central e a largura da banda $G$ em função da potência de deposição dos filmes antes e após a exposição a plasmas de $\mathrm{SF}_{6}$.

Observa-se que após o processo de fluoração $\bar{\varpi}_{\mathrm{G}}$ desloca-se de forma considerável para maiores freqüências quando $\mathrm{P} \geq 50 \mathrm{~W}$. Este comportamento é observado tanto para os filmes depositados por 5 como por 10 minutos, indicando aumento na proporção de ligações $\mathrm{sp}^{2}$ pelo efeito do tratamento de flúor na estrutura.

Alguns autores mostram que o mecanismo de fluoração dos filmes de a-C:H ocorre pela substituição dos átomos de hidrogênio por átomos de flúor na rede estrutural desse material (BUTTER et al., 1997; SAH, 1985). A probabilidade de 
fragmentação de ligações $\mathrm{C}-\mathrm{H}$ é maior que a de ligações $\mathrm{C}-\mathrm{C}$, pois as energias da ligação $\mathrm{C}-\mathrm{H}$ são menores que as envolvidas nas ligações $\mathrm{C}-\mathrm{C}$, estimulando a substituição de átomos de hidrogênio por átomos de flúor. Tal processo contribui para a diminuição da proporção de ligações $\mathrm{sp}^{3}$.

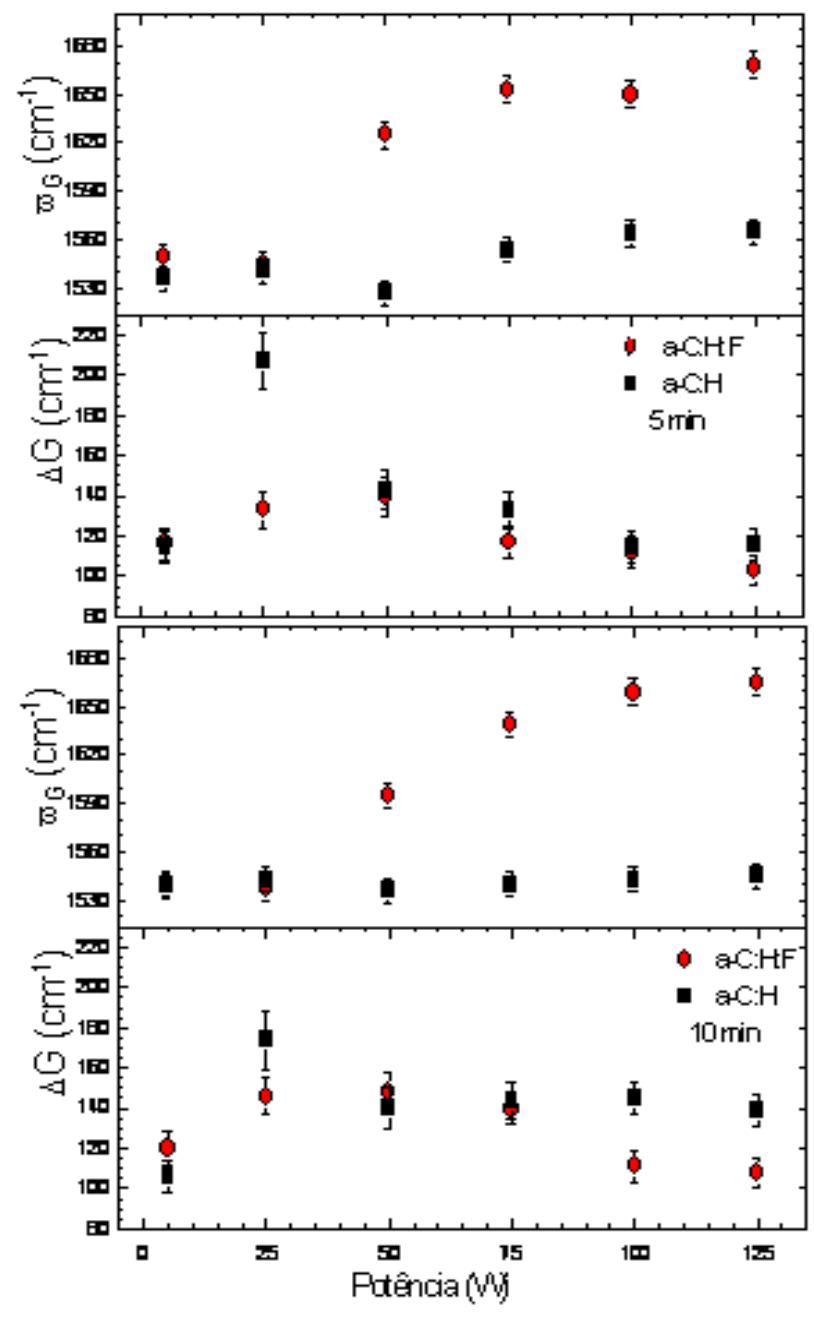

Figura 39 - Posição central $\left(\varpi_{\mathrm{G}}\right)$ e largura $(\Delta \mathrm{G})$ da banda $\mathrm{G}$ em função da potência para os filmes de a-C:H depositados por 5 e 10 minutos antes e após exposição ao plasma de $\mathrm{SF}_{6}$.

É interessante notar também que, para ambos os tempos de deposição, a posição da banda $G$ manteve-se inalterada após a fluoração para os filmes com caráter polimérico $(5$ e $25 \mathrm{~W})$. Isto significa que o tratamento não altera a microestrutura destas camadas. Para ambos os tempos de deposição, $\Delta \mathrm{G}$ não varia de forma significativa com a fluoração dos filmes. A diferença mais pronunciada foi observada no filme depositado com $25 \mathrm{~W}$ de potências por 5 minutos. De uma forma geral, pode- 
se dizer que $\Delta \mathrm{G}$ diminui com o aumento da potência acima de $50 \mathrm{~W}$, revelando aumento na ordem da estrutura e, portanto, na proporção de carbono com hibridização $\mathrm{sp}^{2}$. A partir destas análises pode-se concluir que o tratamento dos filmes em plasmas de $\mathrm{SF}_{6}$ não alterou as tendências observadas nos filmes não fluorados com a variação da potência. Ele simplesmente intensificou algumas características como o deslocamento da banda $\mathrm{G}$ revelando a presença da espécie eletronegativa na superfície.

A figura 40 mostra os espectros XPS de longa varredura dos filmes de a-C:H tratados em plasmas de $\mathrm{SF}_{6}$. Observam-se nestes espectros contribuições devidas ao carbono (aproximadamente a 285,0 eV), nitrogênio (aproximadamente a 400,0 eV), oxigênio (aproximadamente a $533.0 \mathrm{eV}$ ) e flúor (aproximadamente a 685,0 eV). A presença deste último componente confirma a incorporação de flúor na superfície pelo tratamento pós-deposição em plasmas de $\mathrm{SF}_{6}$.

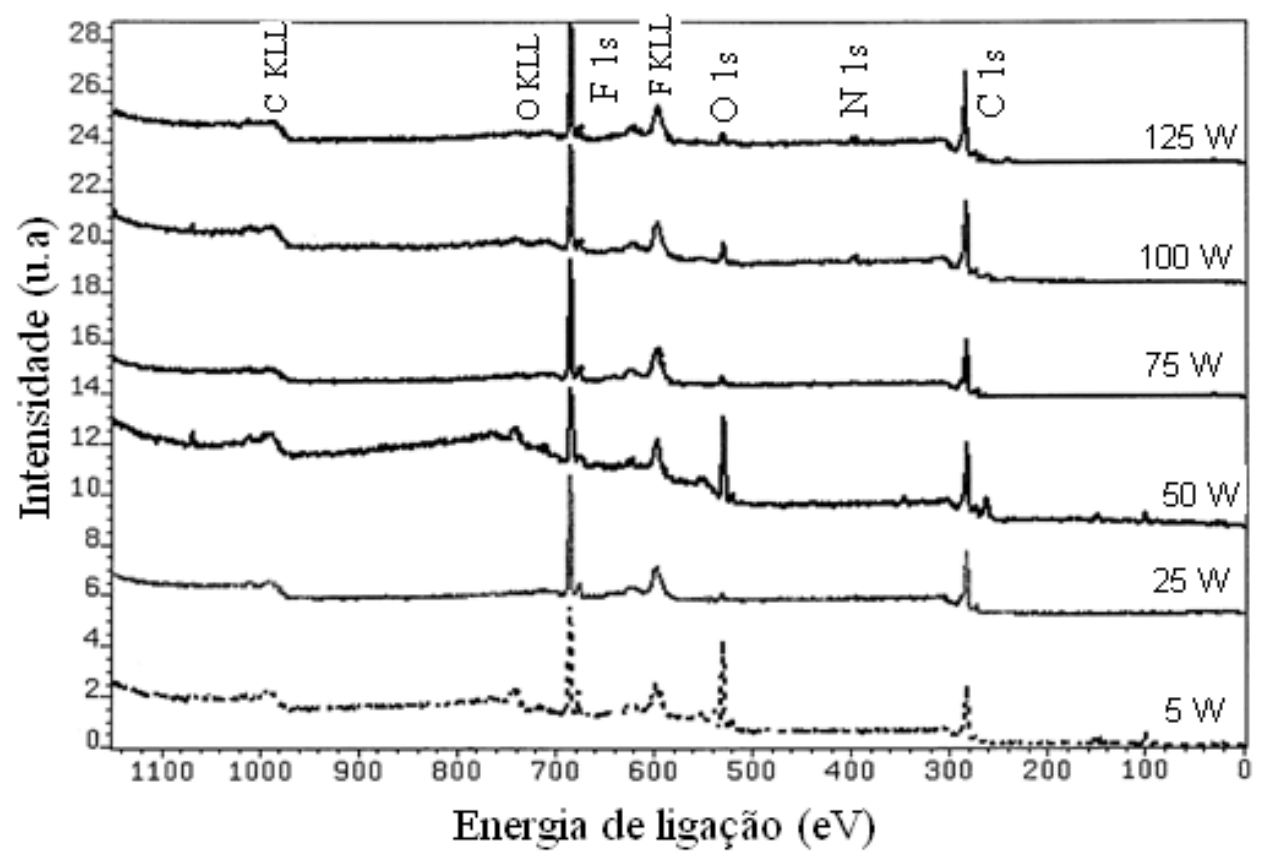

Figura 40 - Espectros de longa varredura (survey) dos filmes de a-C:H depositados em diferentes potências, após tratamento em plasmas de $\mathrm{SF}_{6}$.

Os espectros de alta resolução do pico $\mathrm{C}$ 1s foram adquiridos e ajustados com cinco Gaussianas. As mesmas três componentes obtidas nos espectros dos filmes não fluorados (seção 5.1) foram observadas neste caso em 284,5 eV (C-C e/ou C-H), 286,6 eV (C-O e/ou C - CF) e 288,6 eV ( $\mathrm{C}=\mathrm{O}$ e/ou C-F) . As outras duas componentes foram 
observadas em 290,8 (C-F $)$ e 292,0 eV $\left(\mathrm{C}_{2} \mathrm{~F}_{3}\right)(\mathrm{CLARK}, 1980$; MA et al., 1998; DURRANT et al., 1996; DA COSTA, 2000; DA COSTA, 2001; YAO et al., 2004; AHN, 2005; AHN et al., 2008; BENDAVID et al., 2009). Na tabela 8 são apresentadas tais ligações juntamente com suas energias e respectivas proporções nos espectros de cada um dos filmes.

Tabela 8 - Tipos de ligações químicas, suas energias de ligação e respectivas proporções nos filmes de a-C:H, depositados por 5 e 10 minutos e tratados em plasmas de $\mathrm{SF}_{6}$.

\begin{tabular}{|c|c|c|c|c|c|}
\hline \multirow[b]{2}{*}{$\begin{array}{l}\text { Potência } \\
\text { (W) }\end{array}$} & \multirow[b]{2}{*}{ Tipo de Ligação } & \multicolumn{2}{|c|}{5 minutos de deposição } & \multicolumn{2}{|c|}{10 minutos de deposição } \\
\hline & & $\begin{array}{c}\text { Energia de } \\
\text { ligação }(\mathrm{eV})\end{array}$ & Proporção (\%) & $\begin{array}{c}\text { Energia de } \\
\text { ligação } \\
(\mathrm{eV})\end{array}$ & $\begin{array}{c}\text { Proporção } \\
(\%)\end{array}$ \\
\hline \multirow{5}{*}{5} & $\mathrm{C}-\mathrm{C}$ e/ou C-H & 284,8 & 61 & 284,8 & 43 \\
\hline & $\mathrm{C}-\mathrm{O}$ e/ou C-CF & 286,6 & 18 & 286,1 & 33 \\
\hline & $\mathrm{C}=\mathrm{O}$ e/ou C-F & 288,6 & 10 & 288,1 & 11 \\
\hline & $\mathrm{C}-\mathrm{F}_{2}$ & 290,8 & 8 & 289,9 & 7 \\
\hline & $\mathrm{C}_{-} \mathrm{F}_{3}$ & 292,8 & 3 & 291,7 & 6 \\
\hline \multirow[t]{5}{*}{25} & C-C e/ou C-H & 284,8 & 65 & 284,8 & 40 \\
\hline & C-O e/ou C-CF & 286,5 & 17 & 286,1 & 33 \\
\hline & $\mathrm{C}=\mathrm{O}$ e/ou $\mathrm{C}-\mathrm{F}$ & 288,4 & 9 & 287,7 & 13 \\
\hline & $\mathrm{C}-\mathrm{F}_{2}$ & 290,4 & 7 & 290,7 & 12 \\
\hline & ${\mathrm{C}-\mathrm{F}_{3}}$ & 292,4 & 2 & 292,5 & 2 \\
\hline \multirow{5}{*}{50} & $\mathrm{C}-\mathrm{C}$ e/ou C-H & 284,8 & 66 & 284,8 & 39 \\
\hline & C-O e/ou C-CF & 286,5 & 14 & 286,7 & 10 \\
\hline & $\mathrm{C}=\mathrm{O}$ e/ou $\mathrm{C}-\mathrm{F}$ & 288,5 & 9 & 288,6 & 10 \\
\hline & $\mathrm{C}-\mathrm{F}_{2}$ & 290,6 & 7 & 290,6 & 9 \\
\hline & $\mathrm{C}-\mathrm{F}_{3}$ & 292,7 & 4 & - & - \\
\hline \multirow{5}{*}{75} & C-C e/ou C-H & 284,8 & 64 & 284,8 & 58 \\
\hline & $\mathrm{C}-\mathrm{O}$ e/ou C-CF & 286,5 & 15 & 286,2 & 24 \\
\hline & $\mathrm{C}=\mathrm{O}$ e/ou $\mathrm{C}-\mathrm{F}$ & 288,4 & 10 & 287,9 & 11 \\
\hline & $\mathrm{C}-\mathrm{F}_{2}$ & 290,6 & 9 & 290,3 & 5 \\
\hline & $\mathrm{C}_{-} \mathrm{F}_{3}$ & 292,4 & 2 & 292,2 & 2 \\
\hline \multirow{5}{*}{100} & C-C e/ou C-H & 284,8 & 61 & 284,8 & 64 \\
\hline & $\mathrm{C}-\mathrm{O}$ e/ou C-CF & 286,5 & 20 & 286,4 & 22 \\
\hline & $\mathrm{C}=\mathrm{O}$ e/ou $\mathrm{C}-\mathrm{F}$ & 288,4 & 10 & 288,3 & 8 \\
\hline & $\mathrm{C}-\mathrm{F}_{2}$ & 290,6 & 7 & 290,3 & 4 \\
\hline & $\mathrm{C}-\mathrm{F}_{3}$ & 292,9 & 2 & 292,4 & 2 \\
\hline \multirow{5}{*}{125} & $\mathrm{C}-\mathrm{C}$ e/ou C-H & 284,8 & 64 & 284,8 & 45 \\
\hline & $\mathrm{C}-\mathrm{O}$ e/ou C-CF & 286,6 & 18 & 286,2 & 33 \\
\hline & $\mathrm{C}=\mathrm{O}$ e/ou $\mathrm{C}-\mathrm{F}$ & 288,5 & 9 & 288,2 & 6 \\
\hline & $\mathrm{C}-\mathrm{F}_{2}$ & 290,6 & 7 & 290,2 & 6 \\
\hline & $\mathrm{C}-\mathrm{F}_{3}$ & 292,5 & 2 & 291,9 & 4 \\
\hline
\end{tabular}


A partir das informações contidas nesta tabela, construiu-se o gráfico da figura 41, no qual se pode acompanhar os comportamentos dos diferentes tipos de grupos com a variação da potência. Para os filmes depositados durante 5 minutos, nota-se que a concentração de ligações C-C e C-H, é predominante ( 63\%). Já para os filmes depositados durante 10 minutos, a concentração destas espécies varia de acordo com a potência em que os filmes foram depositados. Para potências de 5 a $50 \mathrm{~W}$ há redução de 20 a 30 \% na proporção de ligações C-C e/ou C-H em comparação à obtida nos filmes depositados por 5 minutos.

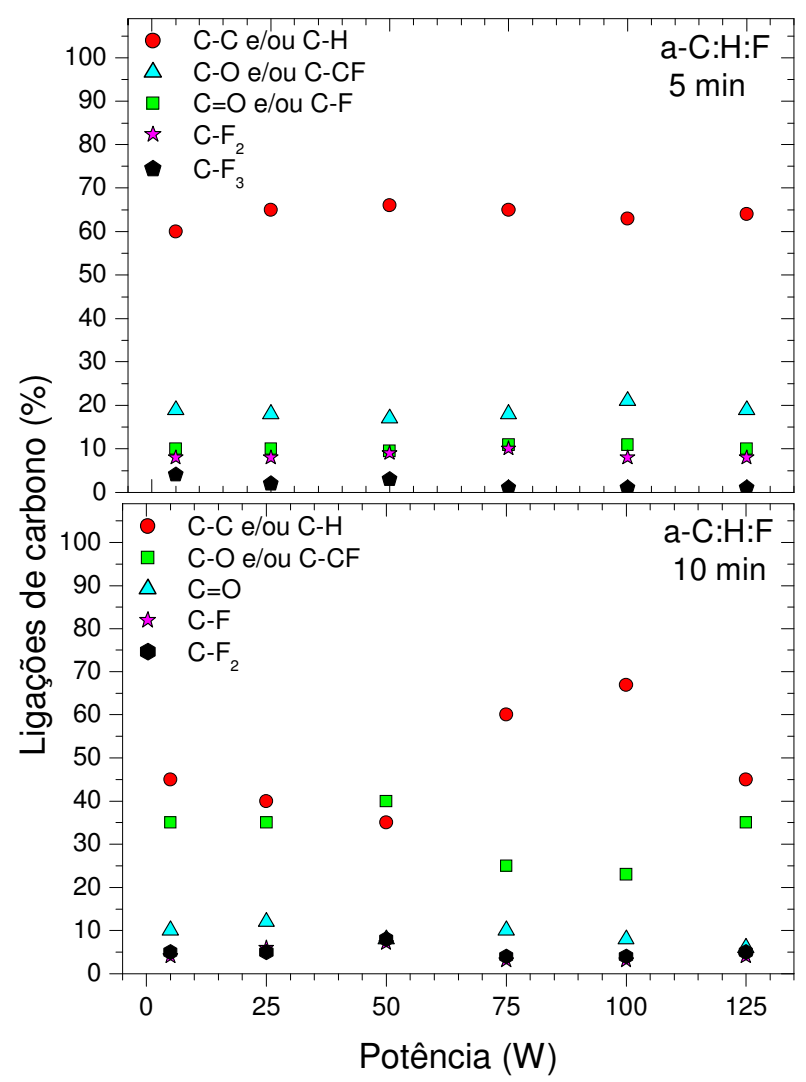

Figura 41 - Proporção das espécies presentes nas amostras de a-C:H (depositados por 5 e 10 minutos) em função da potência, após tratamento em plasma de $\mathrm{SF}_{6}$. Dados obtidos a partir da deconvolução do pico fotoelétrico C $1 \mathrm{~s}(284,8 \mathrm{eV})$.

A proporção de grupos $\mathrm{C}-\mathrm{O}$ e/ou C-CF segue tendência exatamente oposta à observada em $\mathrm{C}-\mathrm{H}$, revelando que os grupos $\mathrm{C}-\mathrm{H}$ perdidos são devidos à substituição do hidrogênio pelo oxigênio e flúor. Por fim, as concentrações de grupos $\mathrm{C}=\mathrm{O}$ e/ou 
$\mathrm{C}-\mathrm{F}, \mathrm{C}-\mathrm{F}_{2}$ e $\mathrm{C}-\mathrm{F}_{3}$ são progressivamente menores que as de grupos $\mathrm{C}-\mathrm{O}$ e/ou C-CF e, dentro da precisão da técnica, permanecem constantes com a potência e com o tempo de deposição.

No pico fotoelétrico $\mathrm{C}$ 1s foi observado que a energia de ligação do átomo de carbono ligado a um átomo de hidrogênio $(\mathrm{C}-\mathrm{H})$ e/ou ao carbono $(\mathrm{C}-\mathrm{C})$ é de $284,8 \mathrm{eV}$. Quando flúor substitui o átomo de hidrogênio, formando ligação $\left(C-F_{n}\right)$, causa perturbações nas cadeias, deslocando esta ligação para 288,6 eV (ligação C-F), 290,8 eV $\left(\mathrm{C}-\mathrm{F}_{2}\right)$ ou 292,8 (C-F $)_{3}$. A ligação C-CF $(286,6 \mathrm{eV})$ é devida a uma distorção na ligação C-C gerada pela perturbação que o flúor, ligado ao primeiro vizinho de carbono, causa na ligação C-C. Essas perturbações são causadas pela alta eletronegatividade do flúor.

O surgimento de grupos $C-F_{n}$ é uma conseqüência da formação de radicais livres na estrutura pelo tratamento pós-deposição. A alta afinidade entre o flúor, presente no plasma de tratamento, e o hidrogênio de grupos $\mathrm{C}-\mathrm{H}$ do filme, leva a formação de grupos HF que são voláteis e então removidos da fase sólida. A maior parte dos radicais gerados será passivada pelo próprio flúor durante o tratamento. Somente uma pequena proporção de ligações pendentes será deixada ativa e será saturada por recombinações com oxigênio atmosférico.

$\mathrm{O}$ pico $\mathrm{O} 1 \mathrm{~s}$ foi decomposto em dois componentes para os filmes depositados em plasmas de 5 e $125 \mathrm{~W}$ de potência e três componentes para os filmes depositados com 25, 50, 75 e $100 \mathrm{~W}$ de potência. O componente mais intenso, a aproximadamente $533,0 \mathrm{eV}$, corresponde a espécie química C-O. Já o componente em torno de 531,8 eV está associado a ligações $\mathrm{C}=\mathrm{O}$ e o componente a mais alta energia, mostra a presença de hidroxila $(-\mathrm{OH})$ nestes filmes. Tais resultados estão de pleno acordo com os obtidos a partir do pico $\mathrm{C}$ 1s. O tempo de deposição não alterou significativamente as proporções destas ligações.

O espectro de alta resolução do pico $\mathrm{F}$ 1s é ajustado por alguns autores (WOCHNOWSKI, 2007; BENDAVID, 2009) com apenas um componente, de largura relativamente grande em aproximadamente $687 \mathrm{eV}$. Neste trabalho, ele foi ajustado com dois componentes para os espectros dos filmes depositados em plasmas de 25, 50 e $75 \mathrm{~W}$ de potência, em $687,0 \mathrm{eV}\left(-\mathrm{CHFCH}_{2}-\right)_{\mathrm{n}}$ e $688,0\left(-\mathrm{CF}_{2} \mathrm{CH}_{2}\right)_{\mathrm{n}}$ e três 
componentes para os filmes depositados com 5, 100 e $125 \mathrm{~W}$ de potência, relativas às ligações $\left(-\mathrm{CHFCH}_{2}-\right)_{\mathrm{n}}$ em 687,0 eV, $\left(-\mathrm{CF}_{2} \mathrm{CH}_{2}-\right)_{\mathrm{n}}$ em 688,0 eV e $\left(-\mathrm{CF}_{2}-\mathrm{CF}_{2}\right)_{\mathrm{n}}$ em 689,7 eV (FERRARIA, 2003). A proporção de cada espécie relativa ao total de grupos foi calculada a partir da área dos picos e é apresentada na figura 42 em função da potência.

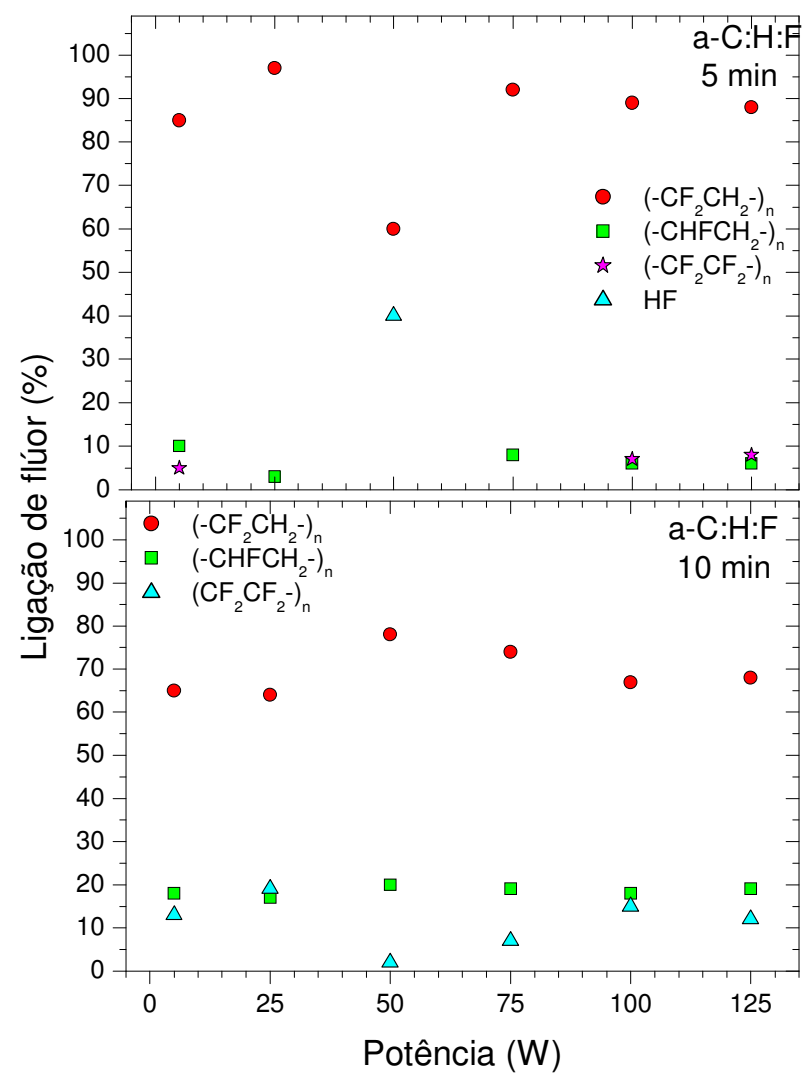

Figura 42 - Proporção de espécies fluoradas presentes nas amostras, depositadas por 5 e 10 minutos, em função da potência. Valores determinados a partir das áreas das contribuições do pico $\mathrm{F}$ $1 \mathrm{~s}(687 \mathrm{eV})$.

O filme preparado com $50 \mathrm{~W}$ durante 5 minutos apresentou cerca de $60 \%$ de grupos ($\left.\mathrm{CF}_{2} \mathrm{CH}_{2}-\right)_{\mathrm{n}}$ onde dois hidrogênios da cadeia são substituídos por flúor e $40 \%$ de grupos HF resultantes de interações plasma-superfície e também da adsorção desta espécie formada no plasma. Para as demais amostras, o grupo $\left(-\mathrm{CF}_{2} \mathrm{CH}_{2}-\right)$ é predominante com mais de $80 \%$ do total de espécies. Com proporções bem menores $(\leq 10 \%)$, 
aparecem os grupos $\left(-\mathrm{CHFCH}_{2}-\right)_{\mathrm{n}}$ e $\left(-\mathrm{CF}_{2} \mathrm{CF}_{2}\right)_{\mathrm{n}}$. Para os filmes que foram depositados por 10 minutos, a ligação $\left(-\mathrm{CF}_{2} \mathrm{CH}_{2}-\right)$ n é predominante $(60-75 \%)$ e em menores proporções $(\sim 18 \%)$, aparecem os grupos $\left(-\mathrm{CHFCH}_{2}-\right)_{\mathrm{n}} \mathrm{e}\left(-\mathrm{CF}_{2} \mathrm{CF}_{2}-\right)_{\mathrm{n}}$.

A figura 43 apresenta os valores das concentrações atômicas das espécies químicas presentes nos filmes de a-C:H(F), depositados durante 5 e 10 minutos, em função da potência.

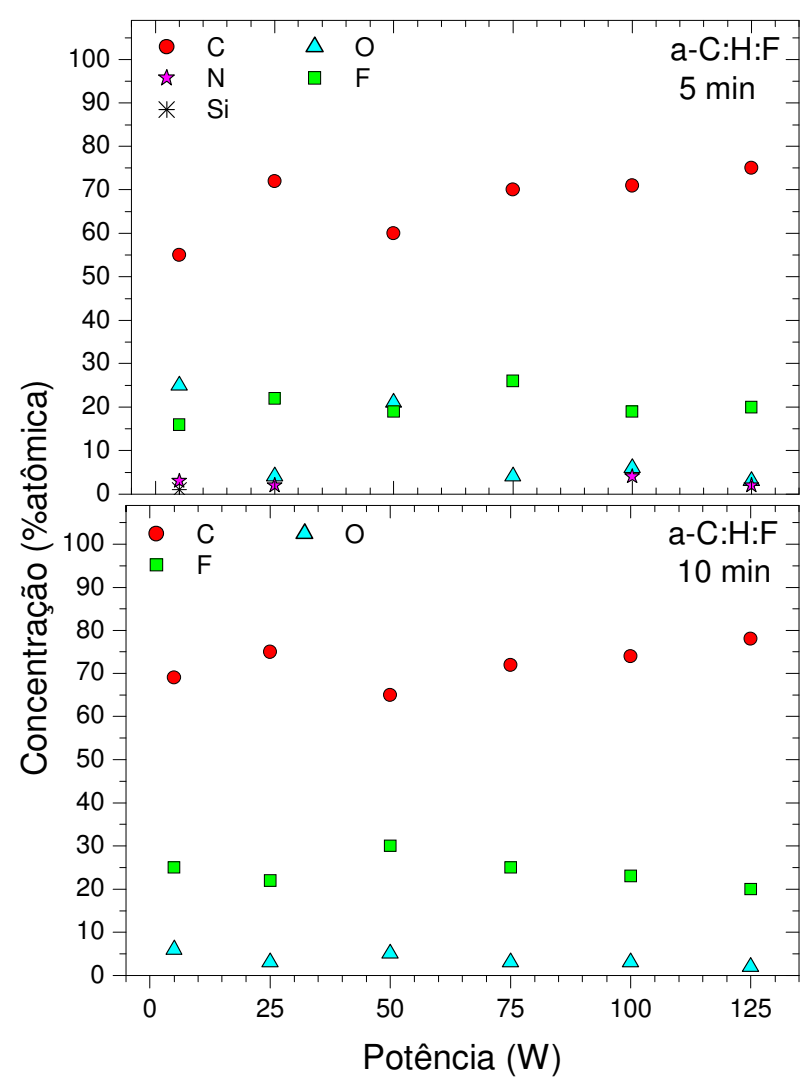

Figura 43 - Concentrações relativas das espécies presentes nos filmes de a-C:H(F), depositados por 5 e 10 minutos, em função da potência.

Observam-se, nesta figura, duas tendências bastante claras em função da natureza dos filmes. Para os filmes poliméricos $(5 \leq \mathrm{P} \leq 25 \mathrm{~W})$ a concentração relativa de $\mathrm{C},[\mathrm{C}]$, cresce enquanto a concentração relativa de $\mathrm{O}$, [O], diminui com o aumento de P. A proporção de flúor, $[\mathrm{F}]$, permanece praticamente constante, mas é evidente a incorporação desta espécie na estrutura. Para os carbonos amorfos hidrogenados 
$(50 \leq \mathrm{P} \leq 125 \mathrm{~W})$, também há aumento em [C], diminuição em $[\mathrm{O}]$, mas $[\mathrm{F}]$ também diminui com o aumento da potência, mas de forma distinta da observada nos filmes poliméricos. Muito embora estas variações sejam pequenas em relação às incertezas relacionadas às análises XPS, elas são consistentes com a dehidrogenação e grafitização da estrutura, resultando em menores proporções de radicais residuais para a incorporação de contaminantes (O e F).

Então, para os filmes grafíticos, em que a proporção de hidrogênio é diminuída, a superfície satura os radicais residuais criados durante o tratamento com flúor e a proporção de oxigênio é menor nestes materiais. A criação de sítios para a incorporação de flúor também é menos provável em virtude da menor disponibilidade de $\mathrm{H}$ nestes materiais. Quando presente no filme, a proporção de nitrogênio é substancialmente menor que a de oxigênio, embora o mecanismo de incorporação seja o mesmo. Isto revela a menor afinidade do nitrogênio ao carbono do filme em comparação à do oxigênio.

\subsubsection{Espessura e Molhabilidade dos Filmes}

A figura 44 mostra os valores de espessura dos filmes, h, em função da potência para as amostras preparadas por 5 e 10 minutos. As espessuras dos filmes não submetidos ao processo de fluoração (seção 5.1.2), também são apresentados para cada tempo de deposição. Em ambas as curvas de cada gráfico há tendência de redução da espessura com o aumento da potência.

Além dos fenômenos mencionados na seção 5.1.2, a ablação química durante o processo de fluoração também contribui com a redução na espessura. Para os filmes depositados por 5 minutos, a fluoração não induz alterações em h para potências acima de $50 \mathrm{~W}$, pois tais amostras apresentam estrutura mais fortemente conectada $(\mathrm{C}=\mathrm{C})$

além de menores proporções de H. Já para os filmes depositados por 10 minutos, a diminuição de h após fluoração é evidente em toda a faixa de potência investigada e é mais intensa que a anteriormente mencionada. Então, os filmes depositados com o maior tempo tornaram-se menos espessos que os preparados com os menores tempos 
após o tratamento pós-deposição. Tais resultados sugerem que o tempo de deposição afeta a microestrutura do filme de forma a reduzir sua resistência a ataques químicos.

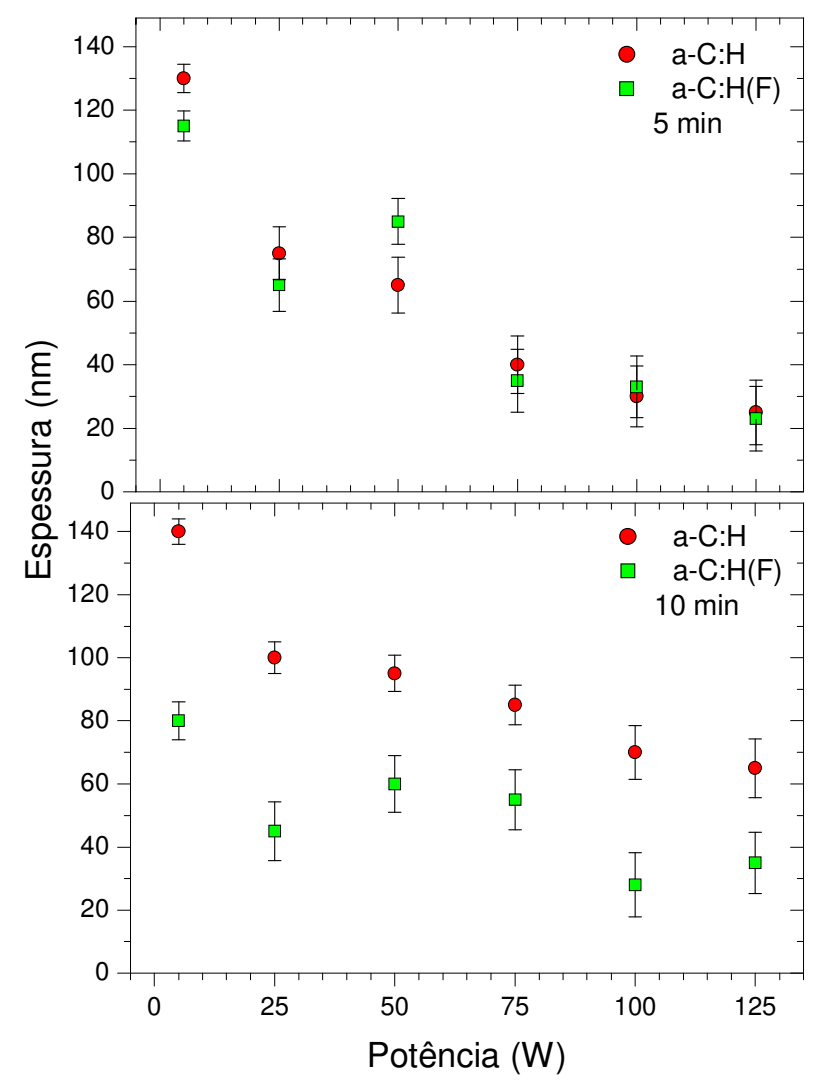

Figura 44 - Espessura dos filmes de a-C:H e a-C:H(F) em função da potência para as deposições com 5 e 10 minutos de duração.

O aumento no tempo de deposição faz crescer o número total de íons que alcança a camada em crescimento, elevando a temperatura da região onde ocorre a deposição. Além disto, deve-se lembrar que carbonos amorfos hidrogenados são eletricamente isolantes e mediante bombardeamento iônico acumulam carga, desenvolvendo um potencial positivo que diminui a velocidade com que os íons penetram na superfície do material (EMMERT,1994). A temperatura de deposição dos filmes e, desta forma, suas propriedades dependem do número de íons que colidem na superfície e de suas energias. $\mathrm{O}$ acumulo de cargas e o aquecimento são fenômenos 
que podem ser apontados como os responsáveis pelas diferenças estruturais observadas nos filmes depositados por 5 e 10 minutos.

O ângulo de contato $(\theta)$ dos filmes preparados em plasmas de diferentes potências por 5 e 10 minutos é apresentado na figura 45 para as amostras comodepositadas e as fluoradas.

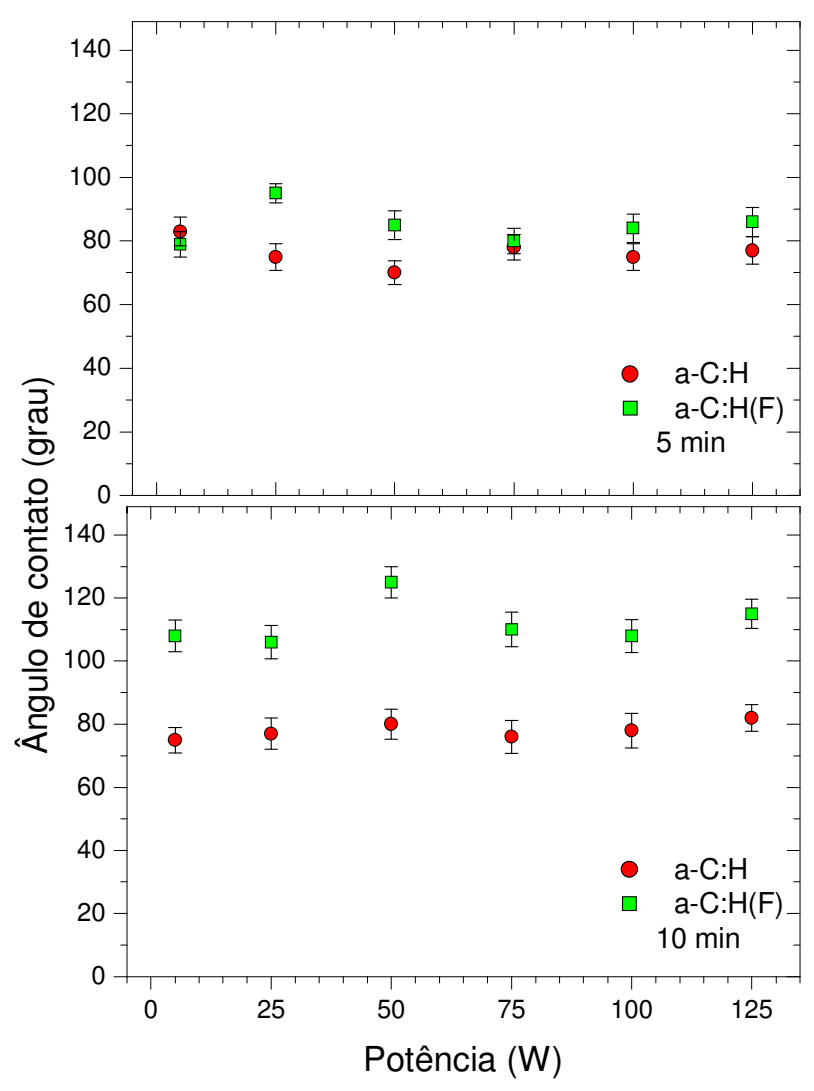

Figura 45 - Ângulo de contato dos filmes de a-C:H em função da potência, para as amostras como-depositadas e as fluoradas.

As medidas foram realizadas 30 dias após a deposição e fluoração e representam uma superfície estável com relação à exposição à atmosfera. De uma forma geral, o ângulo de contato dos a-C:H(F) é maior que dos a-C:H. Isto é conseqüência da incorporação de espécies fluoradas tais como C-F, C-F, C-F 3 , C-CF, e HF formando grupos que exercem forças repulsivas induzindo as moléculas de água.

Dentre os filmes depositados por 5 minutos, aquele obtido a $25 \mathrm{~W}$ de potência alcançou valores de $\theta$ em torno de $93^{\circ}$, podendo ser caracterizado como hidrofóbico. 
Os demais, que apresentaram valores de $\theta$ abaixo de $90^{\circ}$ são hidrofílicos. Ou seja, a incorporação de cerca de $20 \%$ de flúor na estrutura do material (indicada na figura 43) não foi suficiente para torná-los hidrofóbicos.

Todos os filmes fluorados que foram depositados durante 10 minutos apresentam valores de $\theta$ acima de $90^{\circ}$, mostrando que a incorporação de flúor foi suficiente para tornar hidrofóbicos os filmes inicialmente hidrofílicos. Para interpretar tal resultado deve-se salientar que a interação do plasma de $\mathrm{SF}_{6}$ reduz a concentração de oxigênio e induz a incorporação de espécies fluoradas, conforme apresentado na figura 43.

É sabido da literatura que a diminuição na proporção de grupos polares numa superfície, favorece a diminuição da molhabilidade (YU, 2003). Logo, a diminuição da concentração de ligações polares C-O e o surgimento de ligações fluoradas tipo C-F nas superfícies tratadas favoreceram o aumento do ângulo de contato.

A partir destes resultados pode-se afirmar que o ângulo de contato das amostras expostas ao tratamento pós-deposição depende mais fortemente do tempo de deposição que da potência do sinal de excitação do plasma. Além disto, observou-se que os filmes preparados por 10 minutos são mais susceptíveis a alterações estruturais que os depositados por 5 minutos.

\subsubsection{Rugosidade dos filmes}

A figura 46 apresenta os valores da raiz quadrática média (RMS) da rugosidade em função da potência para os filmes de a-C:H e a-C:H(F) depositados por 5 e 10 minutos.

Observa-se nesta figura, para os filmes depositados durante 5 minutos que a fluoração alterou os valores de RMS dos filmes depositados com 50 e $125 \mathrm{~W}$ de potência. Para os demais, valores muito próximos foram obtidos antes e após o tratamento. 


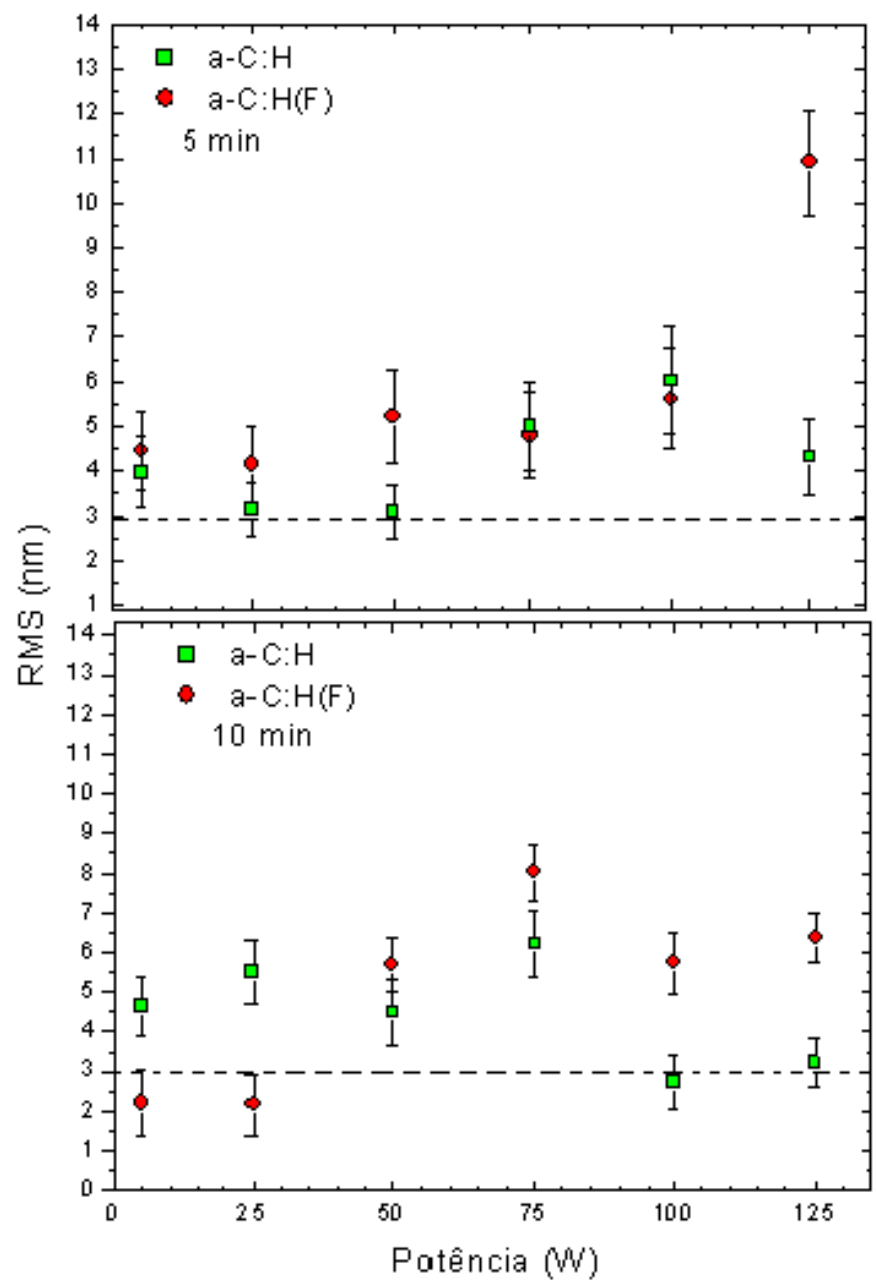

Figura 46 - Rugosidade dos filmes de a-C:H e a-C:H(F), depositados por 5 e 10 minutos, com diferentes potências. A linha pontilhada refere-se ao valor de rugosidade do substrato de silício.

Nos filmes preparados por 10 minutos a fluoração promoveu diminuição em RMS nos filmes poliméricos e aumento considerável nas amostras preparadas com 100 e $125 \mathrm{~W}$. Estes resultados são facilmente entendidos quando se considerada que a razão $\mathrm{I}_{\mathrm{D}} / \mathrm{I}_{\mathrm{G}}$ (figura 38) aumentou após fluoração em todos os carbonos amorfos hidrogenados acima mencionados. Ou seja, aumentou-se a proporção de ligações de carbono com hibridização $\mathrm{sp}^{2}$ que, de acordo com Robertson (2002), ocupam mais espaço que as ligações $\mathrm{C}-\mathrm{C}$ tetragonais (hibridização $\mathrm{sp}^{3}$ ). $\mathrm{O}$ aumento na rugosidade dos filmes é consequência dessa alteração estrutural. 


\subsubsection{Dureza e coeficiente de atrito dos filmes}

A figura 47 mostra a dureza dos filmes de a-C:H e a-C:H(F) depositados durante 5 minutos com potências entre 5 e $125 \mathrm{~W}$.

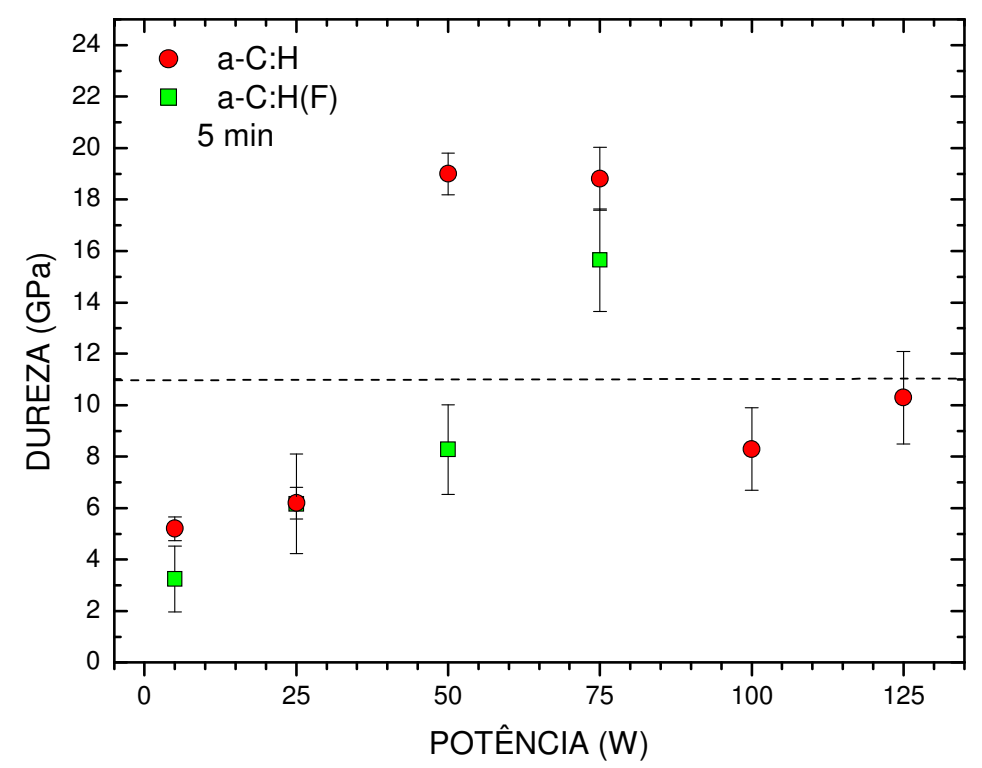

Figura 47 - Dureza em função da potência para os filmes de a-C:H e a-C:H(F) depositados durante 5 minutos. A linha pontilhada representa a dureza do substrato de silício.

Para os filmes poliméricos a fluoração não alterou de forma significativa a dureza dos filmes. Reduções acentuadas na dureza foram observadas para os filmes depositados com 50 e 75 W. A diminuição na proporção de ligações C-C com hibridização $\mathrm{sp}^{3}$ pode ser apontada como o fator responsável por este comportamento (figura 38). Para os filmes com as maiores proporções de precipitados grafíticos (100 e 125 w) a forte interferência das propriedades mecânicas do substrato não permite que a influência do tratamento pós- deposição seja evidenciada nos resultados de dureza. Por esta razão estes resultados não foram apresentados nesta figura.

Os coeficientes de atrito dos filmes de a-C:H e a-C:H:F, depositados por 5 e 10 minutos, são mostrados na figura 48 em função da potência. 


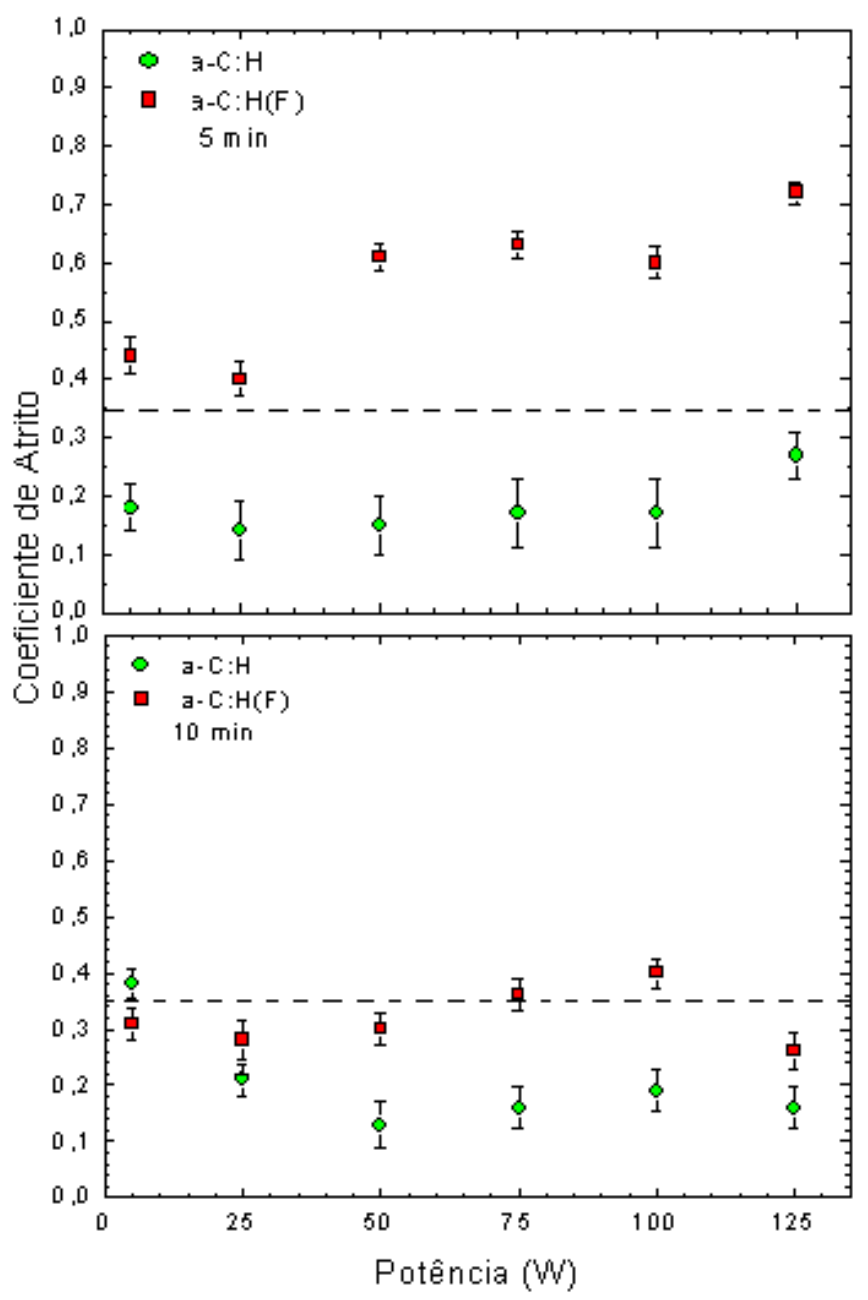

Figura 48 - Coeficiente de atrito $\mu$ dos filmes de a-C:H e a-C:H:F, depositados por 5 e 10 minutos, em plasmas de diferentes potências. A linha pontilhada nessa figura representa o coeficiente de atrito do substrato de silício.

Observa-se nesta figura, que a deposição de filmes de a-C:H diminuiu o coeficiente de atrito do substrato de silício independentemente do tempo e da potência empregados. Entretanto, o processo de fluoração resultou em aumento nos valores de $\mu$ em todos os carbonos amorfos hidrogenados considerados. Este aumento foi mais pronunciado nos filmes preparados com tempo de deposição de 5 minutos. Tais resultados podem estar relacionados com a geração de particulado durante a realização dos testes. A remoção de material do filme seria uma conseqüência da fragilização da estrutura promovida pelo processo de fluoração. 


\subsection{PROPRIEDADES DE FILMES DE CARBONO AMORFO HIDROGENADO FLUORADO}

Nesta seção são apresentados os resultados das propriedades de filmes depositados a partir de plasmas de misturas de acetileno, argônio e hexafluoreto de enxofre $\left(\mathrm{SF}_{6}\right)$. Os plasmas foram estabelecidos pela aplicação de rádiofrequência $(13,56 \mathrm{MHz})$ ao porta-substrato inferior, enquanto o eletrodo superior permaneceu aterrado. As proporções de gases utilizados nas deposições foram de $30 \%$ de $\mathrm{C}_{2} \mathrm{H}_{2}, 65$ $\%$ de $\operatorname{Ar}$ e $5 \%$ de $\mathrm{SF}_{6}$, em relação à pressão total de 9,5 $\mathrm{Pa}$. Os filmes foram depositados durante 5 minutos variando-se a potência de 5 a $125 \mathrm{~W}$.

\subsubsection{Estrutura Molecular e Composição Química dos Filmes}

A figura 49 mostra os espectros de espalhamento Raman dos filmes depositados por PECVD, a partir da mistura de $\mathrm{C}_{2} \mathrm{H}_{2}$, Ar e $\mathrm{SF}_{6}$, em diferentes potências. Observase nesta figura, aumento na largura e na intensidade das bandas das amostras depositadas em potências maiores que $25 \mathrm{~W}$. Para os filmes depositados com 5 e $25 \mathrm{~W}$ foram observados sinais bastante acentuados de luminescência em seus espectros, o que é um indicativo de filmes de natureza polimérica (D'AGOSTINO et al., 1994; JACOBSON et al., 2003).

Para estimar a contribuição das ligações $\mathrm{sp}^{2}$ e $\mathrm{sp}^{3}$ na estrutura, os espectros foram deconvoluídos em duas gaussianas, após remoção de luminescência, segundo o procedimento proposto por Robertson (ROBERTSON, 2002).

Observa-se na figura que a posição central da banda $G\left(\omega_{G}\right)$ desloca-se para maiores números de ondas quando a potência é aumentada de 5 a $50 \mathrm{~W}$ e se desloca para menores números de onda, quando os filmes foram depositados com potências superiores a $50 \mathrm{~W}$. Ou seja, a quantidade de hibridizações $\mathrm{sp}^{3}$ e a quantidade de ligações desordenadas, aumentam de acordo com o deslocamento do centro da banda $\mathrm{G}$ para a esquerda, nos filmes depositados com potências maiores que $50 \mathrm{~W}$. 


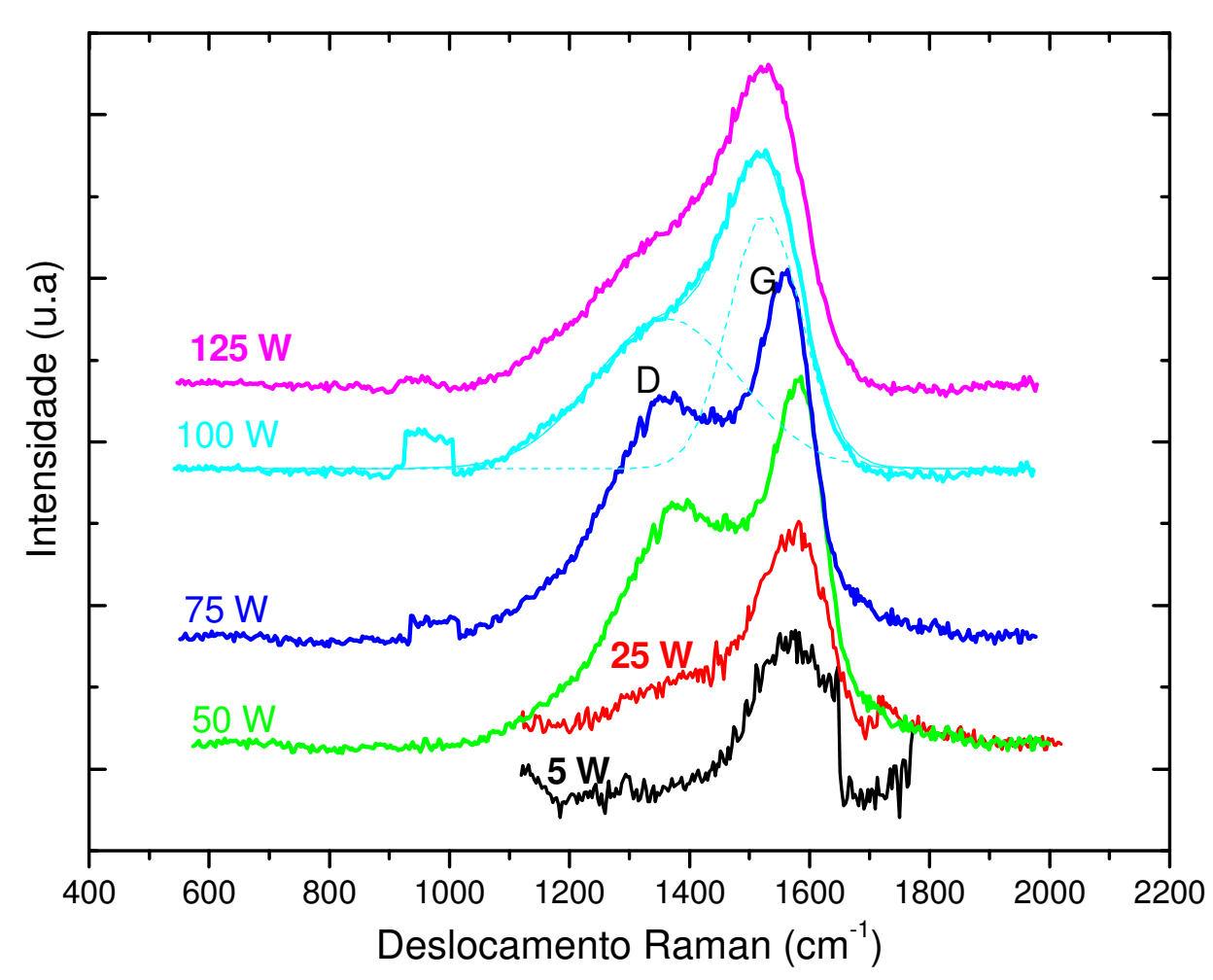

Figura 49 - Espectros de espalhamento Raman dos filmes depositados em diferentes potências.

A posição, largura e a razão entre as intensidades das bandas D e G foram determinadas e estão mostradas na figura 50 em função da potência de deposição.

Observa-se nesta figura, que a razão entre as intensidades das bandas D e G $\left(\mathrm{I}_{\mathrm{D}} / \mathrm{I}_{\mathrm{G}}\right)$ aumenta com o aumento da potência até $50 \mathrm{~W}$ e decresce para maiores potências. Este resultado indica que há diminuição nos tamanhos dos centros grafíticos presentes nos filmes depositados em potências superiores a $50 \mathrm{~W}$. A posição central da banda G aumenta de 1565 para $1585 \mathrm{~cm}^{-1}$ com o aumento da potência até $50 \mathrm{~W}$ e diminui para maiores potências, indicando que a quantidade de hibridizações $\mathrm{sp}^{3}$ diminui no intervalo de 5 a $50 \mathrm{~W}$. 


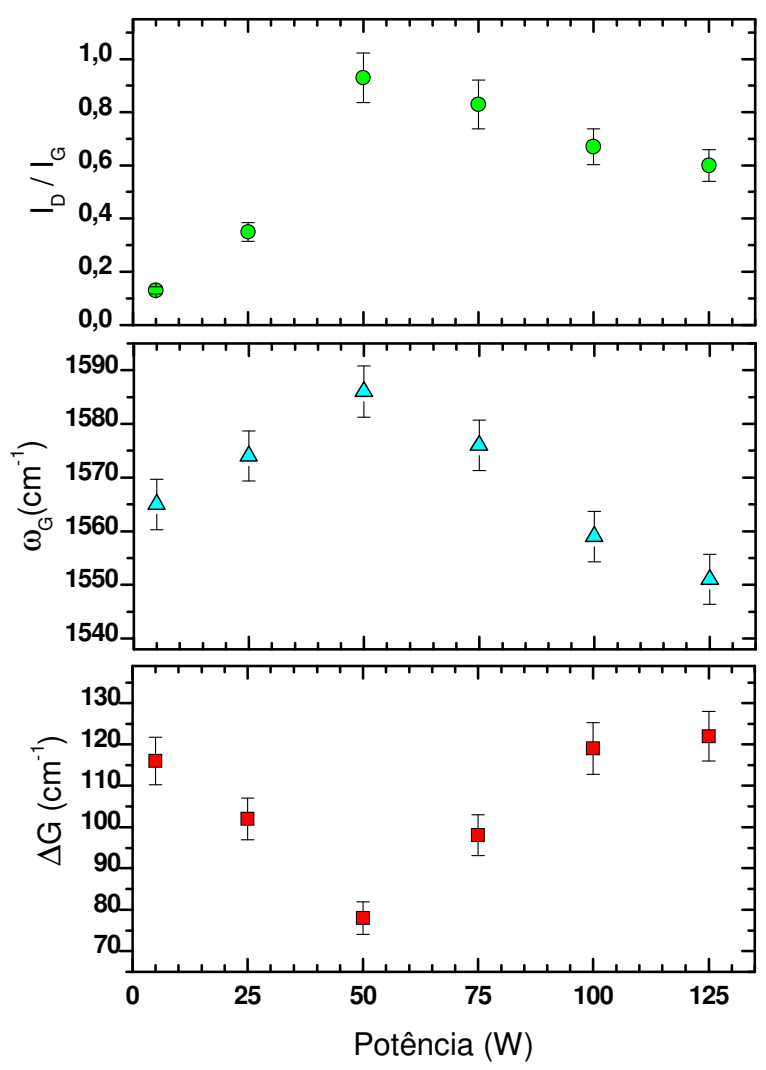

Figura 50 - Razão $I_{D} / I_{G}$, posição central $\left(\omega_{G}\right)$ e largura da banda $G(\Delta G)$ dos filmes, depositados em diferentes potências.

Já a largura da banda $\mathrm{G}(\Delta \mathrm{G})$ diminui no intervalo de potências de 5 a $50 \mathrm{~W}$ invertendo esta tendência para variações de potências acima deste valor. O menor valor de $\Delta \mathrm{G}$ foi observado na amostra preparada em plasmas de $50 \mathrm{~W}$ de potência, revelando menor proporção de sítios $\mathrm{sp}^{3}$ com relação aos demais filmes. É interessante notar que em todos os parâmetros analisados há tendência de crescimento e de queda, sendo o limiar de inversão em $50 \mathrm{~W}$.

Pelo modelo da subimplantação sabe-se que a formação de grupos $\mathrm{sp}^{3}$ na estrutura é favorecida sob condições bastante específicas de bombardeamento iônico, mais especificamente, de energia dos íons que colidem com a camada em crescimento. A energia entregue a estrutura deve ser suficiente para deslocar os centros $\mathrm{sp}^{2} \mathrm{sem}$, todavia, fragmentar os $\mathrm{sp}^{3}$. Pelos resultados obtidos nesta seção nota-se que tal 
processo torna-se cada vez mais favorecido com o aumento da potência de 50 a $125 \mathrm{~W}$.

A partir destes resultados, pode-se concluir que os filmes são carbonos amorfos hidrogenados de diferentes categorias. Quando depositados em plasmas de baixa potência (5 e $25 \mathrm{~W}$ ) apresentam caráter polimérico. Quando a potência é aumentada, cresce a proporção de grupos $\mathrm{sp}^{2}$ (BONETTI, 2006) tornando os filmes tipo grafiticos. Por fim, os filmes podem ser classificados como carbonos amorfos com maior quantidade de ligações tridimensionais quando são depositados em potências maiores que $50 \mathrm{~W}$.

A figura 51 mostra os espectros XPS representativos do substrato de vidro e dos filmes depositados em plasmas de diferentes potências.

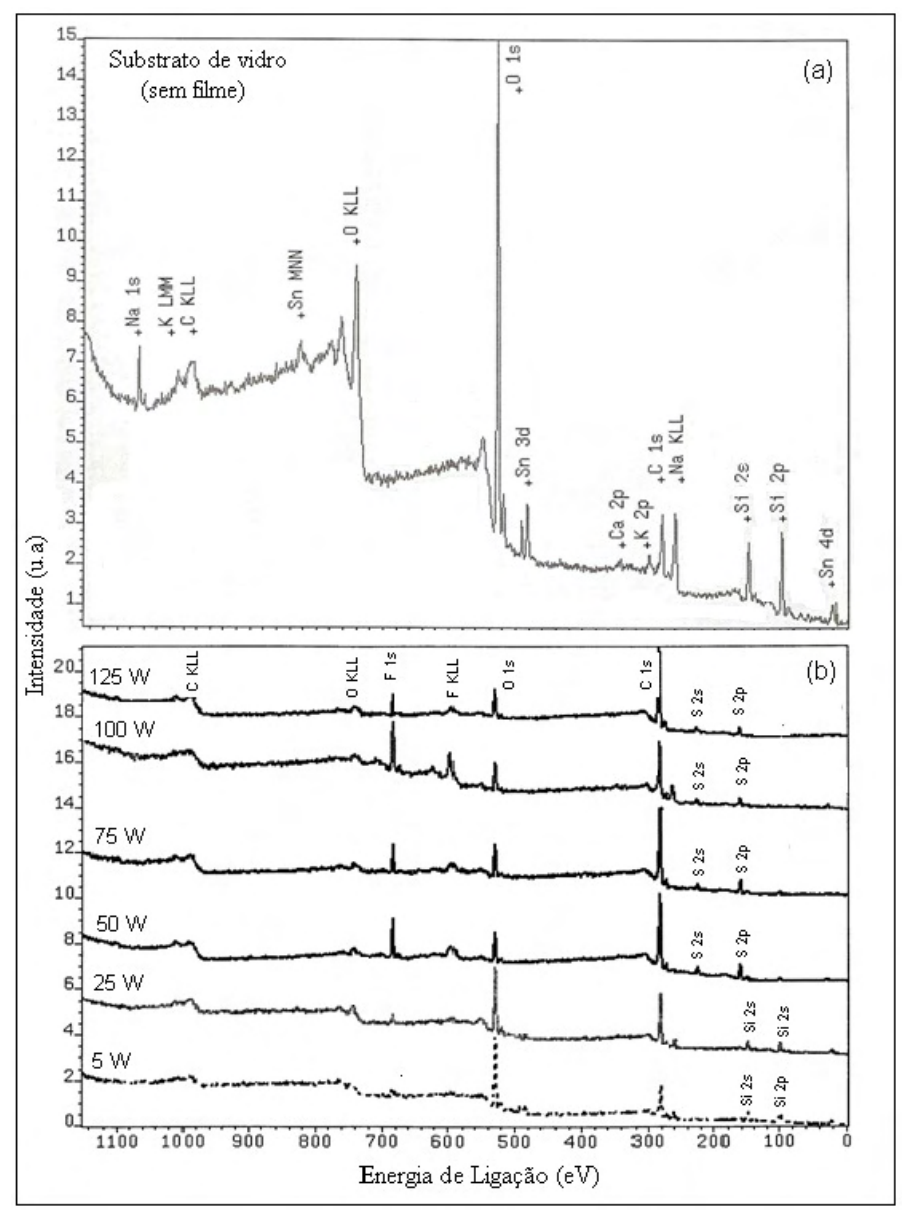

Figura 51 - Espectros XPS de longa varredura do substrato de vidro sem filme (a) e com filmes de a-C:H:F (b) depositados com potências de excitação do plasma de 5 a 125 W. 
Nesta figura, observa-se que o substrato de vidro sem filme apresentou picos de O, Si, Sn, Na, Ca, e K. Já nos filmes depositados sobre o vidro foram evidenciados carbono (aproximadamente a $285 \mathrm{eV}$ ), oxigênio (aproximadamente a $533 \mathrm{eV}$ ), flúor (aproximadamente a $685 \mathrm{eV}$ ), enxofre (aproximadamente a $164 \mathrm{eV}$ ) e silício (aproximadamente a $103 \mathrm{eV}$ ).

O flúor e o enxofre nos filmes provêm do $\mathrm{SF}_{6}$ presente no plasma. No momento em que o plasma, gerado a partir da mistura de $\mathrm{C}_{2} \mathrm{H}_{2}$, Ar e $\mathrm{SF}_{6}$, é estabelecido, o $\mathrm{SF}_{6}$ é fragmentado juntamente com o $\mathrm{C}_{2} \mathrm{H}_{2}$ gerando espécies que irão se recombinar e formar o filme. Com isto, pode-se dizer que os filmes são carbonos amorfos hidrogenados fluorados, a-C:H:F. Já o silício, presente em algumas das amostras, é provavelmente devido ao substrato de vidro.

Filmes crescidos mediante plasmas são fortemente influenciados pela recombinação de radicais livres principalmente durante a deposição. Este fato propiciou que oxigênio residual e/ou vapor d'água adsorvidos nas paredes internas do reator pudessem participar, mesmo em baixa proporção, do processo de deposição, tornando-se assim parte da estrutura dos filmes (TAO, 2004). Como nem todos os radicais livres se recombinam durante o processo de deposição (BIERDERMAN, 1992) oxigênio e nitrogênio atmosféricos também podem ser incorporados quando os filmes são retirados do reator. Ambos os processos contribuem efetivamente para a incorporação de oxigênio em filmes depositados a plasma.

A figura 52 mostra o comportamento das proporções das ligações $\mathrm{C}-\mathrm{C}$ e/ou C-H (284,8 eV), C-O e/ou C-CF (286,5 eV) e C=O e/ou C-F (288,5 eV) resultantes da deconvoluçao do pico C 1s (MOULEDER et al., 1992; TRUSSO, 1999; JIANG, 2000) dos filmes. O aparecimento de carbono ligado ao flúor decorre da remoção de átomos de hidrogênio de grupos C-H através de dois diferentes mecanismos. Primeiramente, a alta afinidade química entre hidrogênio e flúor leva à emissão do hidrogênio ligado, produzindo radicais de carbono. Flúor presente no plasma reage prontamente satisfazendo a ligação pendente. Além disto, a deposição de energia na estrutura pelo impacto de íons velozes também leva à emissão de hidrogênio de grupos C-H cujas energias de ligação são mais fracas que as de carbono-carbono ou carbono-oxigênio. 


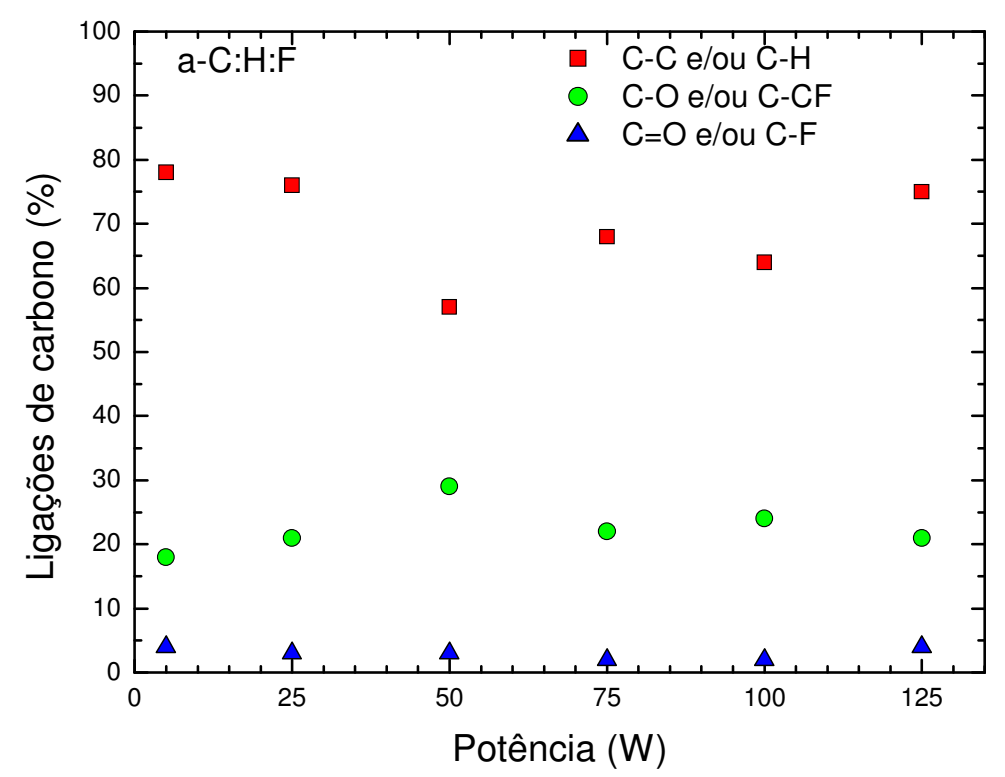

Figura 52 - Proporção das espécies presentes nos filmes de a-C:H:F em função da potência de deposição, conforme a deconvolução do pico C $1 \mathrm{~s}$.

Tal processo também permite que átomos de flúor substituam parte considerável de átomos de hidrogênio durante a deposição dos filmes (FINK et al., 1987; DURRANT et al., 1992; D'AGOSTINO et al., 1994; BENDAVID et al., 2009).

Analisando-se os resultados desta figura observa-se que os filmes são constituídos principalmente por ligações C-C e/ou C-H. Há uma queda na proporção destas ligações com o aumento da potência até $50 \mathrm{~W}$ e um crescimento para as maiores potências. Através da largura da banda G, mostrada na figura 50, observou-se que a proporção de ligações tipo $\mathrm{sp}^{3}$ diminuiu com o aumento da potência até $50 \mathrm{~W}$ e cresceu para maiores potências. Assim a queda inicial em C-C e/ou C-H representa o aumento na grafitização da estrutura com potência até $50 \mathrm{~W}$.

Observa-se na proporção de grupos C-O e/ou C-CF uma tendência inicial de crescimento, com o máximo sendo atingido em $50 \mathrm{~W}$, e posterior queda para maiores potências, indicando que a maior parte do hidrogênio foi substituída por flúor e/ou oxigênio. Em todas as amostras foi constatada a presença de ligações $\mathrm{C}=\mathrm{O}$ e/ou $\mathrm{C}-\mathrm{F}$, 
em proporções menores que a de grupos C-O e/ou C-CF e praticamente constantes com a variação da potência.

Espectros de alta resolução do pico F 1s também foram obtidos e deconvoluídos em componentes em 684,9; 687,4; 688,4 e 689,6 eV. De acordo com a literatura (FERRARIA, 2003) a contribuição de mais baixa energia $(684,9$ eV) é relacionada a ligações S-F, provenientes da fragmentação do $\mathrm{SF}_{6}$. As componentes em 687,4 eV e $688,4 \mathrm{eV}$ são respectivamente atribuídas a grupos $\left(-\mathrm{CHFCH}_{2}-\right)_{\mathrm{n}}$ e $\left(-\mathrm{CF}_{2} \mathrm{CH}_{2}\right)_{\mathrm{n}}$. No trabalho de FERRARIA, que analisou a estrutura química de filmes de Teflon ${ }^{\circledR}$, a contribuição em $689,6 \mathrm{eV}$ foi caracterizada como espécies $\left(-\mathrm{CF}_{2} \mathrm{CF}_{2}-\right)_{\mathrm{n}}$.

A figura 53 mostra o comportamento da proporção destas ligações em função da potência.

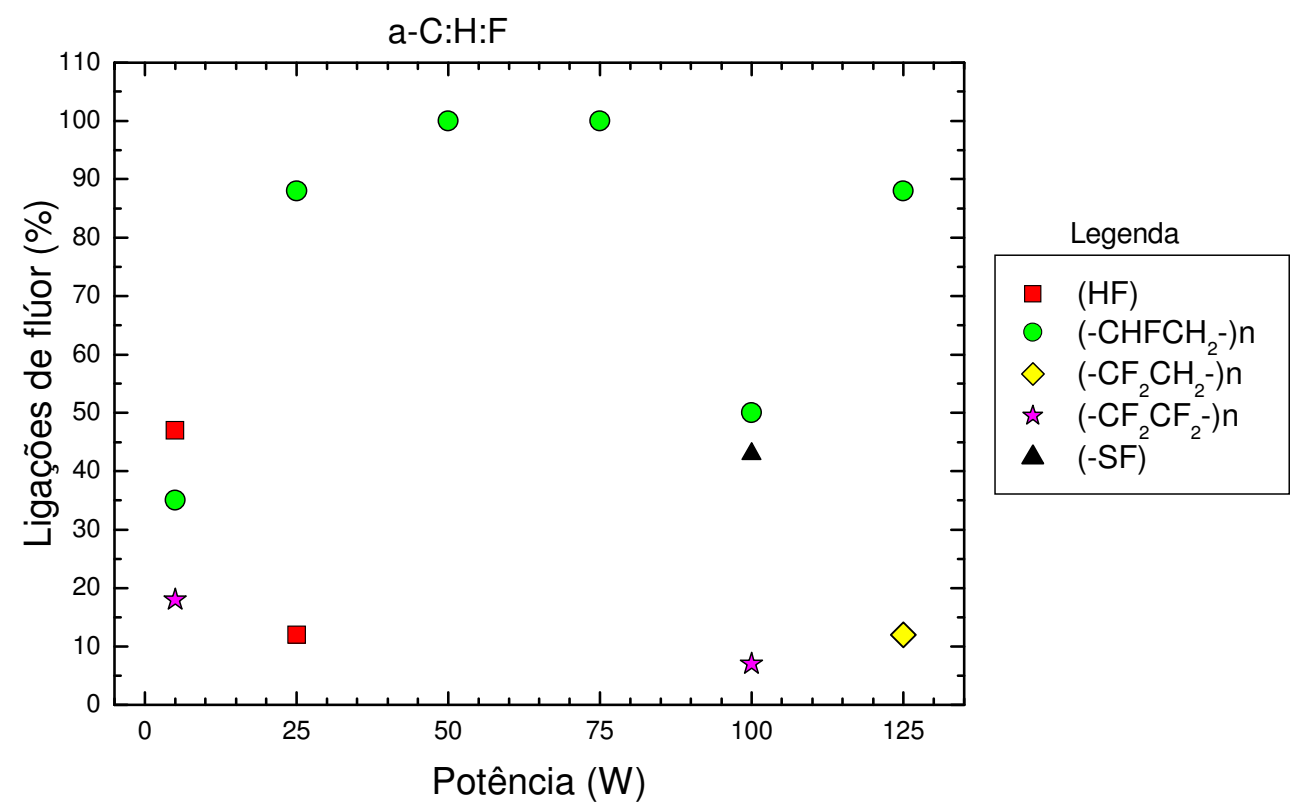

Figura 53 - Proporção de flúor presente nos filmes em função da potência de deposição.

Nos filmes depositados com 5 e $25 \mathrm{~W}$, o flúor aparece ligado ao carbono e ao hidrogênio: em $5 \mathrm{~W}$ nos grupos $\left(-\mathrm{CHFCH}_{2}-\right)_{\mathrm{n}},\left(-\mathrm{CF}_{2} \mathrm{CF}_{2}\right)_{\mathrm{n}}$ e (HF), enquanto que a 25 W nos grupos $\left(-\mathrm{CHFCH}_{2}-\right)_{\mathrm{n}}$ e (HF). Flúor ligado ao enxofre foi detectado na amostra preparada com $100 \mathrm{~W}$ de potência. Nas demais, a ligação $\left(\mathrm{CHFCH}_{2}\right)_{\mathrm{n}}$ prevalece. As variações na concentração de flúor nos diferentes grupos funcionais podem ser 
creditadas à ação do plasma altamente reativo pela presença de $\mathrm{SF}_{6}$. Um conjunto de reações envolvendo elétrons livres, fragmentos moleculares e íons de várias massas, tais como $\mathrm{SF}_{6}^{+}, \mathrm{SF}_{5}^{+}, \mathrm{SF}_{4}^{+}$, com energias cinéticas diferentes, interagem com espécies provenientes do acetileno. Desta interação, pode resultar um conjunto estrutural complexo, onde átomos de flúor substituem átomos de hidrogênio em diferentes proporções nas cadeias. Estatisticamente, podem-se esperar concentrações diferentes de espécies da mesma família na superfície dos substratos visto que o plasma está fora do equilíbrio termodinâmico.

As concentrações atômicas relativas de carbono $[\mathrm{C}]$, oxigênio $[\mathrm{O}]$, flúor $[\mathrm{F}]$, enxofre [S] e silício [Si] nas amostras, também foram determinadas e estão mostradas na figura 54 em função da potência de deposição.

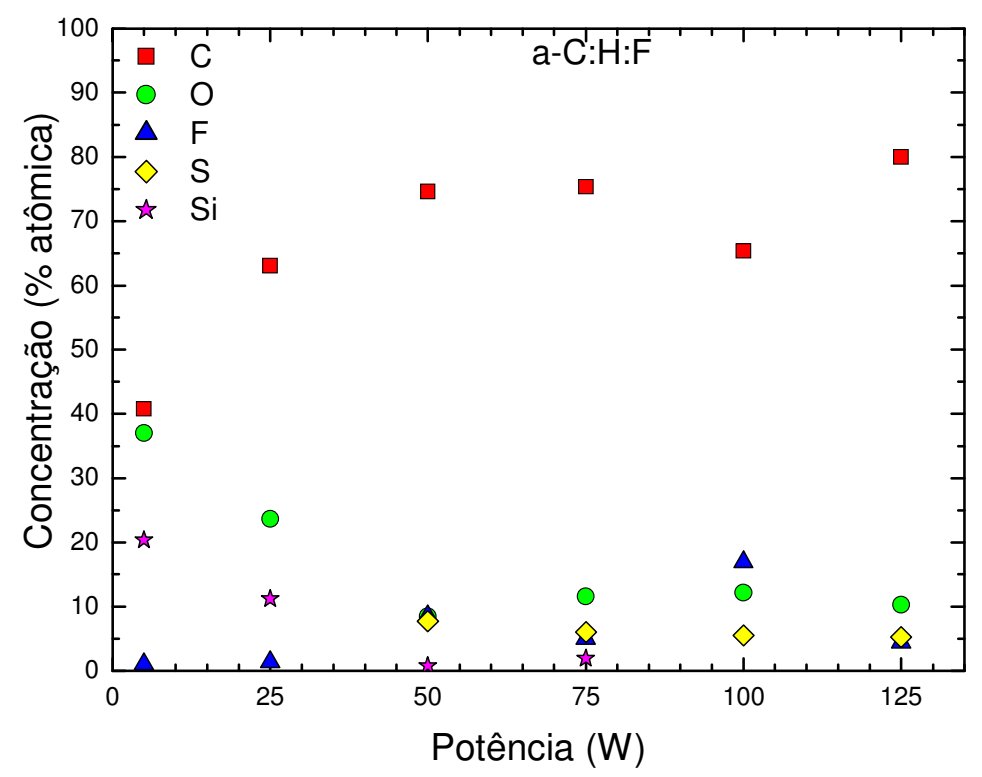

Figura 54 - Concentrações atômicas relativas de carbono, oxigênio, flúor, enxofre e silício nos filmes depositados em diferentes potências.

Pode-se dizer que há crescimento da concentração atômica de carbono nas amostras para maiores potências de deposição. Já a concentração atômica de oxigênio, segue o comportamento contrário: menores proporções de oxigênio foram encontradas nas amostras preparadas com as maiores potências. Embora o grau de 
bombardeamento iônico se intensifique para maiores potências, a proporção de ligações pendentes, ávidas pela captura de oxigênio, não crescem proporcionalmente. Esta tendência é explicada pelo fato da energia depositada pelas colisões iônicas ser utilizada para deslocar centros com hibridização $\mathrm{sp}^{2}$, favorecendo a prevalência de núcleos mais estáveis ao bombardeamento $\left(\mathrm{sp}^{3}\right)$. Com isto, a proporção de radicais livres e, conseqüentemente de oxigênio no filme diminui enquanto a proporção de sítios $\mathrm{sp}^{3}$ cresce.

A concentração atômica de flúor nas amostras se manteve relativamente baixa comparada à concentração atômica de carbono em toda a faixa de potência investigada. Uma das razões para isto é a baixa proporção de $\mathrm{SF}_{6}$ comparada à de $\mathrm{C}_{2} \mathrm{H}_{2}$ na mistura e também a competição entre deposição e ablação pelo efeito de "etching" dos átomos de flúor.

A baixa concentração de enxofre observada (menos de 10\%) foi consequência da baixa afinidade desta espécie com outras presentes no plasma e que participaram do processo de deposição.

\subsubsection{Espessura e Molhabilidade dos filmes}

A figura 55 apresenta o comportamento da espessura h dos filmes em função da potência de deposição.

Os filmes se tornaram progressivamente menos espessos com o aumento da potência. Comportamento similar foi observado nos filmes depositados a partir de plasma de $\mathrm{C}_{2} \mathrm{H}_{2}$ e Ar, sem a presença de flúor na mistura como mostrado na figura 32 .

Com o aumento da potência a concentração de íons de flúor, provenientes da intensa fragmentação do $\mathrm{SF}_{6}$, cresce. Como tais espécies são altamente reativas, cresce a ablação por efeitos químicos e ainda por aquecimento do substrato durante o processo de deposição, reduzindo a velocidade de crescimento dos filmes. A redução na espessura dos filmes de a-C:H:F, também foi observado por outros autores (ENDO, 1995; YOKOMICHI, 1998; BENDAVID et al., 2009). 


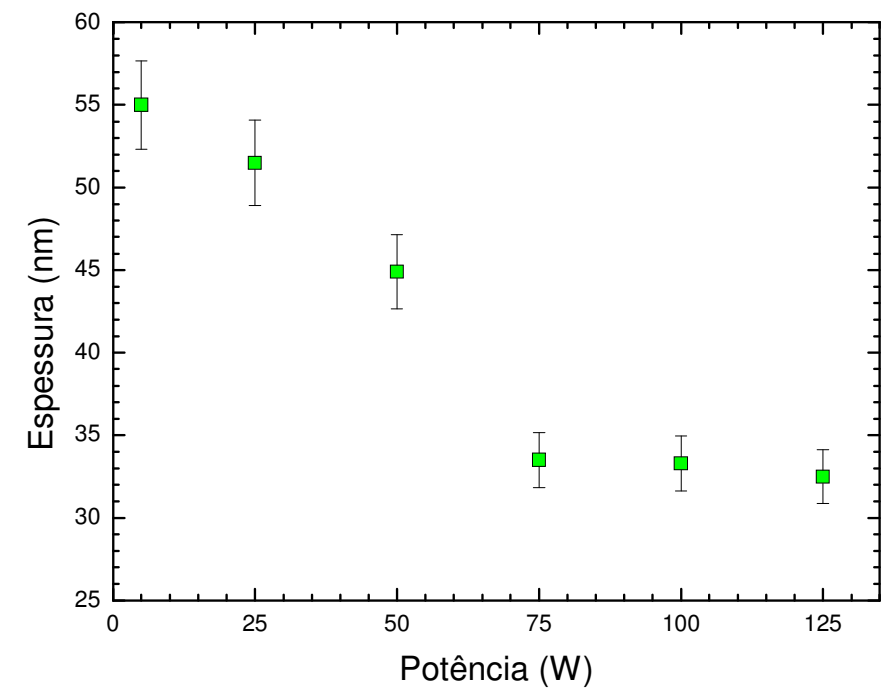

Figura 55 - Espessura dos filmes em função da potência de deposição.

A figura 56 apresenta os valores de ângulo de contato, $\theta$, em função potência de deposição dos filmes, adquiridos 30 dias após a deposição.

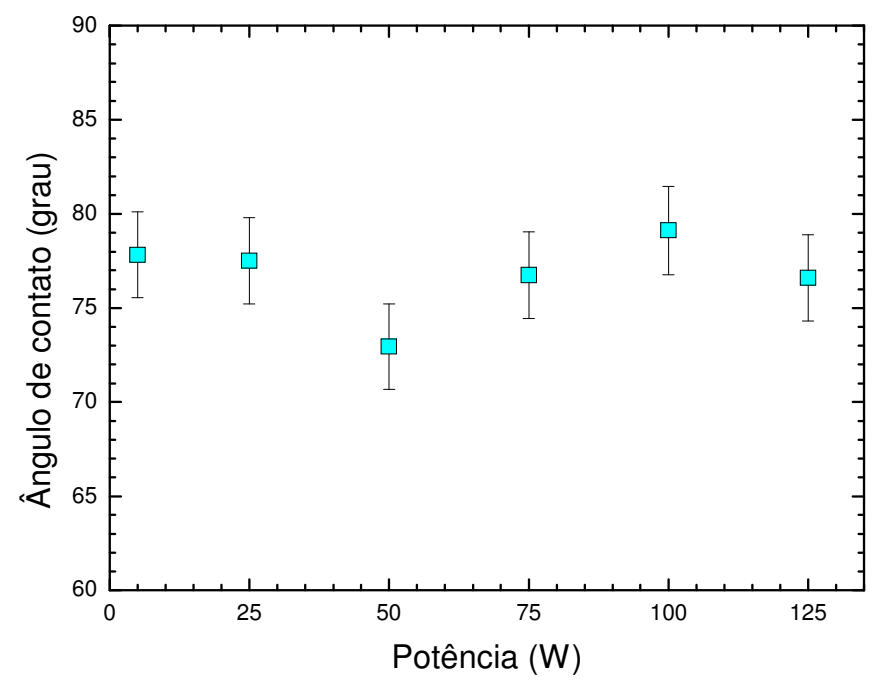

Figura 56 - Ângulo de contato dos filmes em função da potência de deposição.

Observa-se nesta figura que ocorre pouca variação nos valores de $\theta$, de acordo com a potência com que os filmes foram depositados. Este resultado é uma 
consequência da evolução de $\theta$ durante o período em que o filme esteve em contato com a atmosfera. Comportamento e valores semelhantes a estes também foram encontrados para os filmes preparados sem a adição de flúor no plasma como mostrado na figura 33. Logo, a incorporação de flúor evidenciada pelos espectros XPS não ocorreu em proporções suficientes para produzir uma superfície repelente à água ou hidrofóbica. Este efeito pode ser proveniente de grupos fluorados que quando incorporados isoladamente na estrutura promoveriam forças eletrostáticas moderadas atraindo os dipolos da água. Outra hipótese seria a perda constante de grupos fluorados da superfície, pela liberação destas espécies ou ainda pela rotação da cadeia carbônica onde tais grupos encontram-se ligados. Quando se comparam os resultados apresentados nas figuras 52 e 45 nota-se que a fluoração pós-deposição foi mais efetiva no aumento do ângulo de contato dos filmes que a incorporação de flúor na descarga.

\subsubsection{Coeficiente de Atrito dos Filmes}

O coeficiente de atrito $(\mu)$ dos filmes é mostrado na figura 57 em função da potência de deposição. Pode-se observar tendência inicial de queda nos valores de $\mu$ com o aumento da potência até $50 \mathrm{~W}$ e crescimento para potências acima deste valor.

Assim, o processo de deposição envolvendo a mistura acetileno, argônio e hexafluoreto de enxofre desfavorecem o caráter lubrificante da maioria dos filmes depositados nesta condição, quando comparado com os filmes de a-C:H, depositados por 5 minutos, sem a presença de flúor no processo de deposição, como mostrou a figura 35. Contudo, os resultados da figura 57 indicam que as amostras se mostram mais lubrificantes que as amostras de a-C:H, depositadas por 5 e 10 minutos, que foram expostas a tratamentos pós-deposição em plasmas de $\mathrm{SF}_{6}$ (figura 48). 


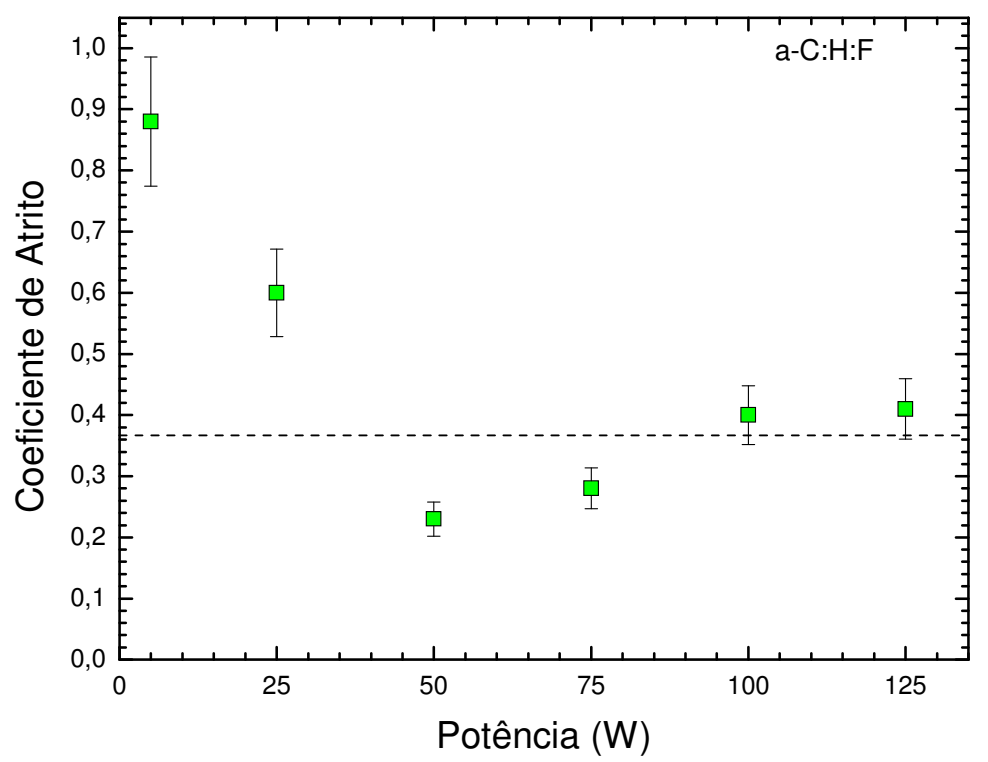

Figura 57 - Coeficiente de atrito dos filmes de a-C:H:F em função da potência. A linha pontilhada representa o valor de $\mu$ para o substrato de silício.

\subsubsection{Rugosidade dos Filmes de a-C:H:F}

Na figura 58, são apresentados os resultados da raiz quadrática média (RMS) da rugosidade dos filmes, em função da potência.

Notam-se variações em RMS com a variação potência. Nos filmes tipo polimérico, a RMS permanece praticamente constante com o aumento da potência, mas tendência de queda é observada com o aumento da potência para $50 \mathrm{~W}$. Para a amostra depositada com $75 \mathrm{~W}$ não houve variação significativa na RMS que permanece no mesmo patamar atingido pela amostra preparada com $50 \mathrm{~W}$. A maior rugosidade foi encontrada para o filme depositado em plasmas de $100 \mathrm{~W}$. O filme depositado em $125 \mathrm{~W}$ delaminou, não sendo possível medir a rugosidade. 
Comparando-se tais resultados com os obtidos na seção 5.1.4 nota-se comportamento bastante similar. Entretanto, os valores de rugosidade foram substancialmente maiores para os filmes depositados na presença de flúor.

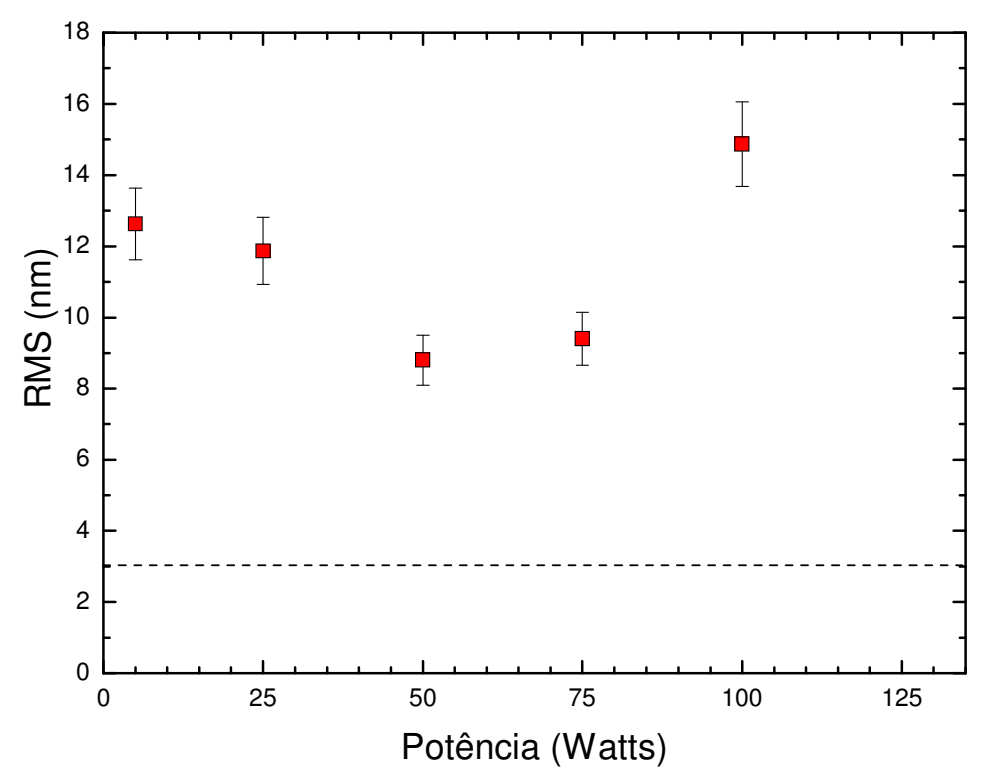

Figura 58 - Rugosidade média quadrática (RMS) dos filmes de a-C:H:F em função da variação de potência. A linha pontilhada refere-se à RMS do substrato de silício.

Para interpretar estes resultados deve-se considerar que a estrutura molecular dos filmes foi modificada pela introdução de flúor na descarga. Através de espectroscopia Raman observou-se crescimento na proporção de núcleos $\mathrm{sp}^{2}$ nos filmes depositados com potências entre 5 e $50 \mathrm{~W}$, aumentando a ordem da estrutura. Já a proporção de grupos $\mathrm{sp}^{3}$ cresce ligeiramente para a faixa de potência entre 75 e 125 W. Este comportamento é o oposto dos observados nos filmes de a-C:H como depositados. Os maiores valores de RMS para os filmes fluorados com relação aos não fluorados também são devidos à maior desordem promovida na estrutura quando flúor está presente.

Através deste estudo observa-se também que as variações no coeficiente de atrito dos filmes são devidas às variações na rugosidade das amostras. Ambas as 
propriedades apresentam as mesmas tendências em todas as faixas de potências investigadas. 


\section{CONCLUSÕES E PERSPECTIVAS FUTURAS}

O presente trabalho revelou que a potência usada nas deposições dos filmes de a-C:H e dos filmes de a-C:H:F foi preponderante para definir estruturas moleculares e composições químicas das amostras.

Para potências entre 5 e $25 \mathrm{~W}$, os filmes depositados em 5 e 10 minutos, apresentaram estruturas poliméricas, em $50 \mathrm{~W}$ apresentou características de a-C:H (carbono amorfo hidrogenado) mais próxima do diamante e acima deste valor, características de material grafitico.

$\mathrm{O}$ tratamento das amostras com plasmas de $\mathrm{SF}_{6}$ não alterou o comportamento tipo polimérico nos filmes depositados em baixas potências e para aqueles depositados acima de $50 \mathrm{~W}$, o caráter grafitico ficou mais acentuado. No entanto, o tratamento a plasma de $\mathrm{SF}_{6}$ promoveu a substituição dos átomos de hidrogênio pelos átomos de flúor na rede estrutural dos filmes de a-C:H, com diminuição na intensidade da banda $\mathrm{G}$ e aumento na intensidade da banda D nos espectros Raman deste material. Como o diâmetro atômico do flúor é maior que do hidrogênio, esta substituição causou aumento na quantidade de defeitos de coordenação, alterando a estrutura e a composição química das amostras tratadas.

Os filmes depositados a partir da mistura $\mathrm{C}_{2} \mathrm{H}_{2} / \mathrm{Ar} / \mathrm{SF}_{6}$ também apresentaram estruturas poliméricas em potências entre 5 e $25 \mathrm{~W}$; em $50 \mathrm{~W}$, estrutura grafitica, e em

potências superiores a $50 \mathrm{~W}$, maior quantidade de ligações $\mathrm{sp}^{3}$ devido à presença de ligações $\mathrm{C}-\mathrm{F}$ e $\mathrm{CF}_{2}$.

Os filmes de a-C:H, depositados em 5 e 10 minutos, se tornaram mais finos quando depositados a potências mais elevadas em função principalmente do bombardeamento iônico e do aquecimento do substrato, promovendo efeito de ablação nas amostras. Tanto o tratamento a plasma com $\mathrm{SF}_{6}$ assim como a deposição dos filmes na atmosfera de $\mathrm{SF}_{6}$ favoreceram reduções nas espessuras dos filmes depositados em potências mais elevadas, reflexo do "etching" de $\mathrm{SF}_{6}$ nos filmes depositados ou tratados.

Todos os filmes de a-C:H que foram depositados durante 10 minutos e tratados em plasma de $\mathrm{SF}_{6}$ apresentaram mudanças de caráter de hidrofílico para hidrofóbico. 
Os filmes de a-C:H apresentaram baixos coeficiente de atrito independentemente da potência e do tempo de deposição utilizada para deposição.

Com todos esses resultados, pode-se dizer que os filmes de a-C:H e os filmes de a-C:H(F) tem qualidades muito importantes no uso como revestimento protetores.

O presente trabalho revelou que a incorporação de flúor nos filmes de a-C:H, através do tratamento em plasmas de $\mathrm{SF}_{6}$, produziu modificações efetivas nas superfícies dos materiais.

O estudo de materiais carbonosos via plasma é bastante amplo e fértil para as pesquisas científicas. Deste trabalho, por exemplo, podem ser utilizadas técnicas de análise de superfícies como SIMS, Aeger, de volume como raio-X com EDS e outras que permitam complementar e melhor definir os componentes químicos dos materiais. Por outro lado, análises óticas e de espectroscopia de massa também podem se tornar úteis, pois inferirão sobre os processos envolvidos nas deposições e tratamentos dos filmes servindo de parâmetro para um controle mais efetivo. 


\section{REFERÊNCIAS}

ADAmsOn, A. W.; GAST, A. P.; Physical Chemistry of Surfaces. New York, Wiley \& Sons, $6^{\text {th }}$ ed., 1997.

AHN, H. J.; et al. Structural and chemical characterization of fluorinated amorphous carbon films (a-C:F) as a liquid crystal alignment layer. Diamond and Related Materials, v. 17, p. 2019-2024, 2008.

ALLEN, M.; LAW, F.; RUSHTON, N.; The effects of diamond-like carbon coatings on macrophages, fibroblasts and osteoblast-like cells in vitro. Clin. Mater. v. 17, p.110, 1994.

ANGUS, J. C. Diamond and diamond-like phases. Diamond and Related Materials, v. 1, p. 61, 1991.

ANGUS, J. C..; KOIDL, P.; DOMITZ, S. in Plasma Deposited Thin Films. J. Mort and F. Jansen Eds. Chemical Rubber, Boca Raton, Fl., p.89, c. 4, 1988.

AVASTHI, D. K.; Effects and uses of ion beams with diamond, DLC and fullerenes films. Pergamum Vacuum, v. 47, n.11, p. 1249-1258, 1996.

BAN, M.; et al. Diamond like carbon films deposited by electron beam excited plasma chemical vapor deposition. Diamond and Related Materials, v. 11, p. 1553-1559, 2002.

BENDAVID, A.; et al. The mechanical and biocompatibility properties of DLC-Si films prepared by pulsed DC plasma activated chemical vapor deposition. Diamond and Related Materials, v. 16, p. 1616-122, 2007. 
BENDAVID, A.; MARTIN, P. J.; RANDENIYA, L.; AMIN, M. S.; The properties of fluorine containing diamond-like carbon films prepared by plasma-enhanced chemical vapor deposition. Diamond \& Related Materials. v.18, p. 66-71, 2009.

BIERDERMAN, H.; OSADA, Y.; in Plasma Polymerization Process (Elsevier, Amsterdam), 1992.

BITTENCOURT, J. A. in Fundamentals of Plasma Physics (Pergamum Press), New York. 1986.

BLACK, J.; in Orthopedic Biomaterials in Research and Practice (Churchill Livingstone, New York, 1988.

BONETTI, L. F.; et al. Adherente a-C:H films deposited by IBAD method. Brazilian Journal of Vacuum Applications, v. 25, n. 4, p. 227-231, 2006.

BONETTI, L. F.; et al. Adhesion studies of diamond-like carbon films deposited on Ti6A14V substrate with a silicon interlayer. Thin Solid Films, v.515, n. 1, p. 375-379, 2006.

BORUKI S. V.; ACHETE C. A.; JACOB W. Hydrogen plasma treatment of poly (ethylene terephthalate) surfaces. Surface and Coating Technology. v. 138, p. 256263, 2001.

BRAUN, A. E.; Sputtering targets adapt to new materials and shrinking architectures. Semiconductor International, ISSN 0163-3767 CODEN SITLDD, v. 21, n. 6, p. 127-134, 1998.

BRISCOE, H. M.; Why Space Tribology? Tribology International, 23, 69, 1990.

BUTTER, R. et al. Production and wetting properties of fluorinated diamond-like carbon coating. Thin Solid Films, v. 311, p. 107-113, 1997. 
BUTTER, R.; et al. In vitro studies of DLC coatings with silicon intermediate layer. Diamond Related Materials, v. 4, p. 857, 1995.

CAPOTE, G.; et al. Deposition of adherente DLC films using a low-cost enhanced pulsed-DC PECVD method. Brasilian Journal of Vacuum Application, v. 25, n. 4, 0. 209-213, 2006.

CAPOTE, G.; Produção e Caracterização de Filmes Finos de Carbono Amorfo Hidrogenado Depositados em Plasmas de Metano Diluídos por Gases Nobres. 181 fls Tese (Doutorado em Física) - Pontifica Universidade Católica do Rio de Janeiro, departamento de Física, R.J., 2003.

CASIRAGHI, C.; FERRARI, A. C.; ROBERTSON, F. Raman spectroscopy of hydrogenated amorphous carbons. Physical Review B, v. 72, 085401 p. 1-14, 2005.

CHEN, G.; ZHANG, J.; YANG, S. Fabrication of hydrophobic fluorinated amorphous carbon thin films by an electrochemical route. Electrochemistry Communications, v. 10, p. 7-11, 2008.

CHOI, S. S. et al. "Deposition of diamond-like carbon films by plasma enhanced chemical vapor deposition", Materials Science and Engineering B, v. 46, p. 133136, 1997.

CLARK, D. T.; SHUTTLEWORTH, D. Esca applied to polymers .27. plasma polymerization .2. Esca investigation of polymers synthesized by excitation of inductively coupled RF plasma in perfluorobenzene and perfluorocyclohexane. Journal of Polymer Science Part A - Polymer Chemistry, v. 18, p. 27-46, 1980.

COEN, M. C. et al. AFM measurements of the topography and the roughness of ECR plasma treated polypropylene. Applied Surface Science 103, p. 27-34, 1996. 
D'AGOSTINO, R. et al. Fluorinated diamond-like carbon films deposited from radio frequency glow discharge in a triode reactor. Journal of Vacuum Science and Technology A: Vacuum, Surfaces and Films, v.12, p. 308-313, 1994.

DA COSTA, M. E. H. M. Propriedades estruturais, Mecânicas Tribológicas e Estabilidade Térmica de Filmes de Carbono Amorfo Fluorado Depositado por PECVD. Tese de doutorado (Física), PUC-Rio, 2000.

DA COSTA, M. E. H. M. et al. Fluorine incorporation into amorphous hydrogenated carbon films deposited by plasma-enhanced chemical vapor deposition: structural modifications investigated by X-Ray photoelectron spectroscopy and Raman spectroscopy. Diamond and Related Materials, v. 10, p. 910-914, 2001.

DA COSTA, M. E. H. M. et al. Effects of thermal annealing on the structural, mechanical and tribological properties of hard fluorinated carbon films deposited by plasma enhanced chemical vapor chemical. Journal of Vacuum Science and Technology A: Vacuum, Surfaces and Films, v. 22, p. 2321-23328, 2004.

DAVIS, C. A.; A simple-model for the formation of compressive stress in thin-films by ion-bombardment. Thin Solid Films. v. 226, n.1, p.30-34, 1993.

DONNET. C.; et al. The role of hydrogen on the friction mechanism of diamond-like carbon films. Tribology Letters, v. 9, n. 3-4, 2000.

DÛ, G. L.; et al. RF plasma-polymerization of acetylene: correlation between plasma diagnostics and deposit characteristics. Surface and Coating Technology, v. 20, p. 5815-5821, 2007.

DURRANT, S. F. et al. Nitrogenation of Diamond by glow discharge plasma treatment. Thin Solid Films 355-356, p. 184-188, 1999. 
DURRANT, S. F., et al. Amorphous hydrogenated fluorinated carbon films produced by PECVD. Surface and Coating Technology, v. 86-87, p. 443-448, 1996.

DURRANT, S. F., MOTA, R. P.; MORAES, M. A. B. Fluorinated polymer-film from RF plasmas containing benzene and sulfur hexafluorine. Thin Solid Films, v. 220, p. 295-302, 1992.

DURRANT, S. F..; et al. Structural and optical properties of amorphous hydrogenated fluorinated carbon films produced by PECVD. Thin Solid Films 304, p. 149-156, 1997.

ELLIS, G.; Los Origenes de Raman, www.ictp.csic.es/ramanft/, 2008.

EMMERT, G. A. "Model for expanding sheaths and surface charging at dielectric surfaces during plasma source ion implantation," J. Vac. Sci. Technol. B, v. 12, p. $880-883,1994$.

ENDO, K.; TATSUMI, T. Fluorinated amorphous carbon thin films grown by plasma enhanced chemical vapor deposition for low dielectric constant interlayer dielectrics. Journal of Applied Physics, v. 78, p.1370-1372, 1995.

ERDEMIR, A.; DONNET, C.; Tribology of diamond, diamond-like carbon, and related films, in: B. Bhushan (Ed.), Handbook of Modern Tribology, CRC Press, p. $871,2001$.

ERDEMIR, A.; The role of hydrogen in tribological properties of diamond-like carbon films. Surface and Coating Technology, v. 146-147, p. 292-297, 2001.

FEDOSENKO, G.; et al. Pulsed PECVD deposition of diamond-like carbon films, Diamond and Related Materials, v. 11, p. 1047-1052, 2002. 
FERRARI, A. C.; ROBERTSON, J. Interpretation of Raman spectra of disordered and amorphous carbon. Physics Review B, v. 61, m. 20, p. 14095-14107, 2000.

FERRARI, A. C. Determination of bonding in diamond-like carbon by Raman Spectroscopy. Diamond and Related Materials, v. 11, p. 1053-1061, 2002.

FERRARIA, A. M.; SILVA, J. D. L.; REGO, A. M. B. XPS studies of directly fluorinated HDPE: problems and solutions. Polymer v. 44, p. 7241, 2003.

FINK, J. et al. Amorphous Hydrogen Carbon Films. E-MRS Symp. Proc. v. 17, p. 475, 1987.

FRANCESCHINI, D. F.; ACHETE, C. A.; FREIRE, F. L. Influence of precursors gases on the structure of plasma deposited. Applied Physics Letters, v. 68, p. 2645, 1996.

FREIRE, F. L. Jr.; et al. Film growth and relationship between microstructure and mechanical properties of a-C:F films deposited by PECVD. Diamond and Related Materials, v. 10, p. 125-131, 2001.

FREIRE, F. L. Jr. Amorphous hydrogenated carbon films: effects of nitrogen and fluorine incorporation on the film microstructure and mechanical properties: a review Journal Non-Crystalline Solids, v. 304, p. 251-258, 2002.

GALVÃO, J. R.; et al. Ion irradion effects on a-C:H, a-C:N:H and a-C:F:H films. Nuclear Instruments and Methods in Physics Research B, v. 20, p. 409-413, 2006.

GIELEN, J. W. A. M.; SANDEN, M. C. M.; SCHRAM, D. C.; Deposition of amorphous carbon layers from $\mathrm{C}_{2} \mathrm{H}_{2}$ and $\mathrm{CF}_{4}$ with an expanding thermal arc plasma beam set-up, Thin Solid Films, v. 271, p. 56-63, 1995. 
GUNTHER, J.; RESCHKE, J. Metal-carbon layers for industrial application in the automotive industry. Surface Coating Technology, v. 60, p. 531, 1993.

GRILL, A. "Diamond-like carbon: state of the art", Diamond and Related Materials, v.8, p. 428-434, 1999.

GRILL, A.; PATEL, V. Diamond-like carbon. Diamond and Related Materials v. 2, p. $1519,1993$.

GRILL, A.; PATEL, V.; C. J.; Novel low k dielectrics bead on diamond like carbon materials. J. Eletrochem. Soc. v.145, p. 1649, 1998.

GUERINO, M.; et al. The influence of nitrogen on the dielectric constant and surface hardness in diamond-like carbon (DLC) films. Diamond and Related Materials, v. 13, p. 316-319, 2004.

HAKOVIRTA, M.; TIAINEM, V. M.; PEKKO, P.; Techniques for filtering graphite macroparticles in the cathodic vacuum arc deposition of tetrahedral amorphous carbon films, Diamond and Related Materials, v. 8, p. 1183-1192, 1999.

HAMAGAWA, Y.; TOKAYMA, T.; OKAMOTO, H. blue light emission from a-C:H by thin film electroluminescence structure cell. Journal of Non-Crystalline Solids, v. 115, p. 180-182, 1989.

HASEBE, T.; et al. Fluorinated diamond-like carbon as antithrombogenic coating for blood-contacting devices. Journal Biomed. Mater. Res., 76 A, p. 86-94, 2006.

HATADA, R.; BABA, K. Preparation of hydrophobic diamond like carbón films by plasma source ion implantation. Nuclear Instruments and Methods in Physics Research B, v. 148, p. 655-658, 1999. 
HAUERT, R. A Review of Modified DLC Coatings for Biological Applications. Diamond and Related Materials, v. 12, p. 583, 2003.

HUTCHINGS, R.; SHORT, K. T.; TENDYS, J. Investigation of plasma immersion ion implanted surfaces by instrumented indentation. Surface and Coating Technology. n.83, p. 243-249, 1996.

INAGO, M.; Carbon: Materials structure, texture and intercalation, Solid State Ionics, vol. 86-88, pp. 833-839, 1996.

JACKSON, S. T.; NUZZO, R. G.; Determining hybridization differences for amorphous carbon from the XPS C 1s envelope. Applied Surface Science 90, p. 195203, 1995.

JACOB, W. S. Surface reactions during growth and erosion of hydrocarbon films. Thin Solid Films, v. 326, p. 1-2, 1998.

JACOBSOHN, L. G.; FRANCESCHINI, D. F. DA COSTA, M. E. H. M.; FREIRE, F. L. Structural and mechanical characterization of fluorinated amorphous-carbon films deposited by plasma decomposition of CF4 - CH4 gas mixtures. Journal of Vacuum Science \& Technology A - Vacuum Surfaces and Films, v. 18, p. 2230-2238, 2000.

JIANG, M.; NING, Z.; Influence of deposition pressure on the structure and properties of fluorinated diamond-like carbon films prepared by RF reactive magnetron sputtering. Surface \& Coating Technology v. 200, p. 3682-3686, 2006.

JIANG, Y. B.; ZHANG, H. X.; CHENG, D. J.; YANG, S. Z.; Thin Solid Films v. 52, p. $360,2000$. 
KUO, S. C.; KUNHARDT, E. E.; SRIVATSA, A. R.; Deposition of diamond-like carbon film using electron cyclotron resonance plasma. Appl. Phys. Lett. v. 59, p. $2532,1991$.

KEUDELl, A. V.; SELlinger, T. S.; JACOB, W. J. Vac. Sci. Technology A. 19, p. 1001-1022, 2001.

KO, H. J.; et al. Structural and electrical studies on fluorinated amorphous carbon films as intermetal dielectric layer in ULSI devices. Thin Solid Films, v. 506-507, p. 82-86, 2006.

KORMNINOU, P.; et al. Crystalline structures of carbon complexes in amorphous carbon films, Diamond Related Materials, v. 9, p. 703-706, 2000.

KULIKOVSKY, V.; et al. Hardness, intrinsic stress, and structure of the a-C and a$\mathrm{C}: \mathrm{H}$ films prepared by magnetron sputtering, Diamond Related Materials, v. 10, p. 1076-1081, 2001.

KUMAR, S.; et al. Versatile microwave PECVD technique for deposition of DLC and their ordered carbon nanostructures, Vacuum, v. 63, p. 433-439, 2001.

LACERDA, R. G. et al. On the structure of argon assisted amorphous carbon films, Diamond and Related Materials, v. 9, p. 796-800, 2000.

LACERDA, R.G.; MARQUES, F.C. Hard hydrogenated carbon film with low stress. Applied Physics Letters. v.73, n. 5, p. 617, 1998.

LAMPERTI, A.; BOTTANI, C. E.; OSSI, P. M. Elemental distribution in fluorinated amorphous carbon thin films. Journal American Society for Mass Spectrometry. Published by Elsevier inc., v. 16, p. 126-131, 2005. 
LAMPERTI, A.; OSSI, P. Systematic study of amorphous hydrogenated and fluorinated carbon films. Applied Surface Science, v. 205, p. 113-120, 2003.

LEE, J. H.; KIM, D. S; LEE, Y. H.; FAROUK, B. Mechanical properties of a-C:H and a-C:H/SiO ${ }_{x}$ nanocomposite thin films prepared by ion-assisted plasma-enhanced chemical vapor deposition. Thin Solid Films 280, 204, 1996.

LEE; E.H.; et aL. Hardness measurements of $\mathrm{Ar}^{+}$beam treated polyamide by depth sensing ultra load indentation. Journal of Matter Research v. 8, n. 2, p. 377-387, 1993.

LIFSHITZ, Y,; "Diamond-like carbon present status", Diamond and Related Materials, v.8, p. 1659-1676, 1999.

MA, K-X.; et al. Investigation of surface energy for organic light emitting polymers and indium tin oxide. Thin Solid Films v. 371, p. 140-147, 2000.

MA, X.; TANG, G.; SUN, M. Relationship between mechanical properties and chemical group in a-C:F films prepared by RF unbalanced magnetron sputter deposition. Surface and Coating Technology, v. 201, p. 7641-7644, 2007.

MA, Y.; et al.; Structural and electronic properties of low dielectric constant fluorinated amorphous carbon films, Applied Physics Letters, v. 72, n. 25, p. 3353$3355,1998$.

MARINS, N. M. S. Deposição de carbono amorfo hidrogenado sobre instrumento de corte cirúrgico (lâmina de bisturi) Dissertação de Mestrado em Engenharia Biomédica, Área de Bioengenharia. UNIVAP, 2003.

MARSH, H.; Sciences of carbon materials, Carbon, v. 39, p. 957-960, 2001. 
METIN, S.; et al.; Amorphous carbon antireflective coatings in the 10 to $50 \mu \mathrm{m}$ region of the far-IR. Journal Materials Research., v. 9, p. 396-400, 1994.

MOLLER, W.; Plasma-enhanced chemical-vapor deposition. Applied Physics Letters A, 56 (6):527, 1993.

MORO, J. R. et al. Crescimento sucessivos de filmes de diamante CVD em grandes áreas. Revista Brasileira de Aplicações de Vácuo, v. 26, n. 2, p. 83-87, 2007.

MOROSOFF, N.. An introduction to plasma polymerization, in Plasma Deposition, Treatment, and Etching of Polymers, R. D'Agostino Ed., Academic Press, 4 th ed. San Diego, New York, chap. 1, p. 1-93,1990.

MOTA, R. P. Estudo do Processo de Deposição e das Propriedades Estruturais e Óticas de Filmes Poliméricos Preparados em Plasmas de $\mathrm{C}_{2} \mathrm{H}_{2}, \mathrm{C}_{2} \mathrm{H}_{2}-\mathrm{SF}_{6}$ e HMDSO. 137 f., Tese de Doutorado em Ciências, UNICAMP, 1992.

MOTA, R. P. et al. An Actnometric Study of $\mathrm{C}_{2} \mathrm{H}_{2}$ Plasma Polymerization and Film Properties, Journal Vacuum Science Technology A 13 (6) 1995.

MOULEDER, J. F. et al. Handbook of X-Ray Photoelectron Spectroscopy, a reference book of standard spectra for identification. Edit by J. Chastain, Perkin-Elmer Corporation, Physical Electronics Division, Eden Prairie, Minnesota, U.S.A., 1992.

NAGAI, I.; et al. Preparation of diamondlike carbon films by electron cyclotron resonance chemical vapor deposition. Journal App. Phys. v. 67, p. 2890, 1990.

NAKAMURA, T.; et al. Surface modification of diamond-like carbon films with perfluorooctyl functionalities and their surface properties. Surface Science, v. 580, p. 101-106, 2005. 
NASCENTE, P. A. P. Análise de Superfícies por Espectroscopia de Elétrons. Revista Brasileira de Aplicações de Vácuo, v. 17, n. 1, p. 15-22, 1998.

NASCENTE, P. A. P. Materials characterization by X-Ray photoelectron spectroscopy. Journal of Molecular Catalysis A: Chemical 228, p. 145-150, 2005.

NOVIKOV, N. V.; et al. Transition from polymer-like to diamond-like a-C:H films structure and mechanical properties. Diamond Rel. Mater 6, 574, 1997.

$\mathrm{OH}, \mathrm{T}$; $\mathrm{CHOI}, \mathrm{C} . \mathrm{K}$; LEE, K-M. Investigation of a-C:F films as hydrogenated diamond-like carbon and low-k materials. Thin solid Films, v. 475, p. 109-112, 2005.

OLIVER, W. C.; PHARR, G. M. An improved technique for determining hardness and elastic-modulus using load and displacement sensing indentation experiments. Journal of Materials Research, v.7, p. 1564-1583, 1992.

OLIVER, W. C.; PHARR, G. M. Measurement of hardness and elastic modulus by instrumented indentation: advances in understanding and refinements to methodology. Journal of Materials Research, v.19, p. 3-20, 2004.

OWENS, D.K.; WENDT, R.C. Estimation of the surface free energy of polymers. Journal of Applied Polymer Science v.13, p.1741-1747, 1969.

PASTEL, P. W.; VARHUE, W. J. J. Vac. Sci. Technol. A9, 1129, 1991.

PHARR, G. M.; OLIVER, W. C. Measurement of thin-film mechanical properties using nanoidentation. MRS Bulletin, v. 17, n. 7, p. 28-33, 1992.

PRIOLI, R. et al. Nanotribological properties of amorphous carbon-fluorine films. Tribology Letters, 15 (3), 177-180, 2003. 
RANGEL, E. C.; et al. Argon ion implantation inducing modification in the properties of benzene plasma polymers. Nuclear Instruments and Methods in Physics Research B, v. 191, p. 700-703, 2002.

RANGEL, E. C.; et al. Influence of $\mathrm{Ar}^{+}$ion irradiation on the properties of plasma polymerized acetylene films. Surface and Coating Technology, v. 127, p. 93-98, 2000.

RANGEL, E. C.; et al. Optical and electrical properties of polymerizing plasmas and their correlation with DLC film properties. Plasma and Polymers v. 9, n. 1, p. 1-22, 2004.

ROBERTS, E. W. the Advantages and Limitations, of Sputtered Molybdenum, As a Space Lubricant. Fourth European Symposium on Space Mechanisms and Tribology. Cannes, Esa sp, 299, 1990.

ROBERTSON, J. Diamond-like amorphous carbon. Pure Appl. Chem. v. 66, p. 1789, 1994.

ROBERTSON, J.; Deposition mechanism for promoting $\mathrm{sp}^{3}$ bonding in diamond-like carbon. Diamond and Related Materials, v. 2, n. 5-7, p.984-989, 1993.

ROBERTSON, J.; Diamond-like amorphous carbon. Materials Science and Engineering R v. 37, p. 129-281 (Reports: A review journal), 2002.

ROBERTSON, J.; The deposition mechanism of diamond-like a-C:H and a-C. Diamond and Related Materials, v. 3, n. 4-6, p. 361-368, 1994.

ROBERTSON, J. Ultra-thin carbon coating for magnetic storage technology. Thin Solid Films v. 383, p. 81, 2001. 
RODIL, S.; et al. Deposition of carbon nitride films using an electron cyclotron wave resonance plasma source. Diamond and Rel. Mater. v. 9, p. 524, 2000.

RONNING, C.; et al. Ion beam deposition of fluorinated amorphous carbon. Journal of Applied Physics, v. 90, n. 8, p. 4237-4245, 2001.

SAFRAN, S. A. Statistical Thermodynamics of Surfaces, Interfaces and Membranes. Addison-Wesley Publishing Company, 1994.

SAH, R. E.; DISCHLER, B.; BUBENZER, A.; KOIDL, P.; Amorphous carbon coatings prepared by high rate r.f. plasma deposition from fluorinated benzenes, Applied Physics Letters, v. 46, p. 739-741, 1985.

SANCHEZ-LOPEZ, J. C.; et al. Diamond-like carbon prepared by high density plasma, Diamond and Related Materials, vol. 9,pp. 638-642, 2000.

SANTOS, D. C. R.; Efeito da Implantação Iônica por Imersão em Plasmas em Filmes de Hidrocarbonetos Polimerizados a Plasma. Tese de Doutorado em Engenharia Mecânica, área de projetos e materiais, FEG/UNESP, 2004.

SANTOS, L. V.; Estudos das Características Tribológicas de Filmes de DLC para Aplicações em Sistema de Lubrificação Seca. Tese de Doutorado em Ciências, curso de Engenharia Aeronáutica e Mecânica, área de Física e Química de Materiais Aeroespaciais, Instituto Tecnológico de Aeronáutica - CTA, 2004.

SPEAR, K. E.; DISMUKES, J. P.; Synthetic diamond emerging CVD, Science and Technology, John Willey \& Sons, 1993.

SUN, Z.; et al. Morphological features of diamond films grown on diamond-like carbon films synthesized from polymers by chemical vapor deposition, Journal of Crystal Growth, v. 173, p. 402-407, 1997. 
SUN, Z.; SHI, X.; LIU, E.; High rate deposition of diamond-like carbon films by magnetically enhanced plasma CVD, Thin Solid Film, v. 355-356, p. 145-150, 1999.

TAN, I. H.; et al. Polymer treatment by plasma immersion implantation of nitrogen for formation of diamond-like carbon film. Japanese Journal of Apllied Physics, v. 43, 2004.

TAY, B. K.; et al. Study of surface energy of tetrahedral amorphous carbon films modified in various gas plasma. Diamond and Related Materials, v. 13, p. 20722076, 2003.

TEIXEIRA, A. P. G. Caracterização Topográfica e Estrutural de Filmes Poliméricos Provenientes de Acetileno $\left(\mathrm{C}_{2} \mathbf{H}_{2}\right)$ Depositados a Plasma sobre Substratos Lisos e Rugosos. 71 f. Dissertação (Mestrado em Física) - Faculdade de Engenharia do Campus de Guaratinguetá, Universidade Estadual Paulista, Guaratinguetá, 2003.

TRESSAUD, A.; et al. On the nature of C-F bonds in various fluorinated carbon materials: XPS and TEM investigations. Pergamon. J. Physics Solids, v. 57, n. 6-8, p. 745-751., 1996.

TRUSSO, S.; VASI, C.; NERI, F. $\mathrm{CN}_{\mathrm{x}}$ Thin films grown by pulsed laser deposition: Raman, Infrared and X-ray photoelectron spectroscopy study. Thin Solid Films 219, p. 355-356, 1999.

TZENG, S. S..; Mechanical behavior of two-dimensional carbon/carbon composites with interfacial carbon layers, Carbon, v. 37, p. 2011-2019, 1999.

VALENTINI, L.; et al. Analysis of the role of fluorine content on the thermal stability of a-C:H:F thin films. Diamond and Related Materials, v. 11, p. 1100-1105, 2002. 
VALENTINI, L.; et al. Fluorinated amorphous carbon thin films: Analysis of the role of the plasma source frequency on the structural and optical properties. Journal Vac. Sci. Technology A, v. 19, p. 2168-2173, 2001.

VALENTINI, L.; et al. Influence of plasma source frequency on composition and density of fluorinated amorphous carbon thin films. Materials Letters, p. 514-518, 2001.

VALENTINI, L.; et al. Relationship between the optical and mechanical properties of fluorinated amorphous carbon films. Journal of Non-Crystalline Solids, v. 291, p. 153-159, 2001.

VENCAMMEN, K.; et al. A comparative study of state of the art diamond-like carbon films, Surface \& Coating Technology, v. 133-134, p. 466-472, 2000.

VIVENSANG, C.; et al.; Reactive ion etching of diamond and diamond-like carbon films, Diamond and Related Material, v. 3, p. 645-649, 1994.

WALTER, K. C.; et al. Characterizations and performance of diamond like carbon films synthesized by plasma and ion beam based technique, Surface \& Coatings Technology, v. 74-75, p. 734-738, 1995.

WANG, D. Y.; CHANG, C. L.; HO, W. Y.; Characterization of hydrogen-free diamond like carbon films deposited by pulsed plasma technology, Thin Solid Films, v. 355-356, p. 246-251, 1999.

WANG, X.; et al. Interface engineering for covalently bonded disordered thin films: boron nitride and diamond-like carbon. Surface and Coating Technology. v. 131, n 1-3, p.514-519, 2000. 
WANG, X.; et al. Structural properties of fluorinated amorphous carbon films. Journal of Applied Physics, v. 87, p. 621-623, 2000.

WASA, K.; Handbook of sputter deposition technoly principles technology and applications, Noyes Publications, 1992.

WEBB, R. P. et al. The formation of diamond like carbon films due to molecular impacts on graphite, Diamond and Related Materials, v. 7, p. 1163-1166, 1998.

WEILER, M. et al. Highly tetrahedral, diamond-like amorphous hydrogenated carbon prepared from a plasma beam source. Appl. Physics Lett. v. 64, p. 2797, 1994.

WILliAMS, D. H.; FLEMING, I. in Spectroscopy Method in Organics Chemistry (Mac Graw-Hill, New York, chap. 3, 1 ${ }^{\text {st }}$ ed., 40) 1966.

WU, S. Calculation of interface tension in polymer systems. Journal of Polymer Science Part C - Polymer Symposium v. 34, p. 19, 1971.

WU, Z.; YANG, Y.; WANG, J. The effect of annealing on electrical properties of fluorinated amorphous carbon films. Diamond and Related Materials, v. 17, p. 118-122, 2008.

YAAKOV, Z. Work of adhesion of a sessile drop to a clean surface. Journal of Colloid and Interface Science, v. 213, p. 602, 1999.

YANG, H. et al. Deposition of highly crosslinked fluorinated amorphous carbon film and structural evolution during thermal annealing. Applied Physical Letters, v. 14, p. 1514-1516, 1998.

YAO, Z. Q.; et al. Effects of negative low substrate bias voltage on the structure and properties of fluorinated amorphous carbon films synthesized by plasma immersion 
ion implantation and deposition. Surface and Coating Technology, v. 186, p. 131$135,2004$.

YAO, Z. Q.; et al. Structural, mechanical and hydrophobic properties of fluorinedoped diamond-like carbon films synthesized by plasma immersion ion implantation and deposition (PIII-D). Applied Surface Science, v. 230, p. 172-178, 2004.

YASUDA, H. Plasma Polymerization. J. Polym. Sci Macromol Rev. v.16, p.199, 1981.

YASUDA, H.; HSU, T. Plasma Polymerization processes. Surf. Sci. v.76, p.232, 1978.

YASUDA, H. in Plasma Polymerization . Orlando. Academic Press, N. Y., 1985.

YASUDA, H.; WANG, C. R.; Plasma polymerization investigated by the substratetemperature dependence. Journal of Polymers Science Part A - Polymer Chemistry v. 23, p. $87-106,1985$.

YI, J. W., LEE, Y. H.; FAROUK, B.; Low dielectric fluorinated amorphous carbon thin films grown from $\mathrm{C}_{6} \mathrm{~F}_{6}$ and Ar plasma, Thin Solid Films, v. 374, p. 103-108, 2000.

YOKOMICHI, H.; HAYASHI, T.; MASUDA, A. Changes in structure and nature of detects by annealing of fluorinated amorphous carbon thin films with low dielectric constant. Applied Physics Letters, v. 72, p. 2704, 1998.

YOKOMICHI, H.; MASUDA, A. Effect of sputtering with hydrogen dilution on fluorine concentration of low hydrogen content fluorinated amorphous carbon thin films with low dielectric constant. Journal of Applied Physics, v. 86, p. 2468-2472, 1999. 
YU, G. Q.; et al. Properties of fluorinated amorphous diamond like carbon films by PECVD. Applied Surface Science v. 219, p. 228-237, 2003.

YU, G. Q.; TAY, B. K.; SUN, A. Fluorinated amorphous diamond-like carbon films deposited by plasma-enhanced chemical vapor deposition. Surface and Coating Technology, v. 191, p. 236-241, 2005. 


\section{APÊNDICE A}

\section{ARTIGOS COMPLETOS PUBLICADOS, ACEITOS E SUBMETIDOS A PERIÓDICOS}

"Optical and Electrical Properties of Polymerizing Plasmas and Their Correlation with DLC Film Properties", RANGEL, E. C.; CRUZ, N. C.; KAYAMA, M. E.; RANGEL, R. C. C.; MARINS, N. M. S.; DURRANT, S. F., Plasmas and Polymers, v. 9, n. 1, 2004.

"Características Moleculares e Molhabilidade de Filmes de Benzeno Polimerizados a Plasma", MARINS, N. M. S.; CRUZ, N. C.; RANGEL, E. C.; MOTA, R. P.; SANTOS, D. C. R.; HONDA, R. Y. Revista Brasileira de Aplicações de Vácuo, v. 26, n. 4, p. 177-180, 2007.

"Amorphous Hydrogenated Carbon Films Treated by SF 6 Plasma”, MARINS, N. M. S.; MOTA, R. P.; SANTOS, D. C. R.; HONDA, R. Y.; KAYAMA, M. E.; KOSTOV, K. G.; AlgATTI, M. A.; CRUZ, N. C.; RANGEL, E. C. Journal of Physics. Conference Series, v. 167, p. 012054, 2009.

"Development of Amorphous Carbon Protective Coating on Poly (vinyl) chloride" RANGEL, E. C.; SOUZA, E. S.; MORAES, F. S.; MARINS, N. M. S.; SCHERNER, W. H.; CRUZ, N. C. Journal Thin Solid Films. v. 518, p. 2750-2756, 2010.

"Properties of Amorphous Hydrogenated Carbon Films Deposited by PECVD and Modified by SF 6 Plasma”, MARINS, N. M. S.; MOTA, R. P.; HONDA, R. Y.; NASCENTE, P. A. P.; KAYAMA, M. E.; KOSTOV, K. G.; ALGATTI, M. A.; CRUZ, N. C.; RANGEL, E. C. Aceito em Surface \& Coating Technology, 2009. 
"Influência da Potência na Composição Química de Filmes Depositados a Plasma a Partir da Mistura de $\mathrm{C}_{2} \mathrm{H}_{2}$ /Argônio", MARINS, N. M. S.; MOTA, R. P.; NASCENTE, P. A. P.; HONDA R. Y.; CRUZ N. C.; KAYAMA, M. E., KOSTOV, K. G., Algatti, M. A., RAnGel, E. C. Submetido à Revista Brasileira de Aplicações de Vácuo, 2009. 


\section{APÊNDICE B}

\section{TRABALHOS APRESENTADOS EM CONFERÊNCIAS}

"Correlation Between Plasma Phase and Film Properties", MARINS, N. M. S.; CRUZ, N. C.; MOTA, R. P., HONDA, R. Y.; RANGEL, E. C. XXVII CBRAVIC Congresso Brasileiro de Aplicações de Vácuo na Indústria e na Ciência, Itatiba, SP, 2006.

"Preparation of Amorphous Carbon Hydrogenated Films for Corrosion Protection", MARINS, N. M. S.; RANGEL, E. C.; MOTA, R. P., SANTOS, D. C. R.; HONDA, R. Y. XXIX ENFMC - Encontro Nacional de Física da Matéria Condensada, São Lourenço, MG, 2006.

"A Correlation Between the Microstructure and Mecanical Properties of Hydrogenated Amorphous Carbon Film Prepared”, MARINS, N.M. S.; CRUZ N. C.; MOTA R. P., HONDA R. Y.; RANGEL, E. C. XXVIII CBRAVIC - Congresso Brasileiro de Aplicações de Vácuo na Indústria e na Ciência, Natal, RN, 2007.

"Características Moleculares e Molhabilidade de Filmes de Benzeno Polimerizados a Plasma", MARINS, N. M. S.; CRUZ, N. C.; RANGEL, E. C.; MOTA, R. P.; SANTOS, D. C. R.; HONDA, R. Y. XXVIII CBRAVIC - Congresso Brasileiro de Aplicações de Vácuo na Indústria e na Ciência, Natal, RN, 2007.

"Microstructure and Mechanical Properties of Hydrogenated Amorphous Carbon Film Prepared by Plasma”, MARINS, N. M. S.; MOTA, R. P.; HONDA, R. Y.; RANGEL, E. C.; CRUZ, N. C.; KAYAMA, M. E.; KOSTOV, K. G.; SANTOS, D. C. R. $9^{\circ}$ ENCONTRO FISICA DE PLASMAS, São Pedro, SP, 2007.

"Chemical Structure and Wettabily of DLC Films Deposited by Acetylene/Argon Plasma”, MARINS, N. M. S.; MOTA, R. P.; HONDA R. Y.; 
SANTOS, D. C. R.; CRUZ N. C.; KAYAMA, M. E.; KOSTOV, K. G.; ALGATTI, M. A.; RANGEL, E. C. XXIX CBRAVIC - Congresso Brasileiro de Aplicações de Vácuo na Indústria e na Ciência, Joinville, SC, 2008.

"Tayloring the Wettability of Benzene Plasma Polymers Through Chemical Composition and Relief Modification", MARINS, N. M. S.; RANGEL, E. C.; MOTA, R. P.; HONDA, R. Y.; SANTOS, D. C. R., CRUZ, N. C. XXXI ENFMC - Encontro Nacional de Física da Matéria Condensada, Águas de Lindóia, SP, 2008.

"Analysis of Nickel Ions Release from Orthodontics Brackets after Deposition of a-C:H Films", CLARO, A. P. R. A., GUIMARÃES, A. C. M., MARINS, N. M. S., MotA, R. P., GOVEIA, D., ROSA, A. H., REZENDE, D.; ALVES, M. C. R. NANOSMAT, Espanha, 2008.

"Analysis of Ions Release of Orthodontic Archwires Coating with a-C:H Films", SCHNEIDER, S. G.; SCHNEIDER, S.; RODRIGUES, D. J.; MARINS, N. M. S.; HONDA, R. Y.; GOVEIA, D.; ROSA, A. H.; CLARO, A. P. R. A. NANOSMAT, Espanha, 2008.

"Modificação da Molhabilidade de Filmes Poliméricos por Tratamento com Plasma de Hexafluoreto de Enxofre”, TEIXEIRA D. H. P.; MOTA, R. P.; MARINS, N. M. S.; NICOLETI, T. J. PIBIC, São José dos Campos, SP, 2008.

"Plasma Polymerized Acetylene Films Treated by Helium Plasma Immersion Ion Implantation", MARINS, N. M. S.; SANTOS, D. C. R.; MOTA, R. P.; HONDA, R. Y.; ALGATTI, M. A.; RANGEL, E. C. PPS-24 - Proceedings of the Polymer Processing Society 24th Annual Meeting, June 15-19, Salerno, Italy, 2008.

"Amorphous Hydrogenated Carbon Films Treated by SF 6 Plasma”, MARINS, N. M. S.; MOTA, R. P.; SANTOS, D. C. R.; HONDA, R. Y.; KAYAMA, M. E.; 
KOSTOV, K. G.; ALGATTI, M. A.; CRUZ, N. C.; RANGEL, E. C. SLAFES XIX XIX Latin American Symposium on Solid State Physics, October 5-10, Puerto Iguazú, Argentina, 2008.

"Wettability and Molecular Structure of Plasma Deposited Thin Films of Polyvinyl Chloride and Treated in Sulfur Hexafluoride", RANGEL, A. L. R.; FERREIRA, F. H. M.; MARINS, N. M. S.; HONDA, R. Y.; ALGATTI, M. A.; MOTA, R. P. XXXII ENFMC - Encontro Nacional de Física da Matéria Condensada, Águas de Lindóia, SP, 2009.

"Obtention and Caracterization of Amorphous Hydrogenated Carbon Thin Films Treated by Sulfur Hexafluoride", MARINS, N. M. S.; MOTA, R. P.; AlGATTI, M. A.; HONDA, R. Y.; RANGEL, A. L. R.; FERREIRA, F. H. M. XXXII ENFMC - Encontro Nacional de Física da Matéria Condensada, Águas de Lindóia, SP, 2009.

"Properties of Amorphous Hydrogenated Carbon Films Deposited by PECVD and Modified by SF 6 Plasma", MARINS, N. M. S.; MOTA, R. P.; HONDA, R. Y.; NASCEnTE, P. A. P.; KAYAMA, M. E.; KOSTOV, K. G.; AlGATTI, M. A.; CRUZ, N. C.; RANGEL, E. C., PDII\&D - 10 $^{\text {th }}$ International Workshop on PlasmaBased Ion Implantation \& Deposition, September 7-11, INPE, São José dos Campos, SP, 2009.

"Influência da Potência na Composição Química de Filmes Depositados a Plasma a Partir da Mistura de $\mathrm{C}_{2} \mathrm{H}_{2}$ /Argônio", MARINS, N. M. S.; MOTA, R. P.; NASCENTE, P. A. P.; HONDA R. Y.; CRUZ N. C.; KAYAMA, M. E., KOSTOV, K. G., AlgATTI, M. A., RANGEL, E. C. XXX CBRAVIC - Congresso Brasileiro de Aplicações de Vácuo na Indústria e na Ciência, Campos de Jordão, SP, 2009.

"Polimerização e Tratamento a Plasma no PVC Biocompativel", RANGEL, A. L. R.; FERREIRA, F. H. M.; MARINS, N. M. S ; MOTA, R. P. In: XXX CBRAVIC - 
Congresso Brasileiro de Aplicações de Vácuo na Industria e na Ciência, Campos do Jordão, SP, 2009. 